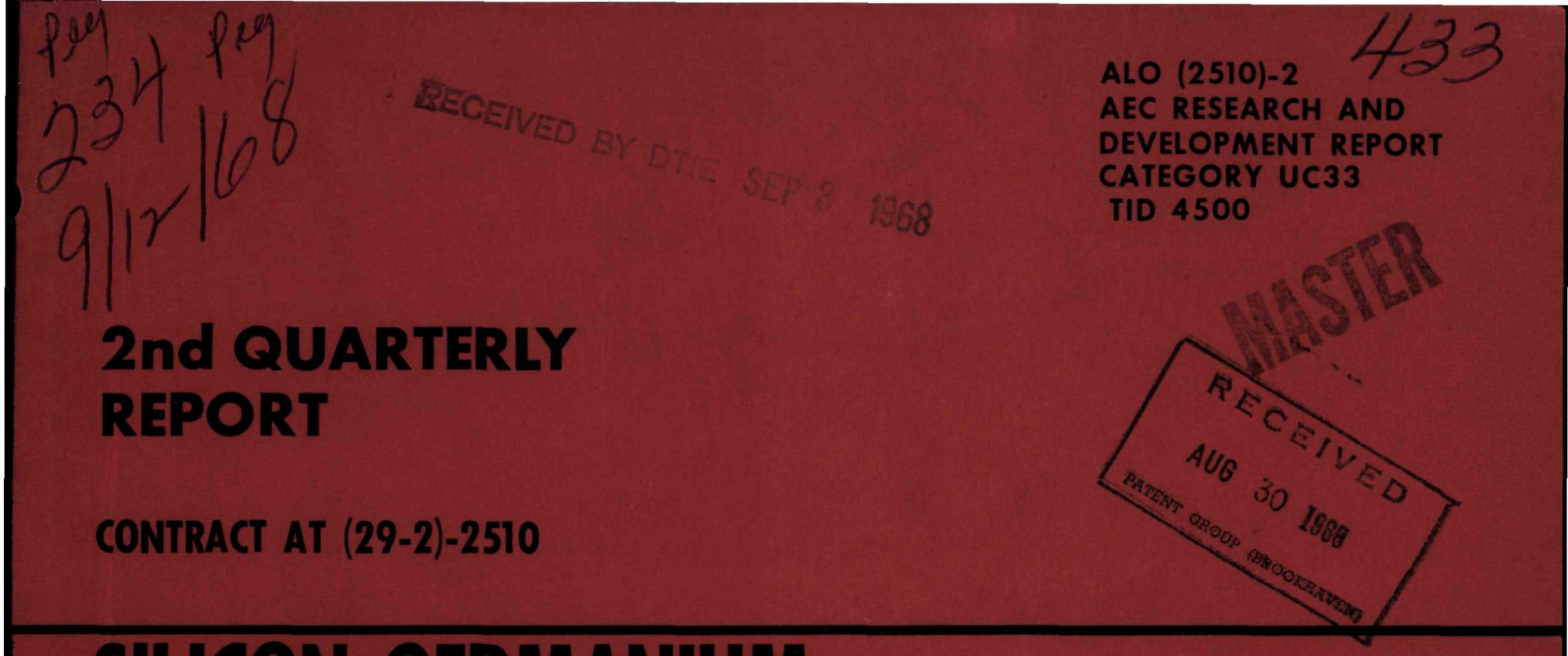

\title{
SILICON GERMANIUM
}

THERMOELECTRIC MATERIALS

AND

MODULE DEVELOPMENT

PROGRAM (U)

THERMOELECTRIC PRODUCTS ENGINEERING SPECIAL COMPONENTS OPERATIONS ELECTRONIC COMPONENTS RCA

415 SOUTH FIFTH STREET HARRISON, NEW JERSEY 07029

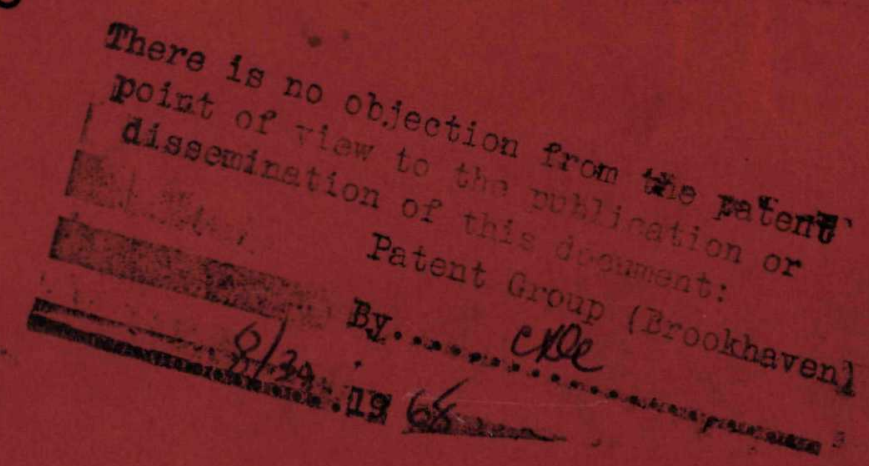




\section{DISCLAIMER}

This report was prepared as an account of work sponsored by an agency of the United States Government. Neither the United States Government nor any agency Thereof, nor any of their employees, makes any warranty, express or implied, or assumes any legal liability or responsibility for the accuracy, completeness, or usefulness of any information, apparatus, product, or process disclosed, or represents that its use would not infringe privately owned rights. Reference herein to any specific commercial product, process, or service by trade name, trademark, manufacturer, or otherwise does not necessarily constitute or imply its endorsement, recommendation, or favoring by the United States Government or any agency thereof. The views and opinions of authors expressed herein do not necessarily state or reflect those of the United States Government or any agency thereof. 


\section{DISCLAIMER}

Portions of this document may be illegible in electronic image products. Images are produced from the best available original document. 
This report was prepared as an account of Government sponsored work. Neither the United States, nor the Commission, nor any person acting on behalf of the Commission:

A. Makes any warranty or representation, express or implied, with respect to the accuracy, completeness, or usefulness of the information contained in this report, or that the use of any information, apparatus, method, or process disclosed in this report may not infringe privately owned rights; or

B. Assumes any liabilities with respect to the use of, or for damages resulting from the use of information, apparatus, method, or process disclosed in this report.

As used in the above, "person acting on behalf of the Commission" includes any employee or contractor of the Commission. or employee of such contractor, to the extent that such employee or contractor of the Commission, or employee of such contractor prepares, disseminates, or provides access to, any information pursuant to his employment or contract with the Commission, or his employment with such contractor. 


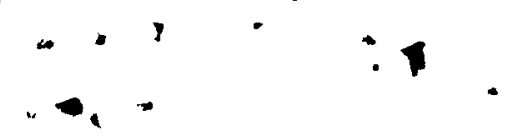

\section{RE/}

\section{ERRATA SHEET}
Reference: ALO (2510)-2
AEC R \& D Report
Category UC 33
TID 4500

Please make the following corrections in your copy(ies) of referenced publication.

Page

27-last line

59-line 13

61-Section d.
Change

"from heat to tail"

"visual"

"described in Section e" "described in Section c" 


\section{ERRATA SHEET $\underline{2}$}

Reference: ALO (2510)-2

AEC R \& D Report

Category UC 33

TID 4500

Please add the following corrections in your copy(ies) of referenced publication.

Page

10-3rd line from bottom

14-6th line from top

16-Sec. b, lst Par. line 1

16-Sec. b, 2nd Par. line 3

25-Sec. c, line 5

52-Last line

61-Line 2
Change

5000

0.05

eveluation

show material

approximately $(0.9)$

Section D,I, a

Thermal strips

To

Figure

Change

To

18-Center group of curves

1.2

500

0.5

evaluation shoe material (approximately 0.9)

Section D,2, a

Terminal strips

31-Following curves should have common convergence point at 6.3 amperes: Load Resistance

Load Voltage

Device Efficiency

Power Output 


\section{LEGAL NOTICE}

This report was prepared as an account of Government sponsored work. Neither the Unted States, nor the Commission, nor any person acting on behalf of the Commission:

A. Makes any warranty or representation, expressed or impled, with respect to the accuracy, completeness, or usefulness of the information contained in this report, or that the use of any information, apparatus, method, or process disclosed in this report may not infringe privately owned rights; or

B. Assumes any liabilities with respect to the use of, or for damages resulting from the use of any information, apparatus, method, or process disclosed in this report.

As uned in the above "per, method, or proces a dif ployee or contrar of the corson

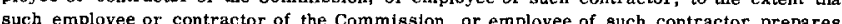
disseminates, or provides access to, any information pursuant to his employment or contract with the Commission, or his employment with such contractor.
ALO (2510)- 2

AEC RESEARCH AND DEVELOPMENT REPORT CATEGORY UC33

TID 4500

\title{
2nd QUARTERLY REPORT
}

\section{SILLON GERMANIUM THERMOELECTRIC MATERIALS AND MODULE DEVELOPMENT PROGRAM (U)}

\author{
BY \\ THERMOELECTRIC PRODUCTS ENGINEERING \\ SPECIAL COMPONENTS OPERATIONS \\ ELECTRONIC COMPONENTS \\ RCA \\ 415 SOUTH FIFTH STREET \\ HARRISON, NEW JERSEY 07029 \\ PREPARED UNDER \\ CONTRACT AT(29-2)-2510 \\ FOR THE \\ ALBUQUERQUE OPERATIONS OFFICE \\ U.S. ATOMIC ENERGY COMMISSION
}

FOR THE PERIOD: APRIL 1, 1968 TO JUNE 30, 1968

Printed in the United States of America

Available from

Clearinghouse for Federal Scientific and Technical Information

National Bureau of Standards, U.S. Department of Commerce

Springfield, Virginia 22151

Price: Printed Copy $\$ 3.00$; Microfiche $\$ 0.65$ 
$\underline{\text { Page }}$

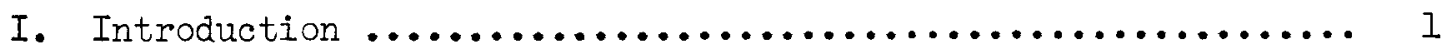

A. SiGe Thermoelectric Materials Technology ............. I

B. Air-Vac Module Development ...................... I

C. Cascaded Converter Development .................... I

II. SiGe Thermoelectric Materials Technology ............... 3

A. Task 1. SiMo Materials and Bond Development .......... 3

1. Chemical and Physical Properties Measurement ...... 3

2. Physical and Chemical Properties Optimization ...... 14

3. Investigation of Production Methods ............ 16

4. Air-Vac Thermocouple Bond Evaluation ............ 17

B. Task 2. Altemate Hot Shoe Materials and Bonds ........ 19

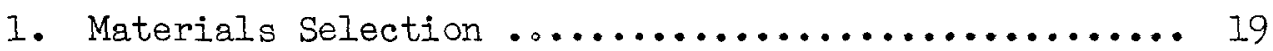

C. Task 3. High Silicon Content Silicon-Germanium Alloys .. 25

1. Physical and Chemical Properties Measurement ...... 27

2. Physical and Chemical Properties Optimization ...... 27

3. High Silicon-Alloy Bond Development ............ 29

4. Cold Shoe Bonds .............................. 29

III. Air-Vac Module Development Program .................. 31

A. Task 1. Design and Analysis .......................... 31

1. Reference Design Modular Array ................... 31

2. Developmental Design Configurations ............ 31

B. Task 2. Process, Bond, and Component Development ...... 37

1. Thermocouple $\ldots \ldots \ldots \ldots \ldots \ldots \ldots \ldots \ldots \ldots \ldots \ldots \ldots . \ldots . \ldots . \ldots$

2. Measurement Techniques ...................... 44 
C. Task 3. Fabrication ......................... 44

1. Reference Design ........................... 44

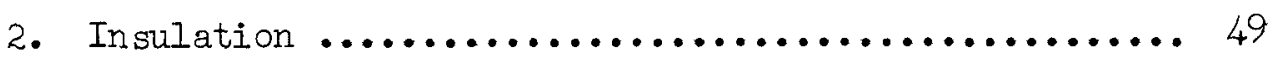

D. Task 4. Test Program - Module and Converter Level ..... 51

1. Test Program ........................... 51

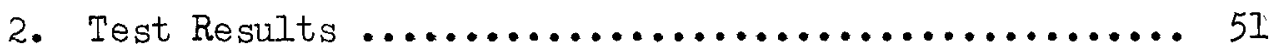

3. Test Facilities ........................... 59

IV. Cascaded Converter Development Program ................. 63

A. Introduction $\ldots \ldots \ldots \ldots \ldots \ldots \ldots \ldots \ldots \ldots \ldots \ldots \ldots \ldots . \ldots \ldots$

1. Analytical Techniques ..................... 63 


\section{LIST OF ILLUSTRATIONS}

Figure No.

$\underline{\text { Title }}$

$\underline{\text { Page }}$

1 Resistivity of Phosphoms-Doped SiMo Alloy as a

Function of Temperature ...................... 4

2 Seebeck Coefficient of Phosphorus-Doped SiMo Alloy as a Function of Temperature

3 Thermal Conductivity of Phosphoms-Doped SiMo Alloy as a Function of Temperature ................... 6

4 SiMo Ingot Structure - p-Type ................. 8

5 Silicon-Molybdenum Phase Diagram ................ 9

6 Silicon - Boron Alloy Showing Eutectic Phase ........ 11

7 SiMo Ingot Stmcture - p-Type Large Mo Particles

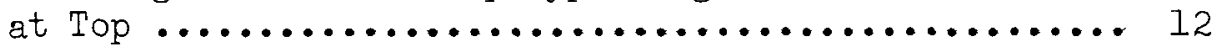

8 Dopant Added vs. Resistivity - Boron and Phosphorus

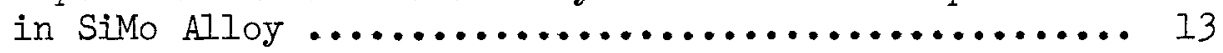

9 SiMo Shoe Material - Aluminum Doped-Disposition of

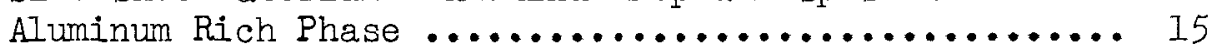

10 Comparison of Hot Pressed SiMo and Vacuum Cast SiMo Bonded to 63.5 at. Percent SiGe .................. 18

11 Typical As-Grown and As-Bonded SiGe Alloy - Phosphorus Doped ................................. 20

12 The Effects of Thermal Exposure on n-Type SiGe to SiMo Bonded Elements ...................... 21

13 N-Type 63.5 at. Percent SiGe and 77.0 at. Percent SiGe Bonded to Silicon Carbide .................... 23

14 N-Type 89.0 at. Percent SiGe Bonded to Silicon Carbide 24

15 SX-4 Graphite Coated With Silicon Silicon-Carbide by Pack Cementation ........................... 26

16 Comparison Between 63.5 at. Percent Si and 80.0 at. Percent Si to Silicon-Molybdenum Bonds ............ 30

17 Module Efficiency as a Function of Element Length (L/A) for a Range of Hot Shoe Sizes, and Insulation Thermal Conduction Planar Developmental Designs IP

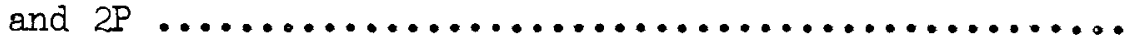




\section{LIST OF ILLUSTRATIONS (Cont。)}

Figure No.

Title

$\underline{\text { Page }}$

18

Module Efficiency as a Function of p-Type Element

Area for a Range of Hot Shoe Areas, and $A_{n} / A_{p}-$

Planar Developmental Design (IPA) - Fibrous

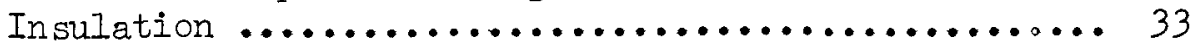

19 Module Efficiency as a Function of Element Length

(I/A) for a Range of Hot Shoe 'Sizes and Heat Fluxes.

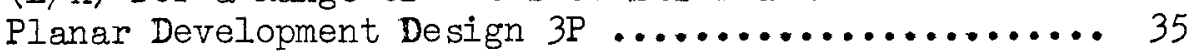

20 Specific Power (Watts) as a Function of Element

Length 1b. for a Range of Hot Shoe Sizes and Heat

Fluxes. Planar Development Design 3P ........... 36

21 Module Efficiency as a Function of Incident Heat Flux

for a Range of Hot Shoe Areas, and $A_{n} / A_{p}-$ Planar

Developmental Design 3P ........................... 38

22 Efficiency as a Function of Element Length Over a Range of Incident Heat Fluxes and Hot Shoe Sizes -

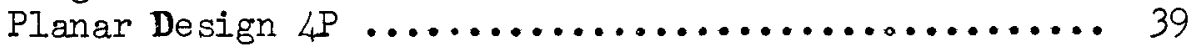

23 Efficiency as a Function of Incident Heat Flux for a Range of Shoe Sizes and $A_{n} / A_{p}$ Ratios ............ 40

24 Frame-Type Air-Vac Thermocouple ............... 43

25 Use of Forming Mandrel to Obtain Proper Relationship

Between two rows of 20-Couple module ............ 45

26 20-Couple Module Secured in Supporting Outer Shell.

Section ................................ 46

27 Application of Thermocouples and Packed Preformed

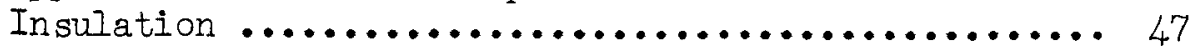

28 Completed Module and Shell Assembly ............. 48

29 5-Watt Air-Vac Converter Efficiency, Power Output,

Cold Shoe Temperature vs. Hot Shoe Temperature ..... 53

30 Reference Design Converter Performance Vs. Load

Current .................................. 54

31 Reference Design Converter Performance vs. Load

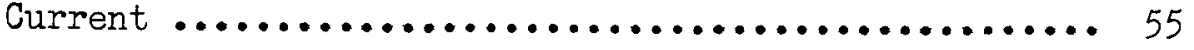

32 Heating-Cooling Curves - Hir Thermal Cycling Test of 4-Couple Reference Design Air-Vac Module ........... 58 


\section{LIST OF TABLES}

Table No.

Title

$\underline{\text { Page }}$

I Summary of Spectrographic Analyses on Silicon-

Germanium Material ....................... 28

II Resistance Measurement $(m \Omega) \ldots \ldots \ldots \ldots \ldots \ldots \ldots \ldots 42$

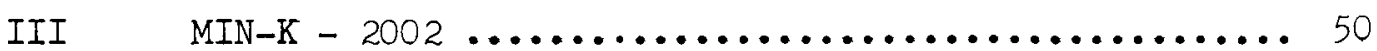

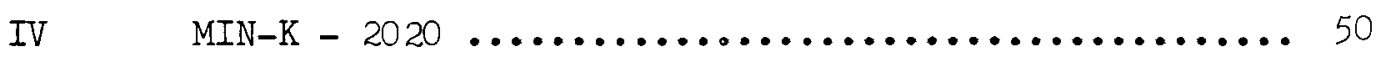

V Performance of 4-Couple Reference Design Module in

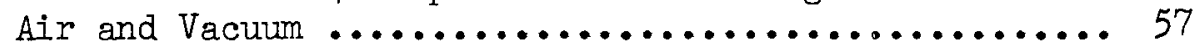

VI Shock and Vibration Tests Results .............. 60 


\section{INTRODUCTION}

This document is the second Quarterly Progress Report for the Silicon Germanium Thermoelectric Materials and Module Development Program. The program, which was started on December 20, 1967, is projected for a two-year period and is divided into the following three subprograms:

A. SiGe Thermoelectric Materials Technology

This subprogram includes the characterization and improvement of the SiMo hot shoe materials and the refinement of the fabrication and bonding techniques; the development of high-conductance alternate hot shoes for use in primary launch environments or in vacuum at temperatures above $900^{\circ} \mathrm{C}$; the development of preparation and bonding techniques for the optimum composition SiGe alloys (75 to 85 at. percent $\mathrm{Si}$ ); and the determination of electrical stability as a function of time, temperature, and environment.

B. Air-Vac Module Development

This subprogram covers the design, fabrication, and test of a progressively improving series of SiGo-thermocouple, module, and array configurations through a range of operating parameters and environmental and thermocouple configuration extremes. To achieve the objective of maximum performance, the improved materials developed in part $A$. will be incorporated as they are available. In addition, a variety of insulation and cold stack materials and module configurations will be examined.

C. Cascaded Converter Development

This subprogram includes the derivation of the necessary analytic tools, the performance of parametrics and, then, detailed configuration analyses, and fabrication and rigorous tests of optimized SiGe hot stage designs of a cascaded system. The SiGe stages will subsequently mate with flat plate and tubular PbTe converters to form complete systems.

During this reporting period of April 1 through June 30, 1968, these were among the major accomplishments:

1. The determination of the resistivity of simo as a function of the dopant concentration; the completion of a detailed metallographic examination of the cast material. (Refer to pages 7 and 14. )

2. The successful preparation of the SiMo hot shoe material by hot pressing; and the fabrication of test thermocouples by the use of hot pressed shoes. (Refer to page 16.)

3. The selection of SIC and coated Graphite for more extensive evaluation as alternate hot shoe materials. The successful 
fabrication and bonding of SiC hot shoes. (Refer to page 22.)

4. The development of a chromium coating to be applied by a pack cementation technique to tungsten cold shoes to allow for air operation at high cold side temperatures. (Refer to page 29 .)

5. The fabrication of the reference design module array, its assembly and instrumentation, and the initiation of performance testing. (Refer to pages 44 and 50.)

6. The completion of performance testing of a 5-watt device, comparing the effect of Dynaquartz and MIN-K 2020 fibrous insulation. (Refer to page 49 .)

7. The continued parametric determination of performance of developmental configurations. (Refer to page 31 .)

8. The successful operation of a four-couple reference design module through a typical mission environmental cycle. (Refer to page 54 .) 


\section{SiGe THERMOELECTRIC MATERIALS TECHNOLOGY}

\section{A. TASK 1. SiMO MATERIALS AND BOND DEVELOPMENT}

The objectives of this task were to characterize and improve the SiMo hot shoe material with respect to the chemical and physical properties and to refine current bonding techniques.

1. Chemical and Physical Properties Measurement

The quarterly report for the period January 1, 1968 to March 31, 1968 described the selection of SiMo castings which were representative of the state-of-the-art. The test-piece geometries for the chemical and physical characterization were described. The technique for bonding n-type to p-type SiMo discs as part of the hot shoe fabrication procedure was related.

a. Chemical Analysis

Boron: Efforts were directed toward developing analytical methods for the determination of $B$ in $p$-type SiGe and SiMo alloys.

As reported previously, this analysis presented several problems. Calorimetric and microgravimetric procedures, suitable on small sample weights with other materials containing boron have not been successful with Si alloys. The classical mannitol-sodium hydroxide titration may be satisfactory if a sufficient quantity (e.g., one gram) of alloy can be placed in solution. A program, currently in process, was initiated to find a suitable solubilizing technique for the SiMo alloy to facilitate B-determination by a wet chemical method. The program includes both acid solution and fusion methods.

Both neutron activation and emission spectroscopy are being explored as methods for B-analysis in SiMo and SiGe alloys. Details of the chemical analyses were reported in the First quarterly $\mathrm{ELO}(2510)-1$.

\section{b. Physical Testing}

Transport Properties: The transport properties of one p-doped $\bar{n}$-type siMo specimen which had a nominal composition of 85 wt. percent $3 i$ were measured. Figure 1 shows the change in electrical resistivity as a function of temperature. Although increasing with temperature, the electrical resistivity is sufficiently low for the material to be considered an effective electrical conductor. Figure 2 plots the Seebeck coefficient which is not a critical factor in hot shoe materials. Figure 3 describes 


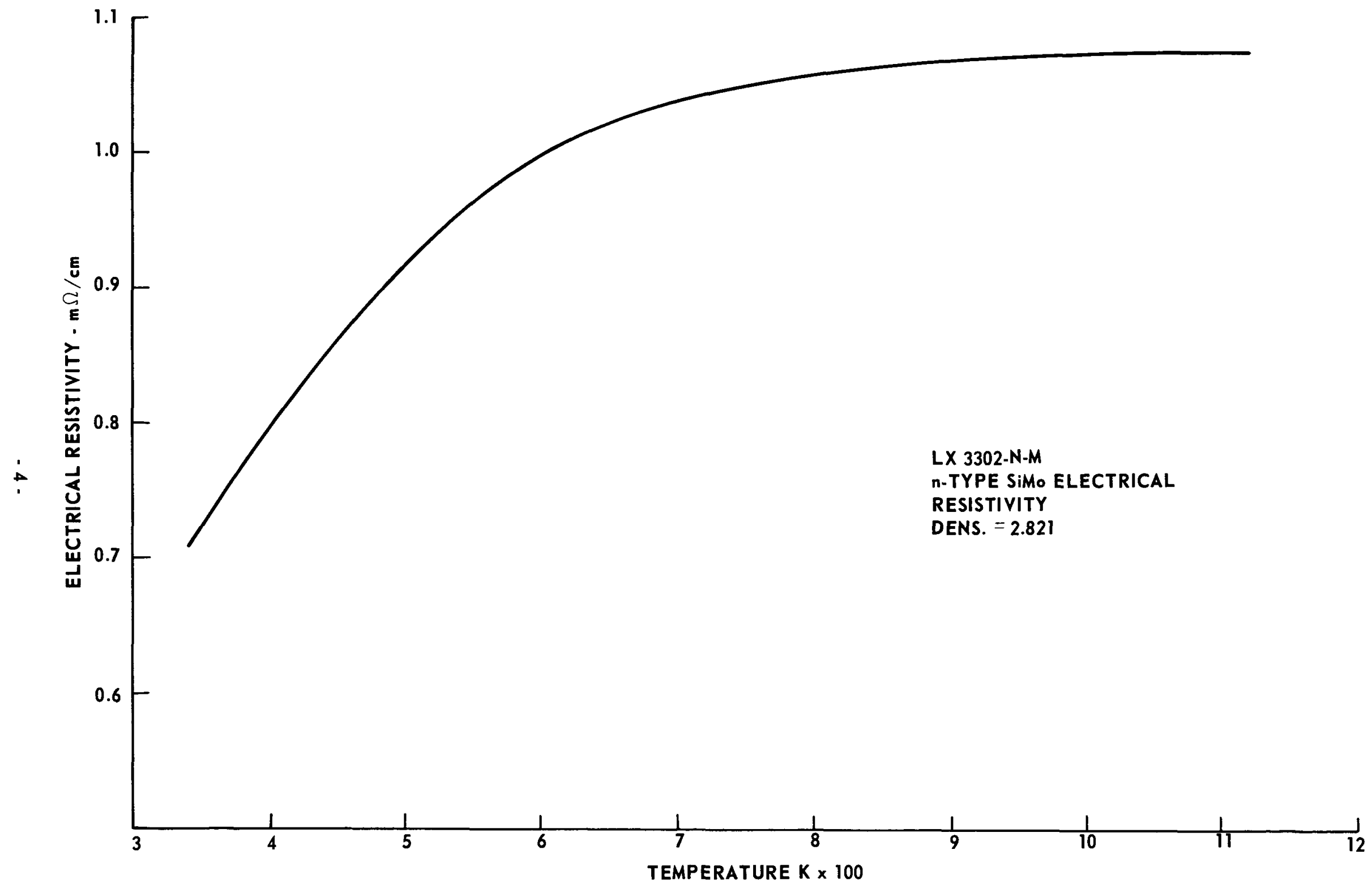

FIGURE 1. ELECTRICAL RESISTIVITY OF PHOSPHORUS-DOPED SIMO ALLOY AS A FUNCTION OF TEMPERATURE 


$$
4
$$




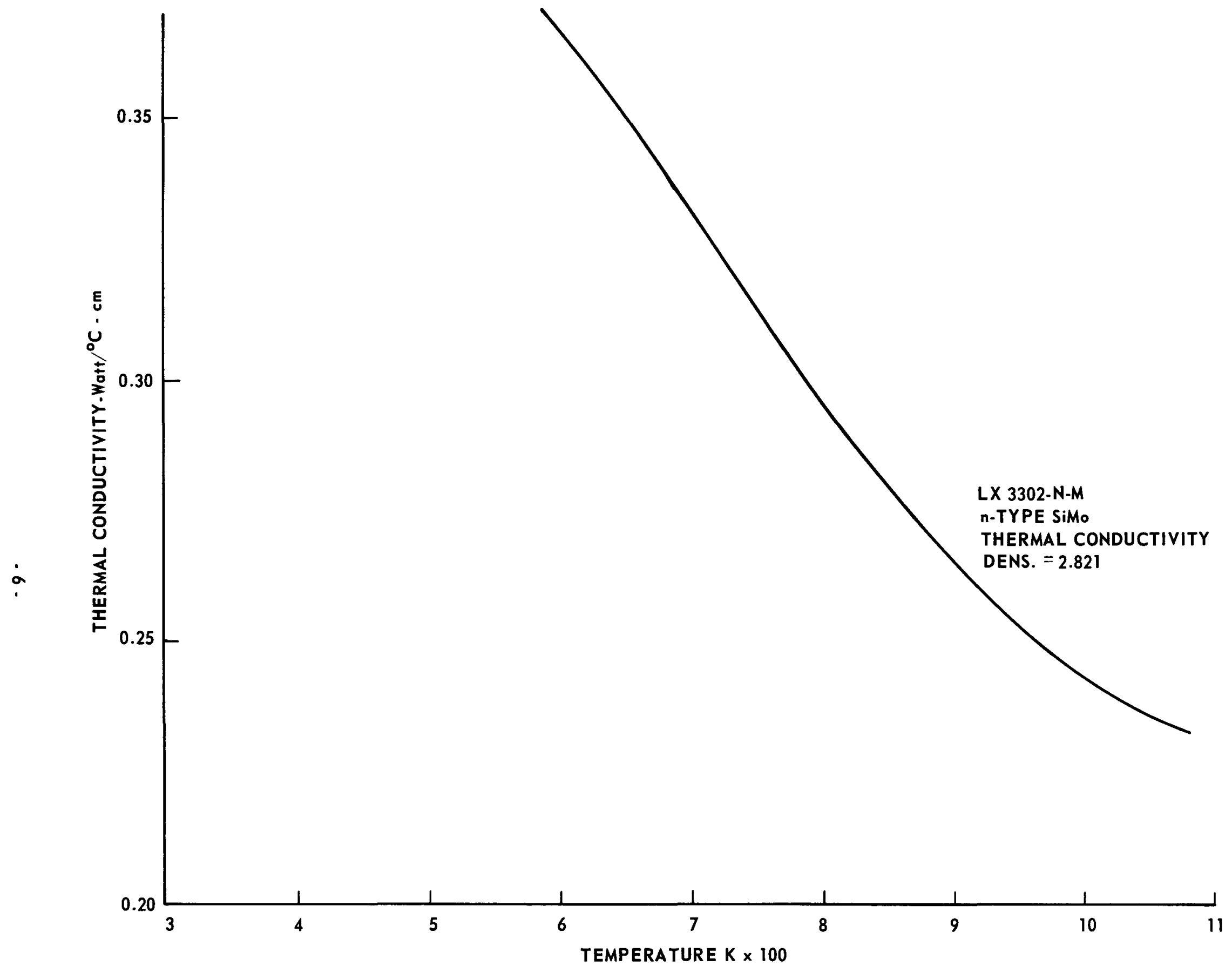

FIGURE 3. THERMAL CONDUCTIVITY OF PHOSPHORUS-DOPED SIMO ALLOY AS A FUNCTION OF TEMPERATURE 
the decrease of the thermal conductivity with increasing temperature. Materials with higher thermal conductivities are still being investigated for use in hot shoe stmuctures (Task 2).

Metallographic_Analysisis: The previous quarterly report described the external appearance and cracking which is frequently noted in SiMo castings. To determine the nature and the extent of the cracks and to show the relationship of microstmucture in cracking, an intermal metallographic study was completed. The results showed that the cracks extend in a general radial direction from the surface toward the core of the ingot. They occur as bands of numerous cracks which increase in number as the band progresses toward the center, and then diminish at various distances. The cracks were not observed as discrete discontinuities in the material but rather were often partially filled in and healed by the molten alloy from the core. This condition is demonstrated in Figure 4 where, of the large number of cracks shown, the larger crack towards the lower right cormer appears partially filled by a flow of molten material. Moreover, all cracks may not occur at the same time and several were observed to traverse one which was previously healed.

Inasmuch as $\mathrm{Si}$ expands approximately ten percent on solidification, the rate at which such solidification occurs becomes critical. In the range of the $85 \mathrm{wt}$. percent Si alloy involved, the partial phase diagram (Figure 5) shows that, for a given cooling rate, the solidification occurs almost instantaneously at approximately $1410^{\circ} \mathrm{C}$, while at the highest Si composition, the alloy solidifies gradually from approximately $1430^{\circ} \mathrm{C}$ and terminates at the eutectic, approximately $1410^{\circ} \mathrm{C}$.

The wider range over which cooling may be affected is more desirable because the expansion which accompanies solidification is more gradual, and dimensional adjustments are more readily affected without cracking. The eutectic composition is therefore undesirable because the rapid cooling of this composition might have a shattering reaction in an ingot.

Metallographic examination of binary SiP and SiB alloys showed them both to have matrix stmuctures. The termary SiMo shoe materials with either B- or P-dopants also exhibited similar matrix structures. Accordingly, the dopant appeared to be a major factor in controlling the matrix structure. The literatural indicates that a dopant concentration in excess of

1. G.L. Pearson, "Electrical Properties of Silicon", Phys. Rev。75, 867-868 (1949). 


\section{CRACKS (BLACK AREAS)}

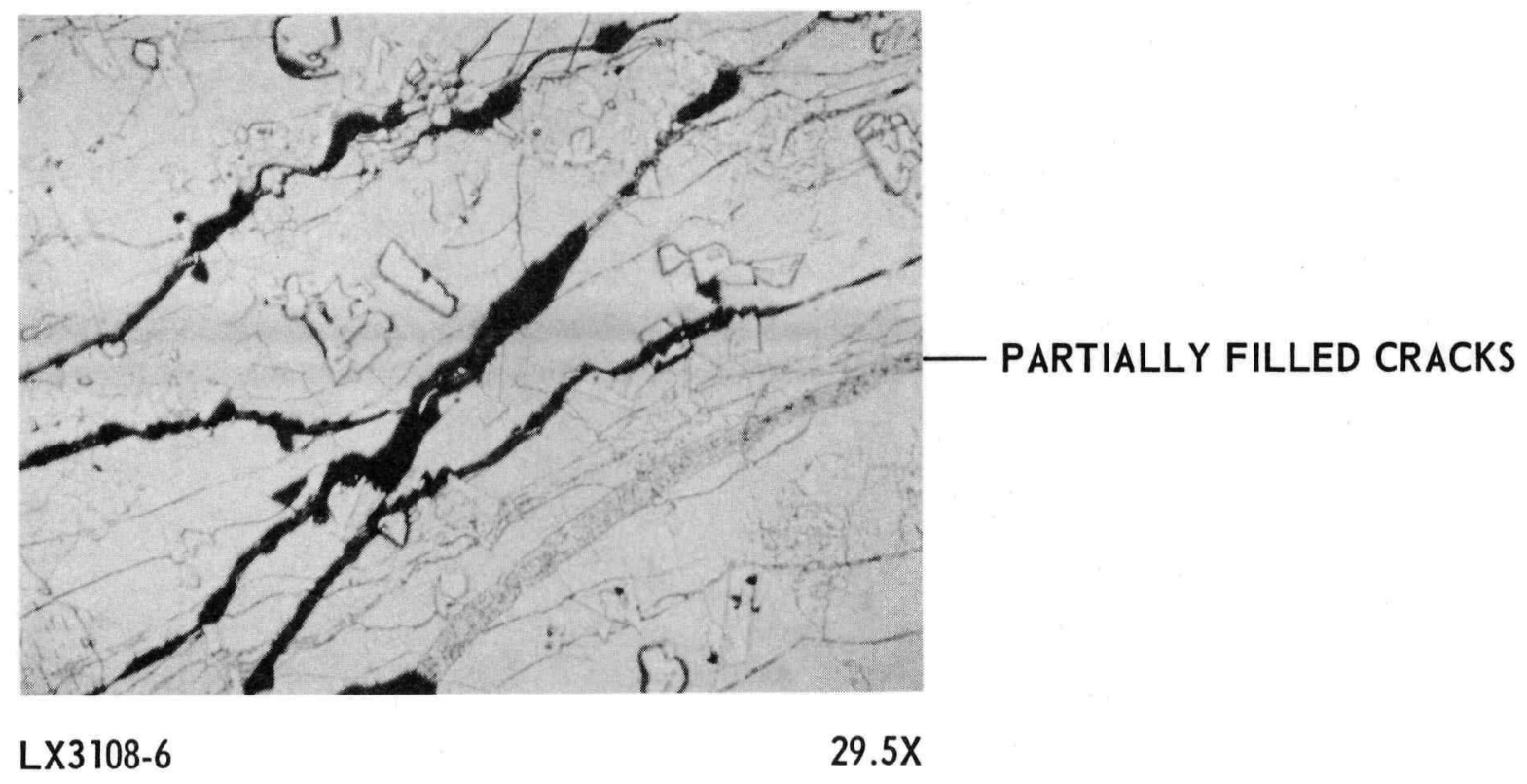

FIGURE 4. SiMO INGOT STRUCTURE p-TYPE 


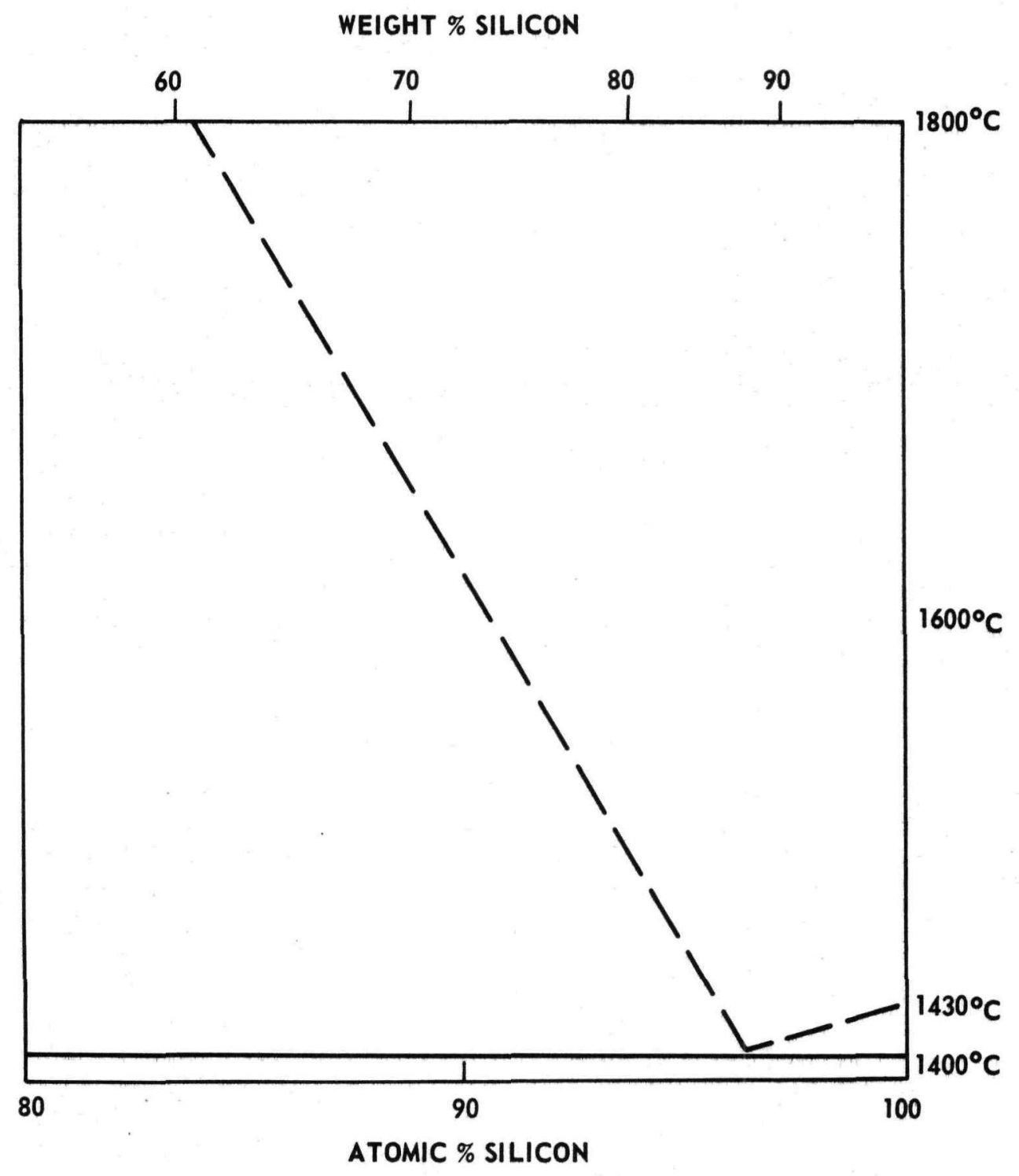

FIGURE 5. SILICON-MOLYBDENUM PHASE DIAGRAM 
0.5 wt percent produces the precipitation of a second phase. In the B-doped material, this excess dopant produced a eutectic-like structure (Figure 6) which affected the solidification rate but did not necessarily enhance the electrical properties. The SiMo shoe material may also be considered as a composite material. In the Bdoped material, the structure appeared similar to that of the SiB binary system, but modified by the addition of a third constituent which remained largely independent of the system as shown in Figure 7. The massive white phase was tentatively identified as pure Mo in the undissolved state. The existence of this excess Mo reflects the unique character of the melting cycle in that it controls both the composition and solidification rate of the alloy.

The metallographic examination of the alloy also showed that the Mo distribution was more concentrated in the lower portions of the ingot and quite sparse toward the top. This condition was also reflected by density measurements which showed a similar gradient.

The metallographic examination of the SiMo alloys indicated that the minimizing of eutectic phases in the alloys reduced rapid dimensional changes and thereby minimized or eliminated cracking. The presence of excess dopant in the form of accumulations at grain boundaries and as undesirable phases, indicated that reduced dopant levels may enhance the physical condition of the resulting ingot without detriment to the electrical properties. The effects of dopant levels on the electrical properties is reported in the section dealing with the optimization of the present shoe material. (See Figure 8.)

\section{c. Bonding}

The First Quarterly Report described the bonding of a series of elements representing state-of-the-art techniques. These elements were made for isothermal testing in air and vacuum at temperatures of 950,1000 , and $1100^{\circ} \mathrm{C}$. A calculation was presented of the electrical contact resistances across the SiGe to SiMo interfaces and the n-type to p-type SiMo bonds. During this reporting period, an additional group of 50 test thermocouples was fabricated for evaluation of the short term characteristics of the materials and bonds under similar conditions. These elements will be exposed for periods of from 25 to 250 hours after which metallographic examination will be completed. Changes in weight, total and contact resistance, and tensile strength will be noted at various downtimes up to 5000 hours life.

The second group of thermocouples demonstrated improved reliability in the measurement of the electrical contact 


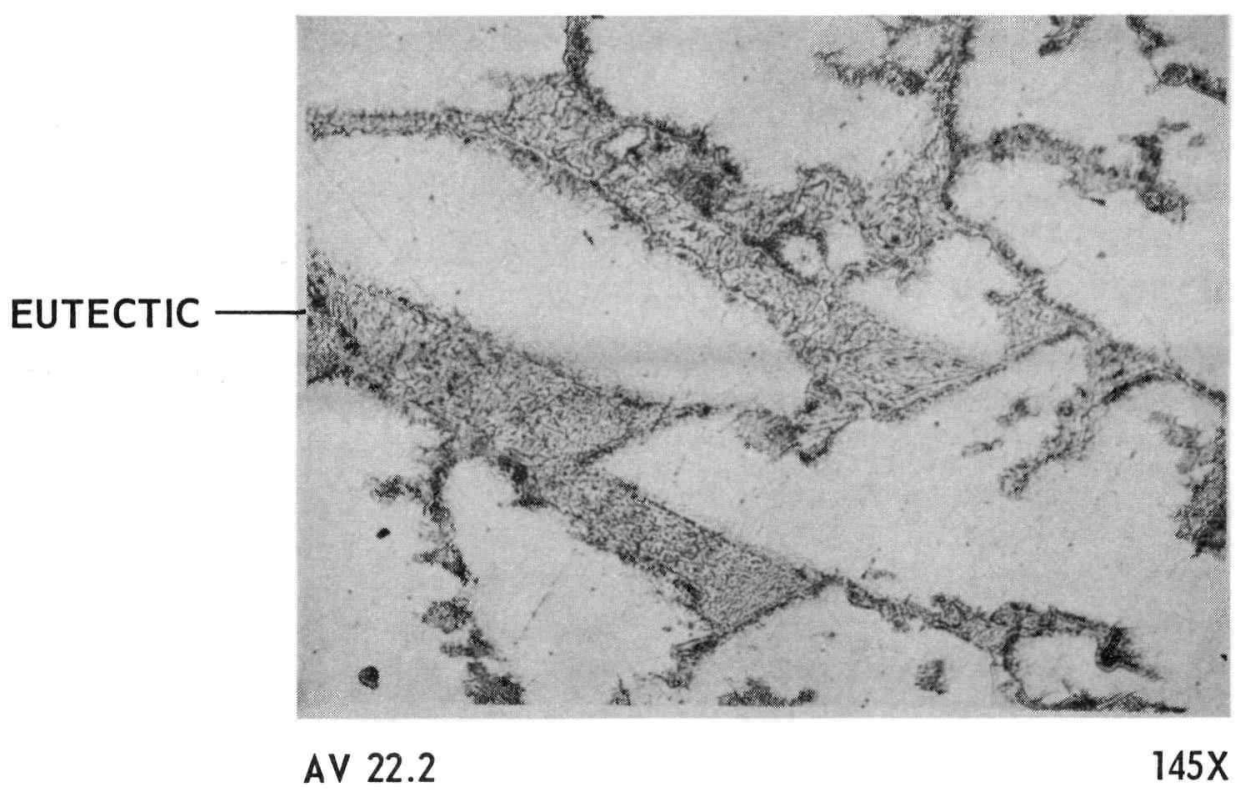

FIGURE 6. SIB ALLOY SHOWING EUTECTIC PHASE 


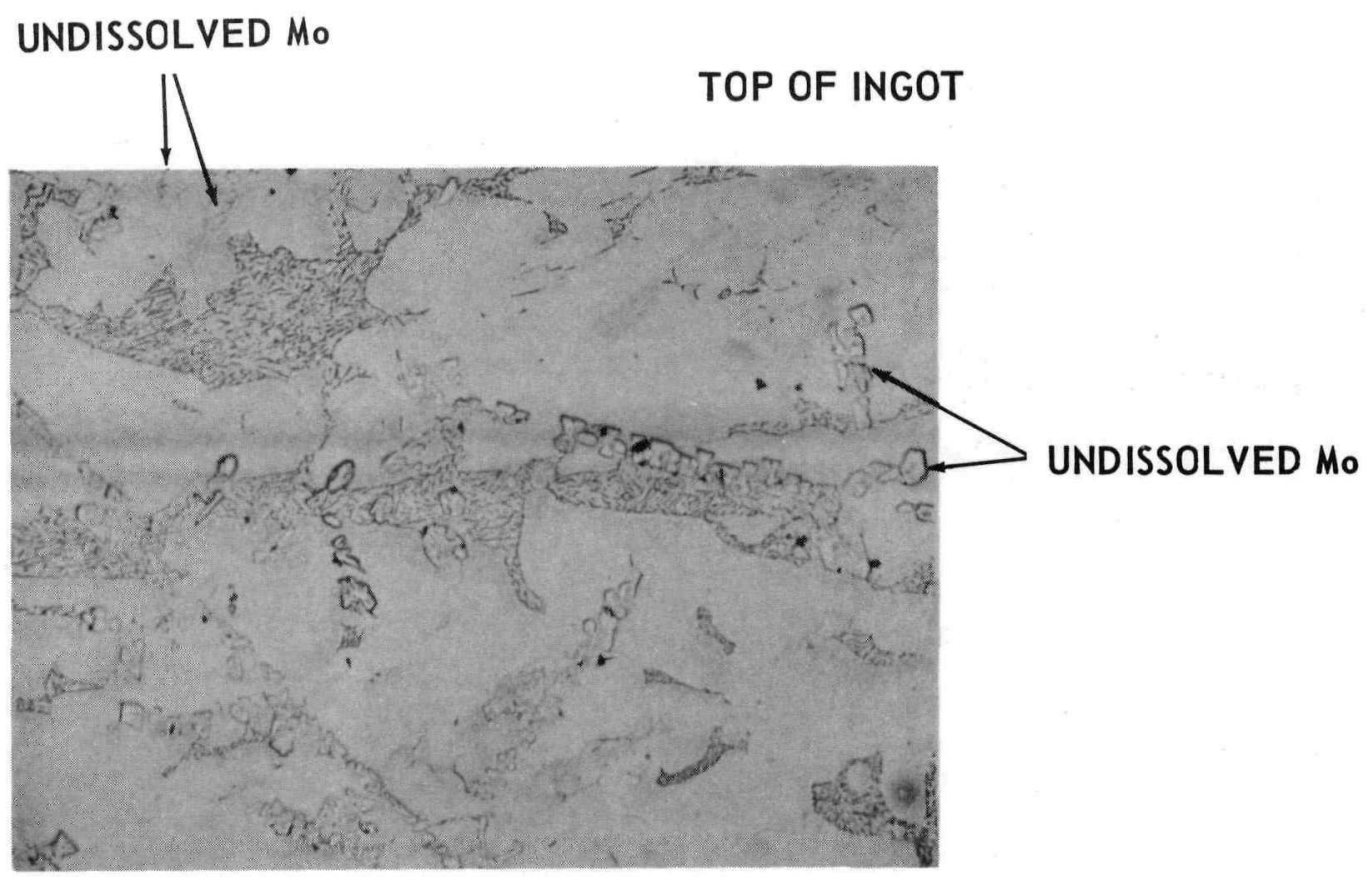

FIGURE 7. SiMo INGOT STRUCTURE - p-TYPE, LARGE Mo PARTICLES AT TOP 


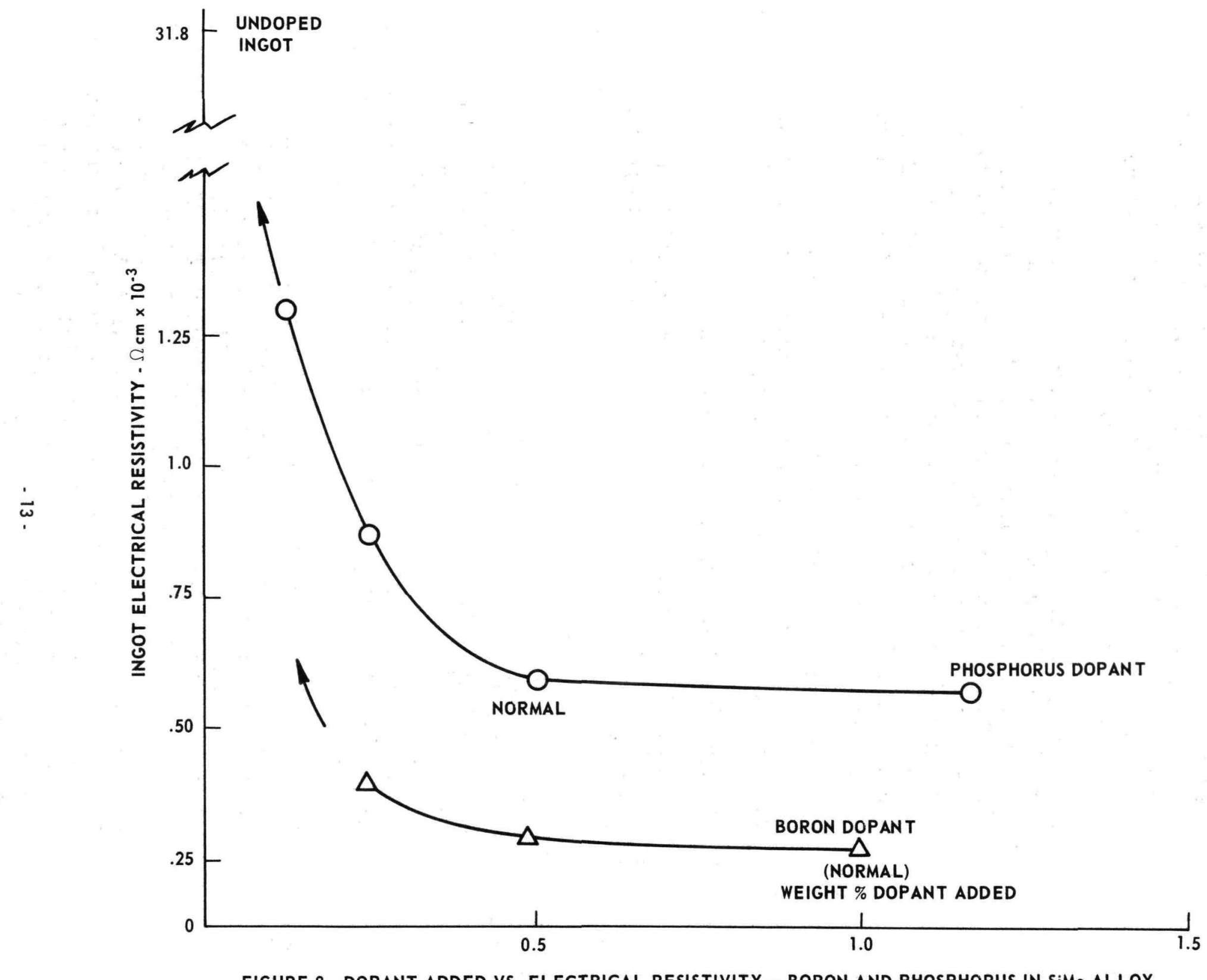


resistances. A better current distribution was achieved during measurement in the couple by an improved method of attaching the current contact leadso The average values of resistance showed no change and a tighter grouping in population was evident. For example, the initial spread of values of the $n-p$ bond was 0.08 to $0.05 \mathrm{~m} \Omega$. The second group with the improved measuring technique showed a spread of 0.08 to $0.26 \mathrm{~m} \Omega$. Similar improvement was experienced with the $\mathrm{p}-\mathrm{p}$ and $\mathrm{n}-\mathrm{n}$ bonds.

Preliminary metallographic examination was conducted of several bonds in the as-bonded condition. A Ge-rich area was evident at the interfaces. The p-type element showed fillets which were generally lacking in the n-type element bond. In some instances, cracking was evident at the edges of the bonds. The location and direction of these cracks indicated that they might have resulted from shock cooling or an expansion mismatch. A continuous bond was present for the most part.

A more detalled analysis will be conducted when lifetested elements become available, at which time the effects of time and temperature will be observed.

\section{Physical and Chemical Properties Optimization}

This portion of the program focuses on methods by which the present SiMo hot shoe material will be optimized with respect to its physical and chemical properties.

\section{a. Dopant Concentration}

The metallographic studies conducted on SiMo ingots doped with $B$ and $P$ indicated the feasibility of lowering the dopant levels to improve the structural soundness of ingots. During this reporting period, a series of n-type-and ptype-doped SiMo alloy ingots were cast to determine the effects of dopant level variations on the electrical, metallographic, and other physical characteristics of the materials.

Figure 8 shows the change in electrical resistivity which occurred when the amount of dopant added to the melt was varied. The curve also indicates that resistivity may be altered by the use of either dopant until a level is reached where additional dopant has a negligible effect on lowering the value. It further indicates graphically that very small amounts of dopant can alter the resistivity greatly. The P-doped ingot containing 0.125 wt. percent dopant has a resistivity of $1.26 \times 10^{-3} \mathrm{ohm} \mathrm{cm}$ in comparison with $31.8 \times 10^{-3} \mathrm{ohm} \mathrm{cm}$ in the undoped ingot. Diffusivity measurements will be made on those ingots containing other than the "normal" amount of dopant to determine the high temperature effects of the variations。 


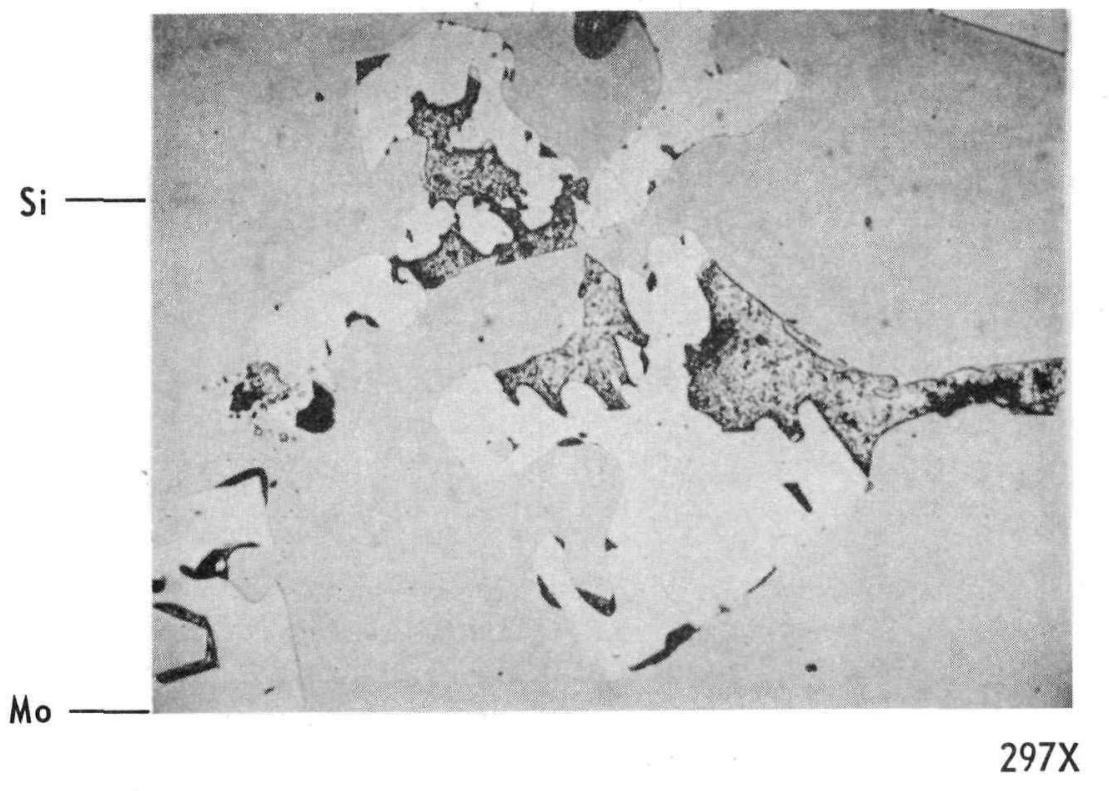

\section{A. ALUMINUM-RICH PHASE ADJOINING WHITE UNMELTED Mo PHASE}

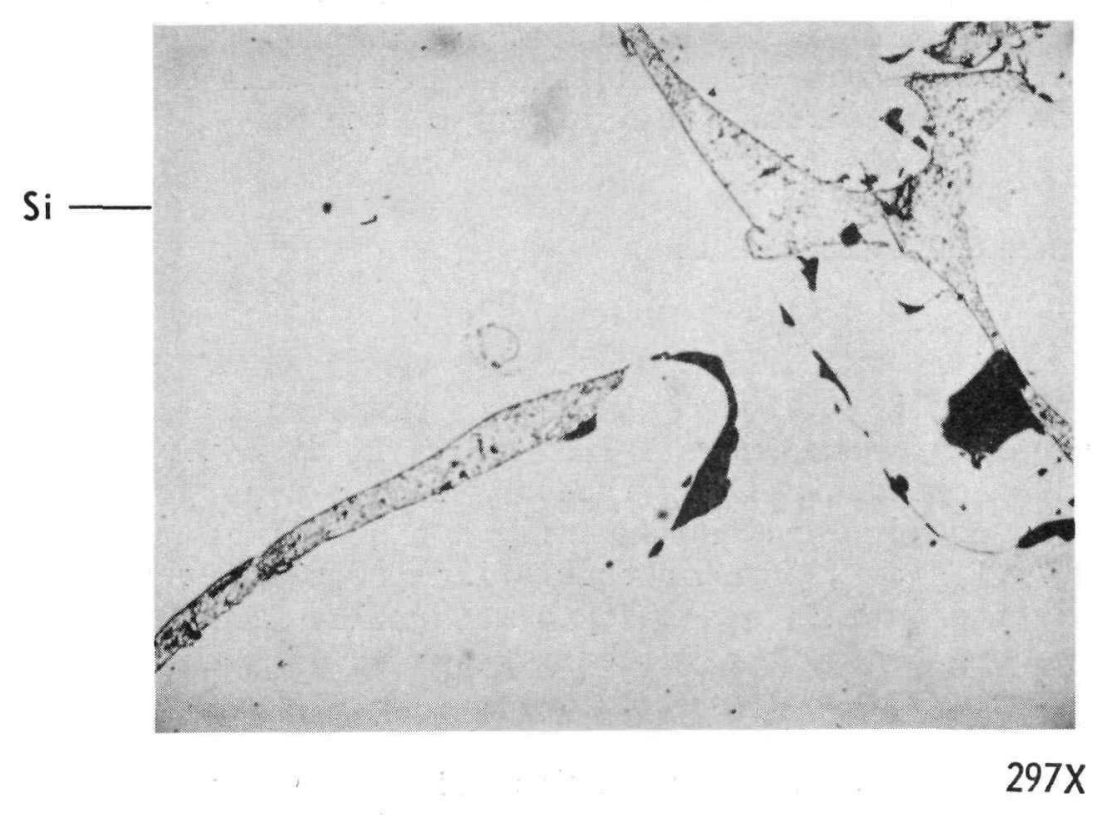
B. ALUMINUM-RICH PHASE ISOLATED IN PRIMARY Si

FIGURE 9. SIMO SHOE MATERIAL - ALUMINUM DOPED-DISPOSITION OF ALUMINUM-RICH PHASE 
The absence of holes in the P-doped ingot containing 0.125 wt. percent was noteworthy in contrast with the heavier doped ingots. The effects of the lower dopant level will therefore be investigated to determine its effects on such porosity in cast ingotso Metallographic analysis of these materials is presently in process.

b. Alternate Dopants

The eveluation of alternate dopants was initiated with the successful casting of an aluminumdoped 85 wt. percent SiMo alloy. In this initial effort, the dopant concentration was maintained at the same level as is used in B-doping. The electrical resistivity of the ingot was measured at $1.18 \times 10^{-3} \mathrm{ohm} \mathrm{cm}$ and had a bulk density of 2.671 grams per cc. (The resistivity of a standard B-doped ingot is approximately $0.26 \times 10^{-3} \mathrm{ohm}$ cm.) The physical and chemical properties of the Aldoped materials will be characterized.

A preliminary metallographic examination revealed that the Al additive had no detrimental effects on the structure relative to its function as a show material. The basic effects of the Al was an Al-rich yellow phase which appeared in two modes. One was predominant and concentrated about the unmelted Mo particles (Figure 9a), and the other was a lesser isolated deposit in the primary Si matrix (Figure 9b). Additional melts will be made to reduce the electrical resistivity of the Aldoped alloy.

\section{Investigation of Production Methods}

a. Hot Pressing

Silicon-molybdenum ( 85 wt。 percent Si) was prepared by vacuum hot pressing. Specimens $1-1 / 8$ inches in diameter were prepared by blending SiB ( powders with Mo powders and subsequently hot pressing. Densities of $2.71 \mathrm{~g} / \mathrm{cm}^{3}$, or near theoretical $\left(2.69 \mathrm{~g} / \mathrm{cm}^{3}\right)$, were achieved with both $\mathrm{P}$ - and B-doped materials. The specimens were pressed to the geometry required for subsequent $n-p$-type disc bonding.

The initial specimens were prepared from SiB or SiP and Mo powders to avoid the precasting and powdering of the $\mathrm{Si} / \mathrm{Mo} \mathrm{Si}_{2}$ alloy which is difficult to pulverize. The use of elemental materials also affords a much greater degree of compositional uniformity within and between hot pressed discs. In subsequent tests, SiP or SiB powders will be blended with Mo $\mathrm{Si}_{2}$ powder and hot pressed to more closely approach the current product cast SiMo alloy composition. 
The hot pressed 1-1/8-inch diameter discs were bonded in the usual manner and subsequently machined into hot shoes of the test configuration. Thermocouples were fabricated from the hot shoes and 63.5 at. percent SiGe. Photomicrographs in Figure 10 compare the SiGe-SiMo bonds obtained with both hot pressed and vacuum cast SiMo. Both bonds are normal and free from voids or other structural defects.

The electrical properties (bulk and contact electrical resistances) of the thermocouples that used hot pressed SiMo hot shoes were comparable to those observed with thermocouples of the same geometry that used vacuum cast SiMo shoes. The test thermocouples were placed in isothermal life in air and vacuum at $1000^{\circ} \mathrm{C}$ to determine electrical changes as a function of time, temperature, and environment.

However, the 1-1/8-inch diameter disc was too small to provide specimens for meaningful determination of thermal and electrical properties of hot pressed SiMo alloys. For this reason, the vacuum hot press was modified to permit the preparation of 2-inch diameter specimens from which bars could be machined for the measurement of the transport properties and the coefficient of thermal expansion. Both $n$ - and p-type diffusivity bars, $1 / 4 \mathrm{x}$ $1 / 4 \times 1-3 / 4$ inches in geometry, were fabricated and submitted for testing. Additional studies on the chemical and physical properties of hot pressed SiMo are in process.

4. Air-Vac Thermocouple Bond Evaluation

A high mass, low thermal inertia experimental furmace was used to test the endurance of SiGe-to-SiMo bonds. The furmace, designed to operate in air between $100^{\circ} \mathrm{C}$ and $1100^{\circ} \mathrm{C}$, has a maximum rate of temperature increase of $100^{\circ} \mathrm{C}$ per minute and a maximum cooling rate of $100^{\circ} \mathrm{C}$ per minute.

The furmace was used to obtain a definite end point for a thermal cycle test in which a test specimen was mounted vertically with a weight attached to the bottom end of a bonded stmucture. If the stresses induced by the thermal cycling cause microcrack formation, the weight will propagate the cracks across the interface and cause the specimen to separate. At this point, the furnace automatically shuts off. The bonded specimens can be mounted so that the weight can produce a tensile force, a shear force, or a bending moment.

Current hot-pull tests involve nominal 85 wt. percent SiMo shoes bonded to a 63.5 at. percent Si pellet by state-of-theart methods; both $\mathrm{n}$ - and p-type elements are included. The thermal cycle sequence is as follows: 

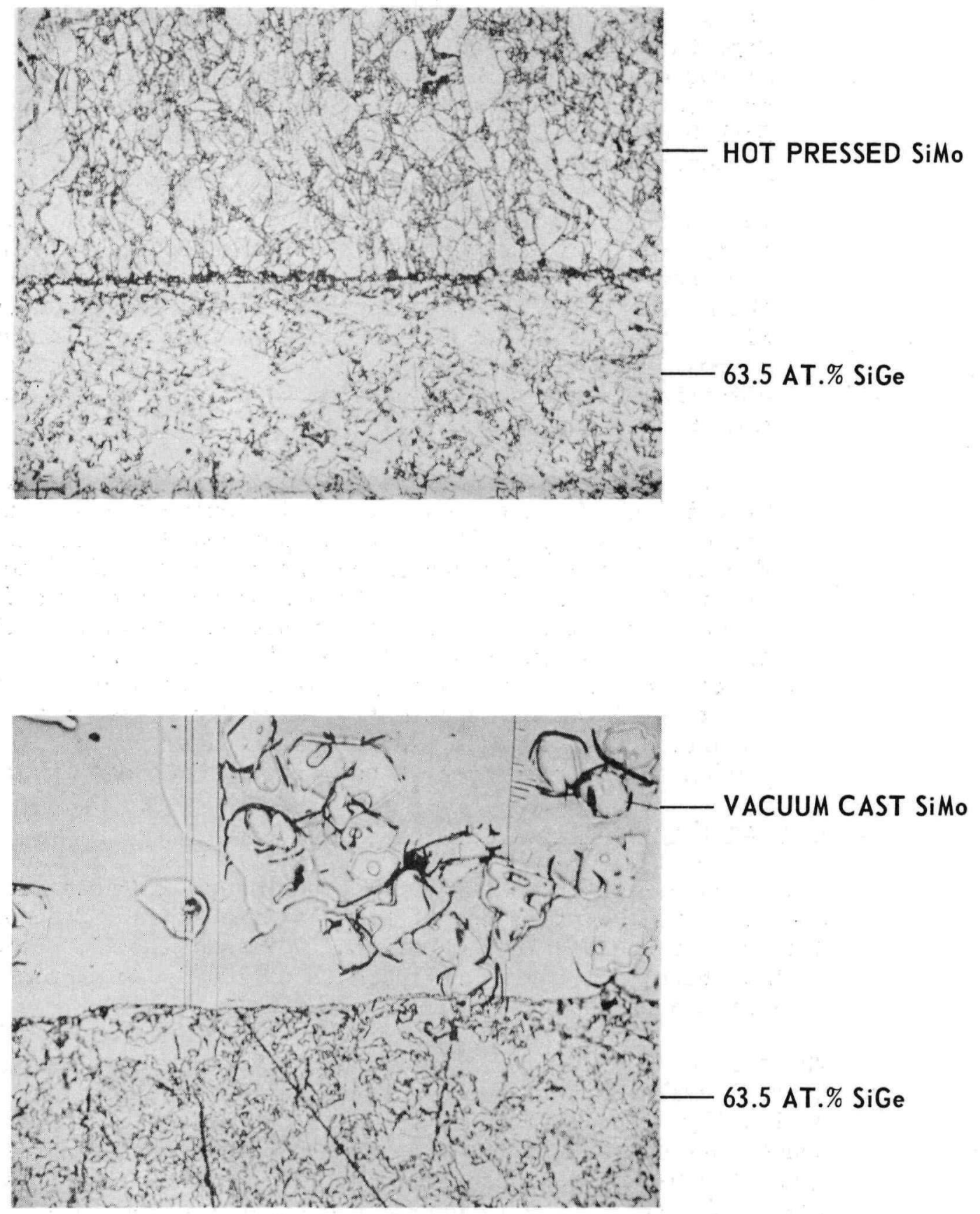

FIGURE 10. COMPARISON OF HOT PRESSED SiMo AND VACUUM CAST SiMo BONDED TO 63.5 ATOMIC \% SiGe 


$$
\begin{aligned}
& \text { Heat } 100^{\circ} \mathrm{C} \text { to } 1100^{\circ} \mathrm{C} \text { in } 11.0 \text { minutes } \\
& \text { Hold } 1100^{\circ} \mathrm{C} \text { for } \\
& \text { Cool } 1100^{\circ} \mathrm{C} \text { to } 100^{\circ} \mathrm{C} \text { in } 13.0 \text { minutes } \\
& \text { Hold } 100^{\circ} \mathrm{C} \text { for } \\
& \text { Total Cycle Time } 42.3 \text { minutes } \\
& \text { Tinutes }
\end{aligned}
$$

Temperature cycling was completed as described on three n-type SiGe elements bonded to n-type SiMo shoes. After 26, 87, and 200 cycles to $1100^{\circ} \mathrm{C}$ in air, the samples were examined metallographically; none of the bonds separated during the test. The specimen showed voids in the SiGe near the bond areas, apparently enlarging in size as the number of cycles increased. Figure 11 shows unetched sections of as-grown SiGe alloy (a) and as-bonded SiGe to SiMo alloy (b). Figure 12 depicts the formation of voids in the thermally exposed specimens.

In normal device operation, the bonds would not be subjected to such extreme temperatures and thermal stresses. Despite the severe conditions, the bonds remained intact and the room temperature contact resistance remained stable indicating the SiMo-to-SiGe metallurgical bond to be exceptionally sound. Although the voids are apparently not detrimental, additional testing to determine their origin is in process.

\section{B. TASK 2. ALTERNATE HOT SHOE MATERIALS AND BONDS}

The first objective of this task was to develop and evaluate high conductance metallic, intermetallic, or composite hot shoes for use in primary launch environments or in vacuum at temperatures above $900^{\circ} \mathrm{C}$. A second objective was to develop and evaluate high-temperature, long-life bonds between SiGe and selected hot shoe materials.

Several factors dictated the selection of hot shoe materials. Included among these were the air and vacuum high temperature operating conditions, the properties of the SiGe alloy to which the hot shoe is bonded, and the electrical and thermal properties of the material. Of primary consideration was the adaptability of the material to production fabrication techniques and to process control limitations.

The altermate materials should form an adherent, stable bond with limited interdiffusion of the hot shoe and SiGe alloy at maximum operating temperature.

\section{Materials Selection}

A literature search and review of prospective hot shoe materials was completed. Two candidate materials, SiC and coated graphite, were selected for a comprehensive evaluation. On the basis of electrical resistivity, thermal expansion, mechanical strength, and high temperature capability, these two 


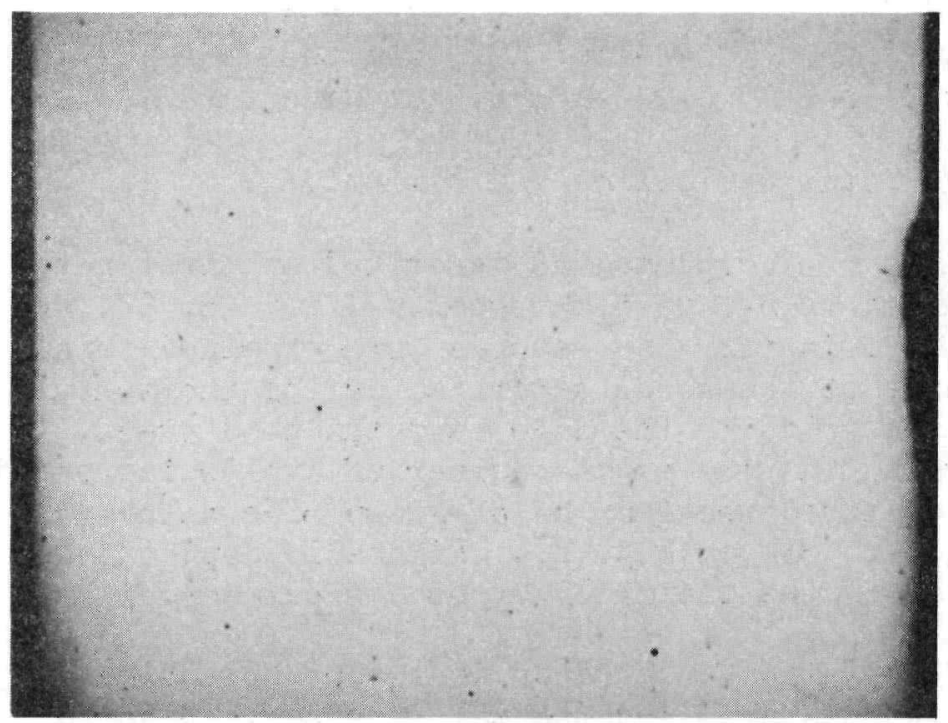

A. 63.5 AT.\% SiGe ALLOY PHOSPHORUS DOPANT AS-GROWN

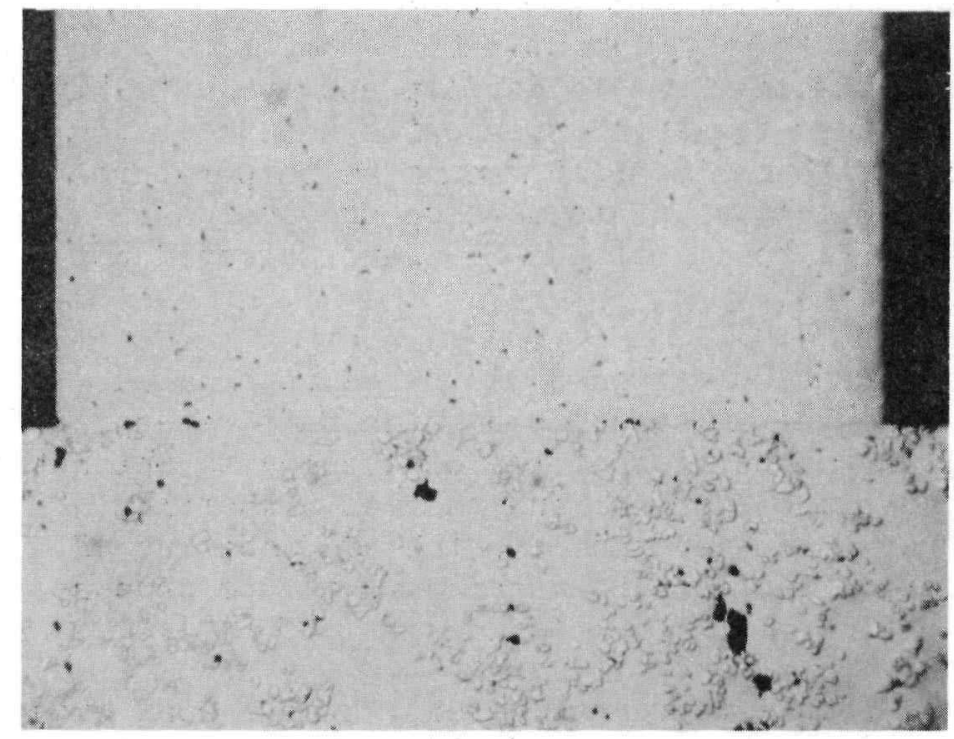

B. ELEMENT $161 \mathrm{~N}$ AS-BONDED

FIGURE 11. TYPICAL AS-GROWN AND AS-BONDED SiGe ALLOY, PHOSPHORUS-DOPED 
A. ELEMENT \#163N 26 CYCLES TO $1100^{\circ} \mathrm{C}$

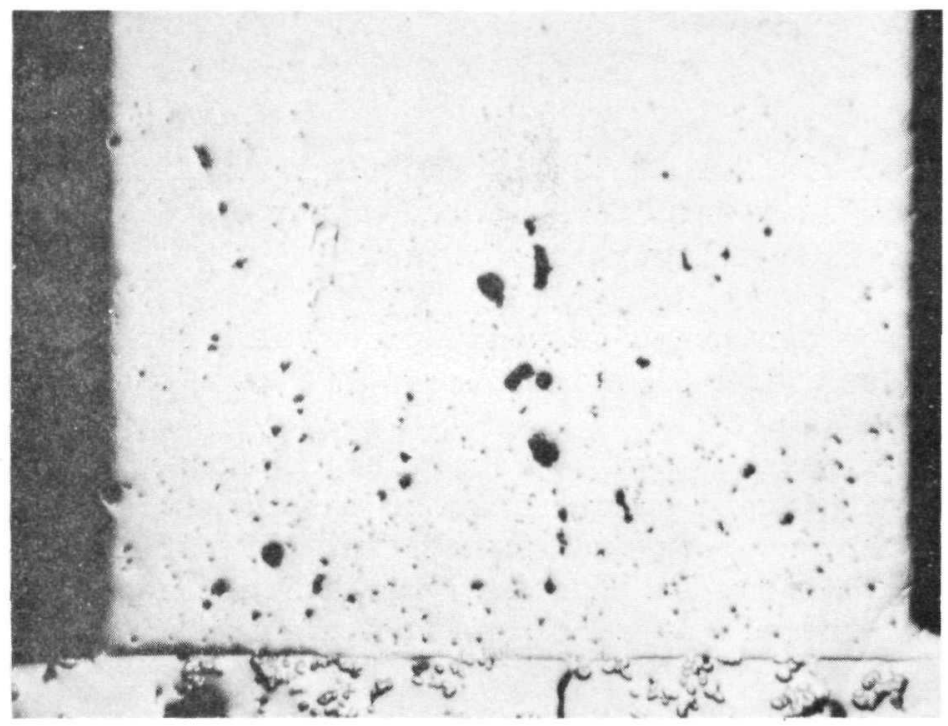

$26.3 \mathrm{X}$

B. ELEMENT \#160N

87 CYCLES TO $1100^{\circ} \mathrm{C}$

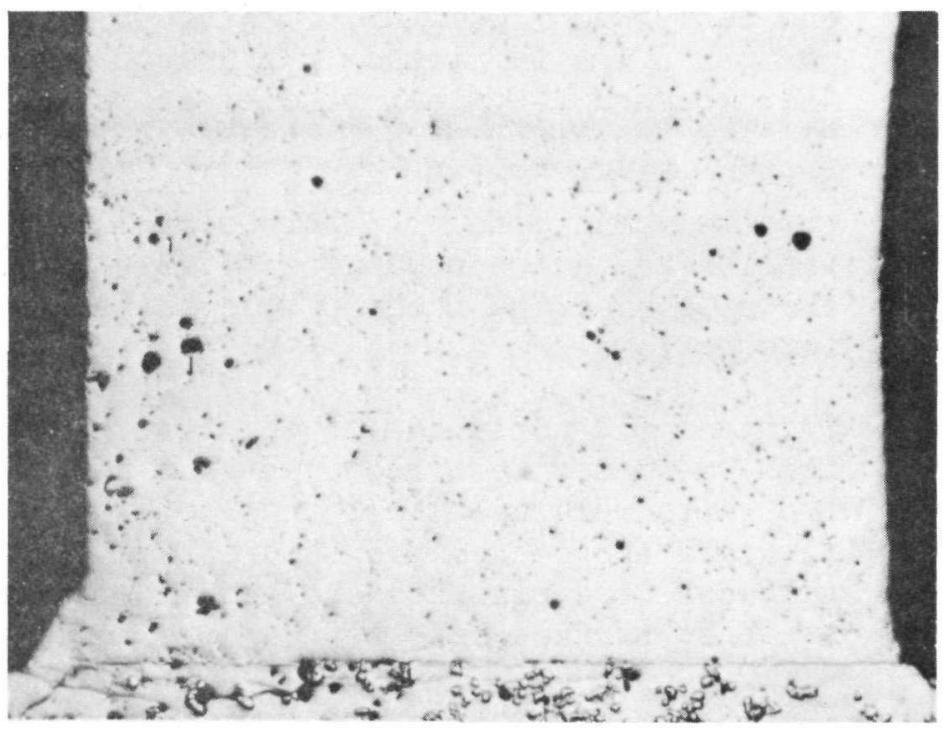

$26.3 x$

C. ELEMENT \#158N

200 CYCLES TO $1100^{\circ} \mathrm{C}$

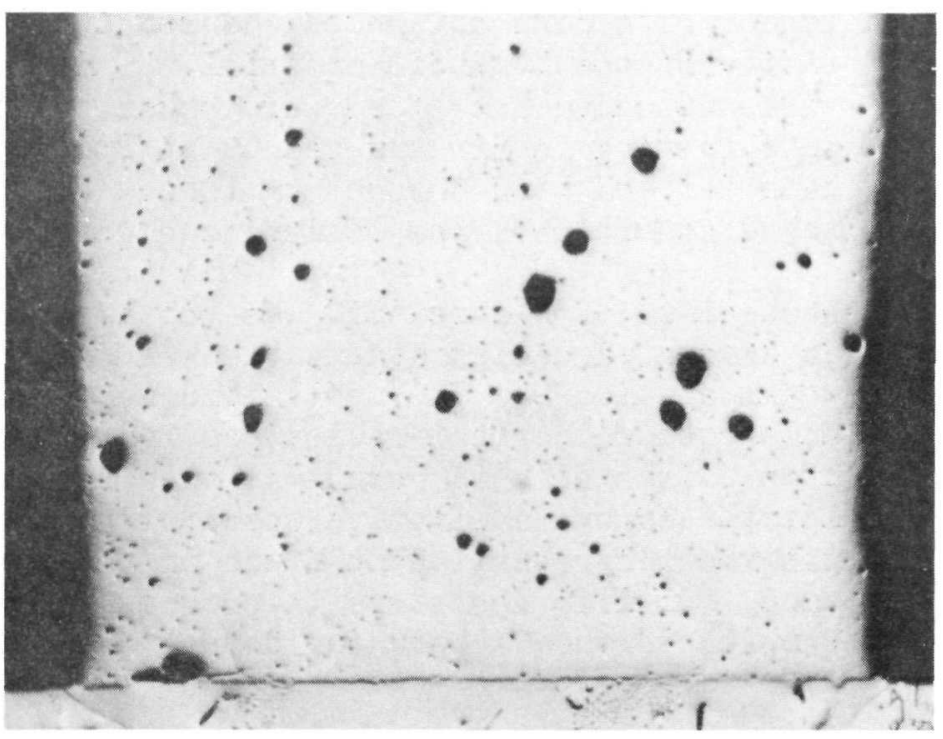

FIGURE 12. THE EFFECTS OF THERMAL EXPOSURE ON n-TYPE SiGe TO SiMo BONDED ELEMENTS 
materials most nearly met the qualifications for an altermate hot shoe structure. Both materials can be bonded to a range of SiGe alloy compositions.

Although graphite requires oxidation-protection, preliminary tests with Si and SiC coatings were encouraging.

A literature survey is being conducted to compile the most recent data concerning the materials commonly used in Air-Vac thermocouples and assemblies. Of particular interest are the oxidation, sublimation, mechanical, and electrical properties of the elemental constituents as well as of the alloys.

\section{a. Silicon Carbide}

By the use of samples of n-type N-doped SiC supplied by the Carborundum Company, bonding to a range of SiGe compositions was initiated. Figures 13 and 14 are photomicrographs of typical bond areas between n-type SiC and 63.5 at. percent, 77 at. percent, and 89 at. percent SiGe. Note that the contact areas appear free of voids, cracks, or other bond defects. This series of tests helped establish tentative bonding schedules for $n$ - and p-type SiC and SiGe over the range of compositions of current interest.

Thirteen SiC hot shoes of the test $(0.100 \times 0.350 \times 0.400$ inch) geometry were received from the Carborundum Company. The parts were identical in size; the densities were uniform and approached the theoretical $3.210 \mathrm{~g} / \mathrm{cm}^{3}$. The shoe surfaces were polished and showed no evidence of porosity or other surface defects.

Ten of the hot shoes were bonded without difficulty into test thermocouples with 63.5 at. percent Si. The bond contact resistances were higher than that normally experienced with SiMo hot shoes, caused by the higher resistivity of the bulk SiC material. The bonded couples and three unbonded hot shoes were submitted for isothermal life testing in air and vacuum at $1000^{\circ} \mathrm{C}$ to determine material and bond changes on life. After 300 hours under these conditions, the resistances remained unchanged.

A specimen of $\mathrm{N}$-doped $\mathrm{SiC}$ was isothermally life tested in an evacuated, sealed quartz tube ( $1 \times 10^{-6}$ Torr) for two weeks at $1100^{\circ} \mathrm{C}$. The negligible weight loss and the unchanged electrical resistance indicated that this form of SiC is stable in vacuum at high temperatures. As identified by qualitative spectrographic analysis, Si was the only constituent found on the inner wall of the tube. Similar tests are in progress with additional samples of the Carborundum Company's SiC. 


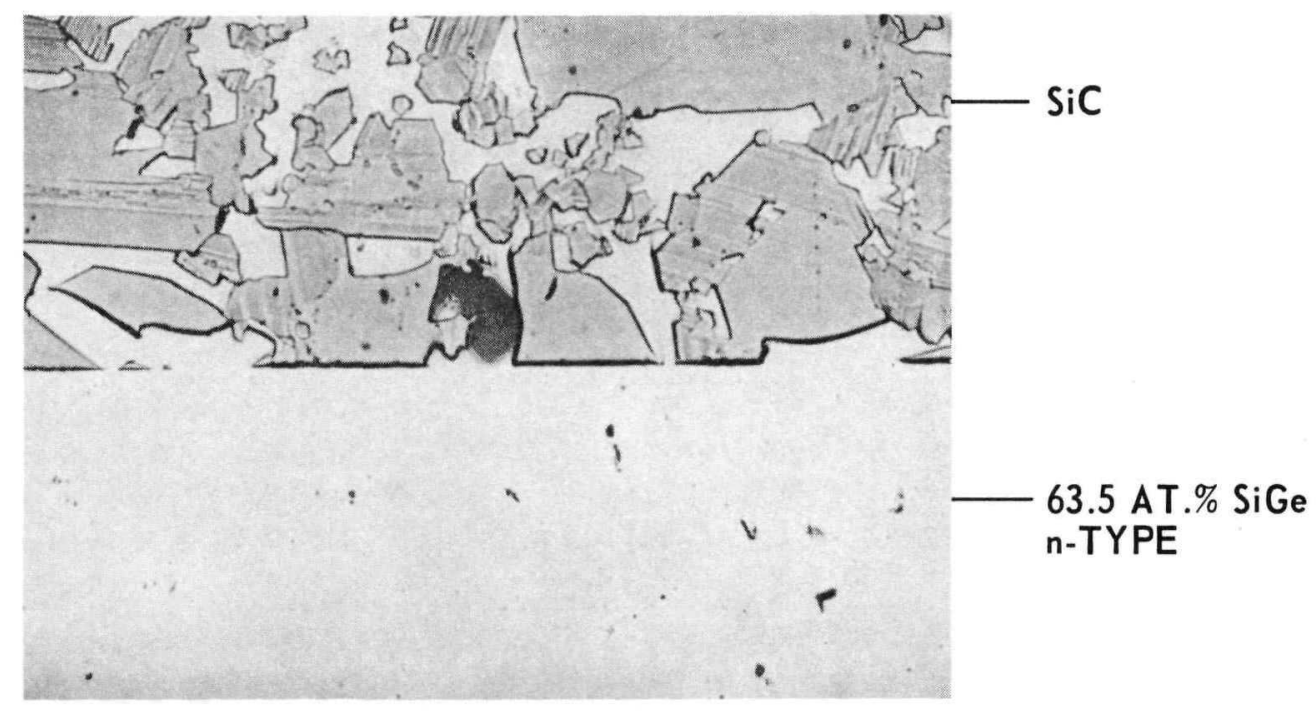

$145 \times$

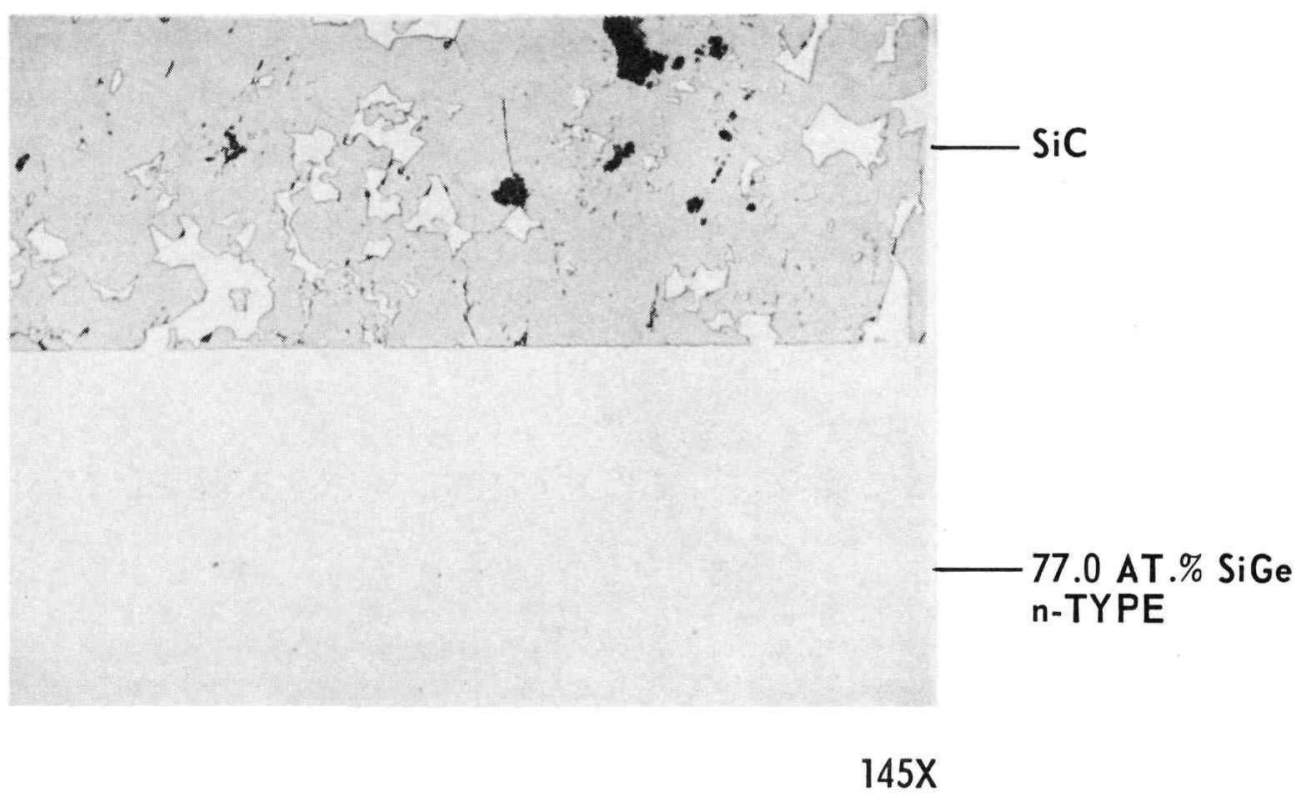

FIGURE 13. n-TYPE 63.5 ATOMIC \% SiGe AND 77.0 ATOMIC \% SiGe BONDED TO SiC 


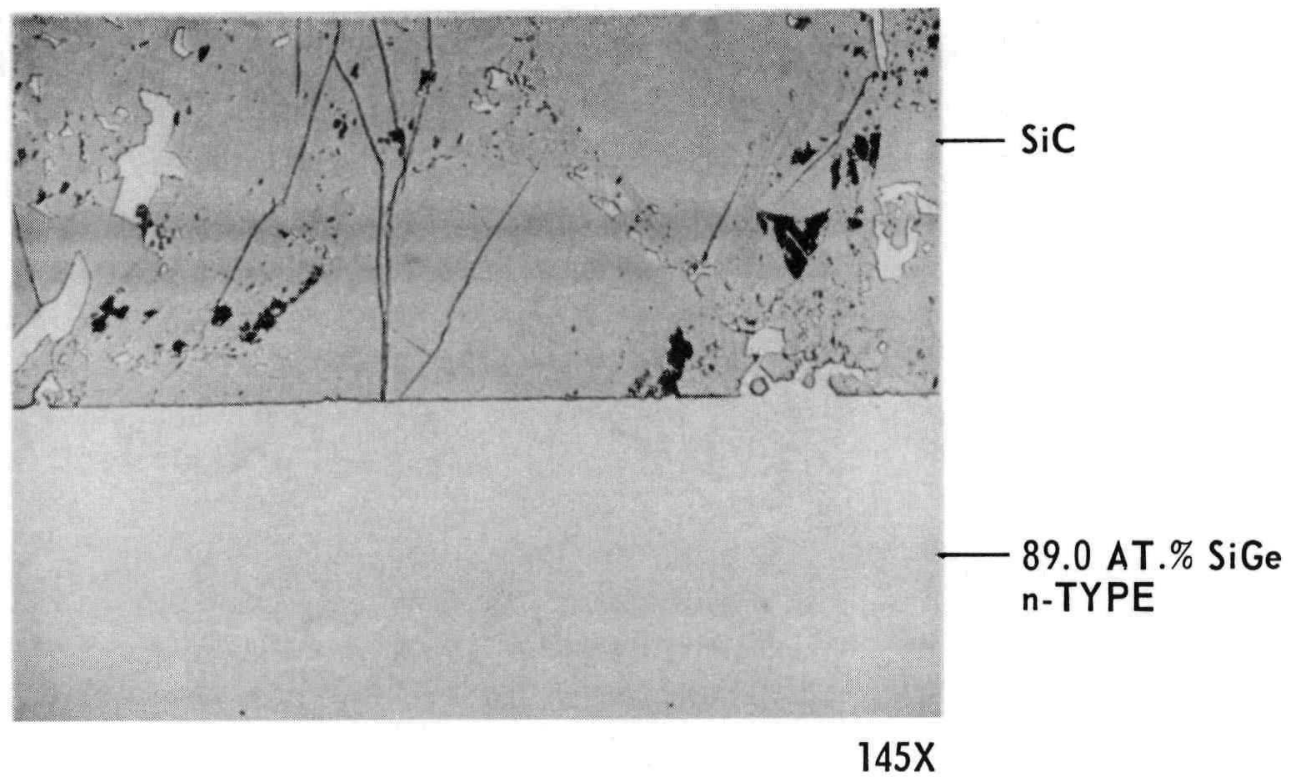

FIGURE 14. n-TYPE 89.0 ATOMIC \% SiGe BONDED TO SiC 
b. Silicon Carbide Coated Graphite

A review of currently available graphite suitable for use as a hot shoe material resulted in the selection of the Speer SX-4 product for evaluation. This material has a thermal coefficient of expansion of $4.8^{\circ} \mathrm{C}^{-1} \times 10^{-6}$ which closely matches SiGe and has a low electrical resistivity, $0.8 \times 10^{-3} \Omega \mathrm{cm}$. The expansion characteristics of $\mathrm{SX}-4$ are isotropic, making the material especially adaptable for coating with $\mathrm{SiC}$ or other suitable materials against oxidation.

The pack cementation process was used to deposit Si on SX-4 graphite for subsequent conversion to SiC. According to the literature, SiC can be obtained by direct synthesis from the elements at temperatures between $1200^{\circ} \mathrm{C}$ and $1400^{\circ} \mathrm{C}$. The test results indicated that the rates of deposition of $\mathrm{Si}$ and the formation of $\mathrm{SiC}$ at $1200^{\circ} \mathrm{C}$ were low. At $1300^{\circ} \mathrm{C}$ the deposition rate improved, but the formation of SiC was still too low. Photomicrographs of specimens processed at $1300^{\circ} \mathrm{C}$ for six hours are shown in Figure 15. Since the Inconel retorts are used for pack cementation, $1300^{\circ} \mathrm{C}$ is the maximum operating temperature.

The most promising method for applying oxidation-resistant coatings to graphite is vapor deposition. Accordingly, a vapor plating chamber was designed and is being fabricated for the controlled application of such coatings. Thin, coherent films of oxides, nitrides, carbides, and metals can be reliably and uniformly applied to hot or cold shoes. In addition, coatings can be applied to thermocouples and other thermoelectric components which require oxidationprotection or sublimation-inhibiting coatings.

\section{c. Silicon}

Test thermocouples consisting of 63.5 at. percent SiGe legs to $\mathrm{Si}$ hot shoes completed 2500 hours of life at $11000^{\circ} \mathrm{C}$ in air. All bonds remained intact and weight changes were negligible. The Si-to-SiGe contact resistances although high, approximately $(0.9 \mathrm{~m} \Omega)$ stabilized, and the test is continuing.

Additional SiP and SiB material was vacuum-cast for fabrication into hot shoes. The shoes will be bonded into couples for a more detailed evaluation of doped Si as a hot shoe material.

\section{TASK 3. HIGH SILICON CONTENT SILICON-GERMANIUM ALLOYS}

Preliminary work at RCA has shown that alloys with approximately 80 at. percent Si are superior to the lower Si-content alloys in terms 


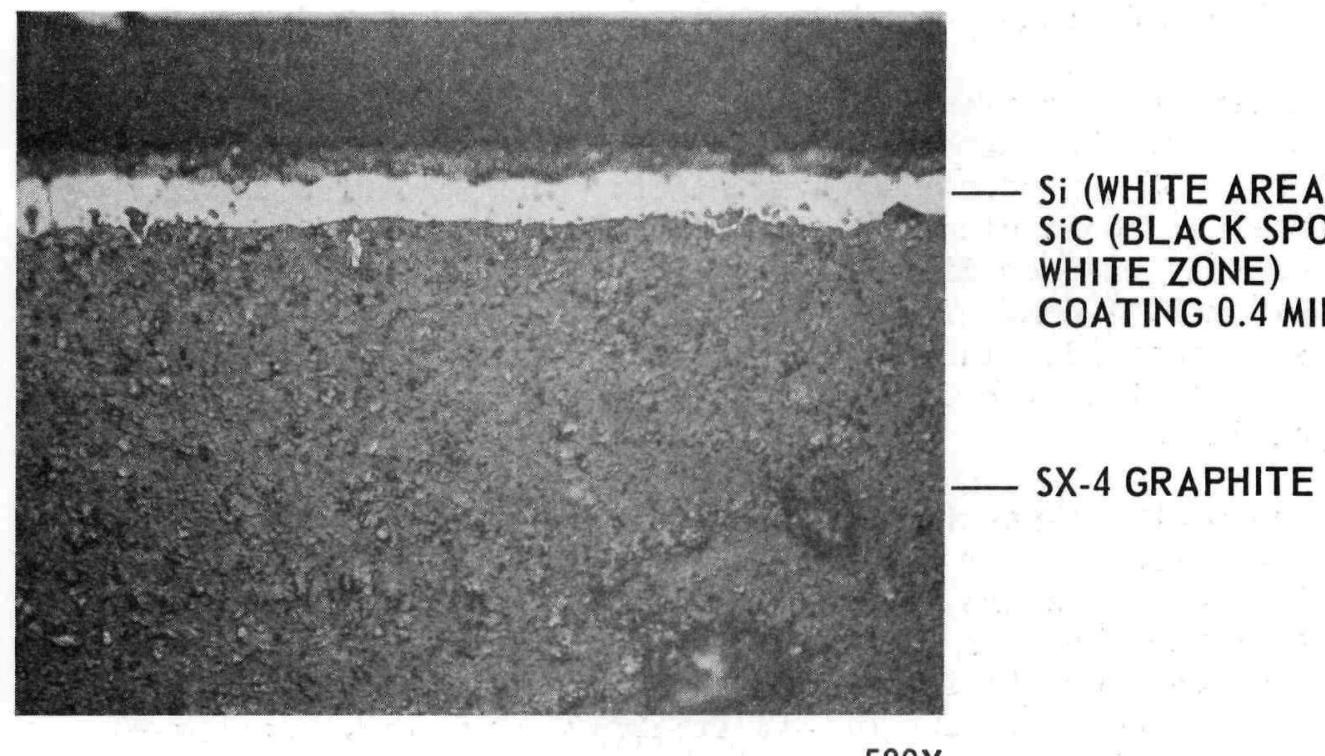

A. Si DEPOSITION ON SX-4 GRAPHITE $1300^{\circ} \mathrm{C} / 6$ HOURS

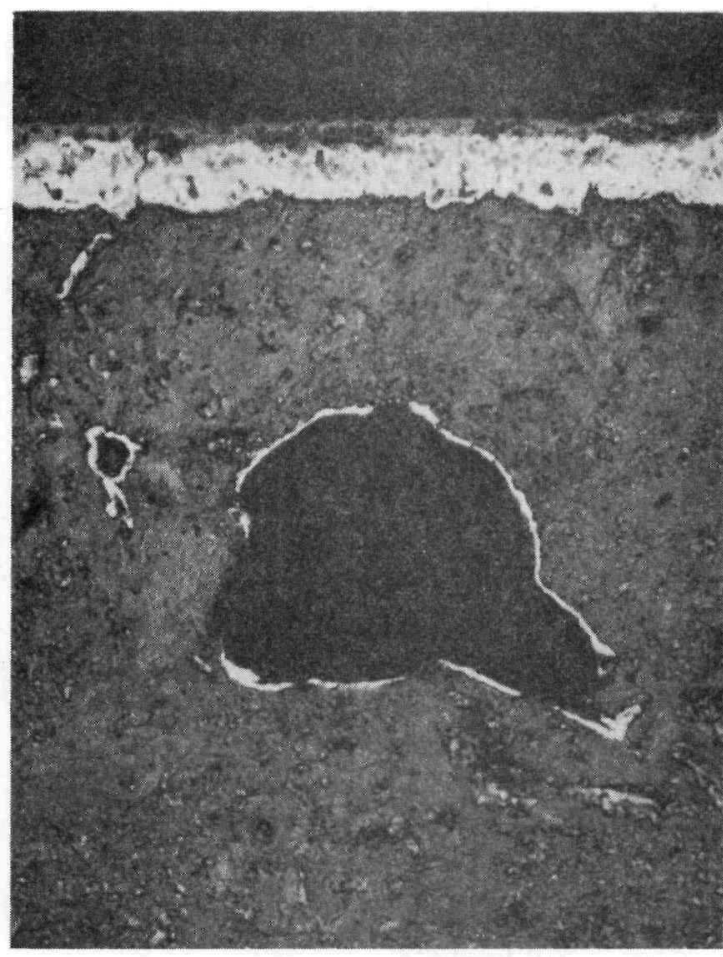

Si (WHITE AREA) AND SiC (BLACK SPOTS IN THE WHITE ZONES)

COATING 0.5 MIL THICK

$430 \mathrm{X}$

B. Si DEPOSITION ON SX-4 GRAPHITE $1300^{\circ} \mathrm{C} / 6$ HOURS

\section{SX-4 GRAPHITE}

NOTE THE SURFACES OF TWO

VOIDS COATED INDICATING

THE GOOD "THROWING POWER" OF THE PROCESS.

FIGURE 15. SX-4 GRAPHITE COATED WITH Si-SiC BY PACK CEMENTATION 
of material efficiency during the preparation of the thermoelements and in long-term stability at elevated temperatures. As a result, improved electrical performance and less mechanical stress through a better thermal expansion-match can be realized through the use of the higher si-content alloys.

The objectives of this task were to determine the optimum SiGe alloy composition, to develop and optimize fabrication and bonding techniques for 63 to 85 at. percent Si alloys, and to establish the electrical and metallurgical stability as a function of time and temperature. To achieve these objectives, it was necessary to identify the physical and chemical properties of the selected alloy compositions and to develop specifications for the preparation of the material.

\section{Physical and Chemical Properties Measurement}

To establish the chemical properties of the material, a series of samples from p-type and n-type SiGe alloys with composition variations from 75 through 85 at. percent Si were submitted for spectrographic analyses for components and impurities. In this initial test, only the head and tail of the zoned ingot were evaluated. These samples represented the extremes present in a zoned ingot after a single zoning pass. Table I summarizes the data reported on these samples. These values are qualitative and are significant only in that they indicate that the impurities are being moved towards the tail of the ingot during the leveling pass. This result is as expected, but because this zoning pass is intended to provide for a level composition with definite crystal orientation from head to tail and for uniform thermoelectric characteristics (Seebeck coefficient and electrical resistivity) along the length of ingot, these characteristics are more reliably measured by other techniques. Composition is reliably measured by determining the density and the crystal orientation by metallographic techniques; the dopant distribution is attained by measurement of the electrical resistivity, Seebeck coefficient, and $\mathrm{Hall}$ mobility.

As a result, spectrographic techniques will be used in future tests only if there is an indication of gross contamination.

\section{Physical and Chemical Properties Optimization}

Both $\mathrm{p}$ - and n-type high Si-SiGe ingots (80 and 85 at. percent $\mathrm{Si}$ were prepared to develop reliable casting techniques with uniform composition and electrical characteristics.

By changing the zone for composition and for zoning temperatures, the variation in the 85 at. percent Si composition was reduced to less than 7 percent from heat to tail. Changes in 
TABLE I

SUMMARY OF SPECTROGRAPHIC ANALYSES ON SILICON-GERMANIUM MATERIAL

\begin{tabular}{|c|c|c|c|c|c|c|c|c|c|c|c|c|c|c|c|c|c|}
\hline & & & $\% \mathrm{Si}$ & & & Ele & ent & & & & & & & & & & \\
\hline$\underline{\text { Samp }}$ & $\mathrm{ple}$ & & Comp. & $\mathrm{Cu}$ & $\mathrm{W}$ & $\mathrm{Ca}$ & AI & $\mathrm{Fe}$ & $\mathrm{Mg}$ & $B$ & $P$ & $\mathrm{Ti}$ & $\mathrm{Na}$ & $\mathrm{Mn}$ & $\mathrm{Sn}$ & $\mathrm{Cr}$ & As \\
\hline 91 & n-Type & Head & 80 & VVET & ND & VFT & VFT & VFT & VFT & ND & $\mathrm{HT}$ & ND & ND & ND & ND & ND & ND \\
\hline & Tail & & & VFT & VFT & VFT & VFT & FT & FT & ND & $\mathrm{HT}$ & ND & $\mathrm{ND}$ & ND & ND & ND & ND \\
\hline 311 & n-Type & Head & 85 & VFI & ND & ND & $\mathrm{ND}$ & VFT & VFT & ND & $\mathrm{HT}$ & ND & ND & ND & ND & ND & $\mathrm{ND}$ \\
\hline & Tail & & & FT & ND & ND & ND & VFT & $\mathrm{ND}$ & ND & $\mathrm{HT}$ & ND & ND & $\mathrm{ND}$ & ND & ND & ND \\
\hline 179 & p-Type & Head & 75 & VVF"T & ND & ND & ND & VFT & ND & $\mathrm{T}$ & ND & ND & ND & ND & ND & ND & ND \\
\hline & Tail & & & VVFT & ND & ND & FT & FT & VFT & $\mathrm{T}$ & ND & ND & $\mathrm{ND}$ & ND & ND & ND & ND \\
\hline 110 & p-Tyрe & Head & 80 & VVET & ND & ND & ND & ND & ND & $\mathrm{T}$ & ND & ND & ND & ND & ND & ND & ND \\
\hline & Tail & & & VFT & $\cdot \mathrm{ND}$ & $\mathrm{T}$ & FT & VFT & FT & $\mathrm{T}$ & ND & ND & ND & ND & ND & ND & ND \\
\hline 425 & p-Type & Head & 85 & VVET & ND & ND & ND & VFT & ND & $\mathrm{T}$ & ND & ND & ND & ND & ND & ND & ND \\
\hline & Tail & & & VVFT & ND & ND & ND & VHT & VFT & $\mathrm{T}$ & ND & ND & $\mathrm{ND}$ & ND & ND & $N D$ & ND \\
\hline
\end{tabular}

CODE (wt. percent)

ND less than 0.00001

VVFT $0.00001-0.0001$

VFT $0.0001-0.001$

FT $0.001-0.01$

T $0.01-0.1$

HT 0.1 - 1.0

H greater than 1.0 of major constituents 
zoning conditions and the cast ingot compositions are still being adjusted to minimize the variations in the ingots.

3. High Silicon-Alloy Bond Development

Development of a bonding schedule for high Si-SiGe alloy with the SiMo hot shoe was initiated. Bonding temperatures and times for 80 at. percent Si material were determined, and samples of both $\mathrm{p}$ - and n-type materials were prepared for evaluation.

Figure $16 \mathrm{a}$ and $16 \mathrm{~b}$, respectively, compare the bond between 63.5 and 80.0 at. percent Si in the SiGe and 85 wt. percent SiMo material. The samples were etched so that the bond area could be easily distinguished. In the non-etched samples, the area was not easily distinguishable in the higher Si material. The bonds were uniform and did not exhibit any extensive reaction or diffusion zones. Comparison of the two photomicrographs shows the distinct absence of Ge-rich area in the 80 percent sample. This observation should prove advantageous in the high temperature operation.

\section{Cold Shoe Bonds}

Tungsten cold shoes were coated with $0.25-$ mil $\mathrm{Cr}$ by pack cementation to protect them against oxidation when operated in air at temperatures higher than $500^{\circ} \mathrm{C}$. This process involved vapor transport of coating reactants, deposition, and diffusion of the coating constituents.

Uncoated and coated tungsten parts were life-tested in air at $600^{\circ} \mathrm{C}$ for two weeks. The uncoated parts showed a weight gain of 7.06 wt. percent, and the Cr-coated part 0.023 wt. percent, indicating substantial oxidation protection. No oxide layer was noted on the coated part; the uncoated tungsten showed evidence of heavy oxidation.

Chromium-coated tungsten shoes were bonded to 63.5 at. percent Si for air life testing. Initial bond contact resistances were low and showed only small changes after two weeks in air at $600^{\circ} \mathrm{C}$. The process parameters for depositing the $\mathrm{Cr}$ coating by pack cementation are being optimized; the primary objective is to achieve reproducibility. 


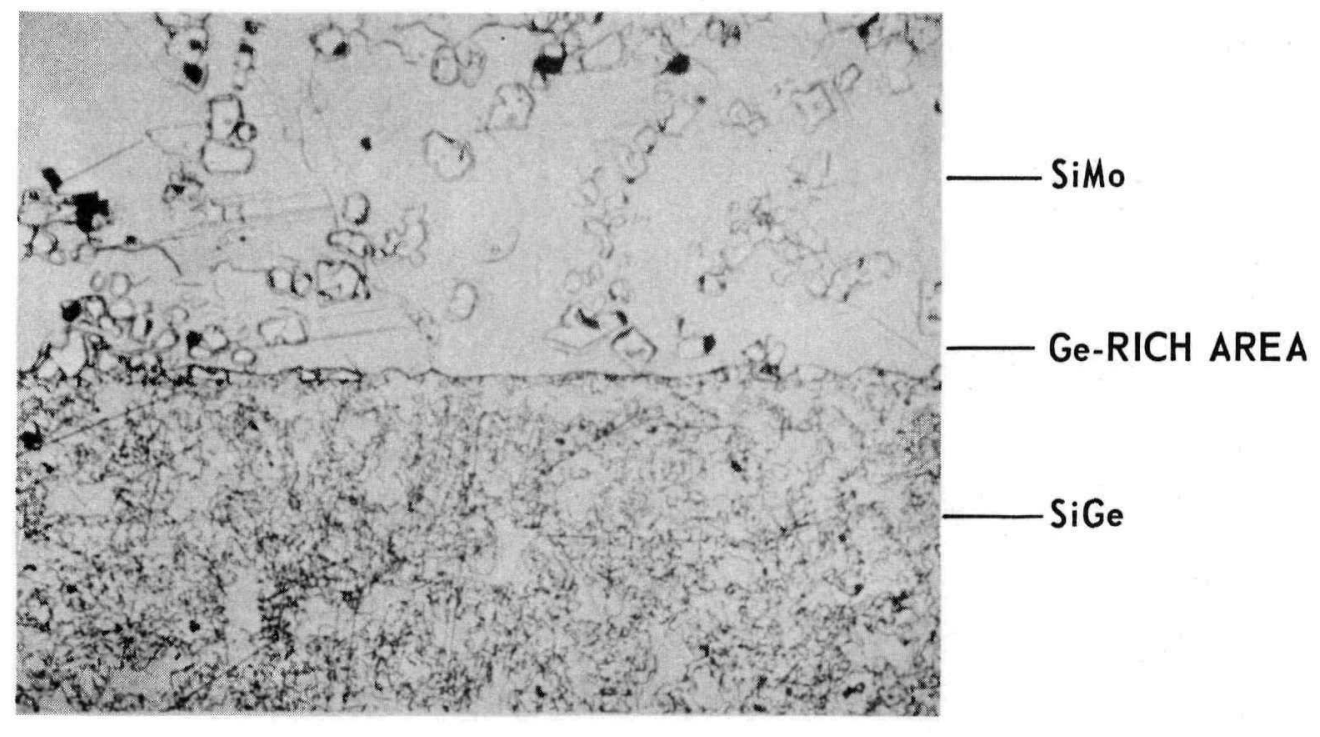

A. 63.5 AT.\% Si 72X

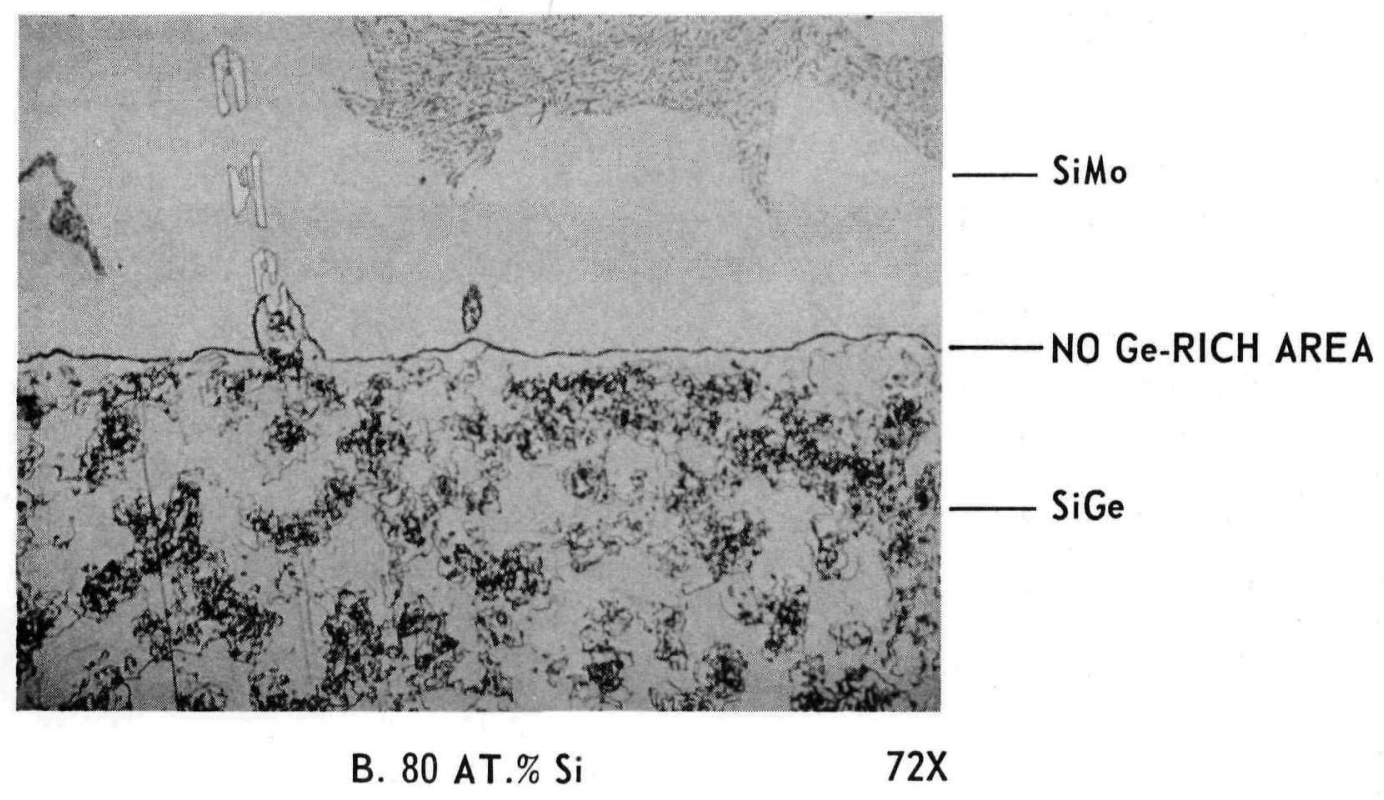

FIGURE 16. COMPARISON BETWEEN 63.5 ATOMIC \% Si AND 80.0 ATOMIC \% Si TO 85 WEIGHT PERCENT SiMo BONDS 
A. TASK 1. DESIGN AND ANALYSIS

1. Reference Design Modular Array

Preliminary estimates of end losses for the reference design modular array were completed. The calculations indicated an over-all device efficiency of 6.35 percent at the design hot junction temperature of $1008^{\circ} \mathrm{C}$ and cold shoe temperature of $190^{\circ} \mathrm{C}$. The parametric data presented in the First Quarterly Report, January - March 1968, did not include end losses. A complete correlation of the reference design modular array measured data with the computer parametric analysis will be made in the 3rd quarterly Report.

2. Developmental Design Configurations

During this quarterly reporting period, the developmental structure design program which was initiated in January through March has continued, using an RCA Spectra 70/40 Time Sharing computer. Planar developmental design configurations, 2P, 3P, and $4 \mathrm{P}$ were completed. Detailed objectives and parameters for each of the above designs can be found in Table IV of the First Quarterly Report ALO (2510)-1.

a. Developmental Design 2P. An additional case was processed by the computer for the low flux density, viz., planar design $2 P$ optimized for high efficiency, using foil insulation. A thermal conductivity of $6.6 \times 10^{-5}$ watts/ ${ }^{\circ} \mathrm{C}-$ $\mathrm{cm}$ for the foil insulation was used instead of the value of $1.1 \times 10^{-5}$ watts $/{ }^{\circ} \mathrm{C}-\mathrm{cm}$ used in the original $2 \mathrm{P}$ design calculations. Although a correct, effective thermal conductivity value for the foil insulation is yet to be determined, the value of $6.6 \times 10^{-5}$ watts/oC-cm appeared more in keeping with those cited by the vendor (LindeUnion Carbide) than a lower value obtained from extrapolation of earlier data. A cross plot showing the effect of insulation on efficiency for various hot shoe sizes (Figure 17) was constructed from the initial parametric analysis of the planar designs $1 \mathrm{P}$ and 2P. These designs are equivalent except for the thermal insulation used.

The analysis of the planar design IP, detailed in the First Quarterly Report, revealed that large element lengthto-area (L/A) ratios were desired for maximum efficiency. However, such large L/A ratios are somewhat difficult to achieve because they create relatively long elements. Consequently, the parametric analysis was rerun with p-type element areas ranging from $0.04 \mathrm{~cm}^{2}$ to $0.1 \mathrm{~cm}^{2}$. The parametric results are indicated in Figure 18. For the parameters 


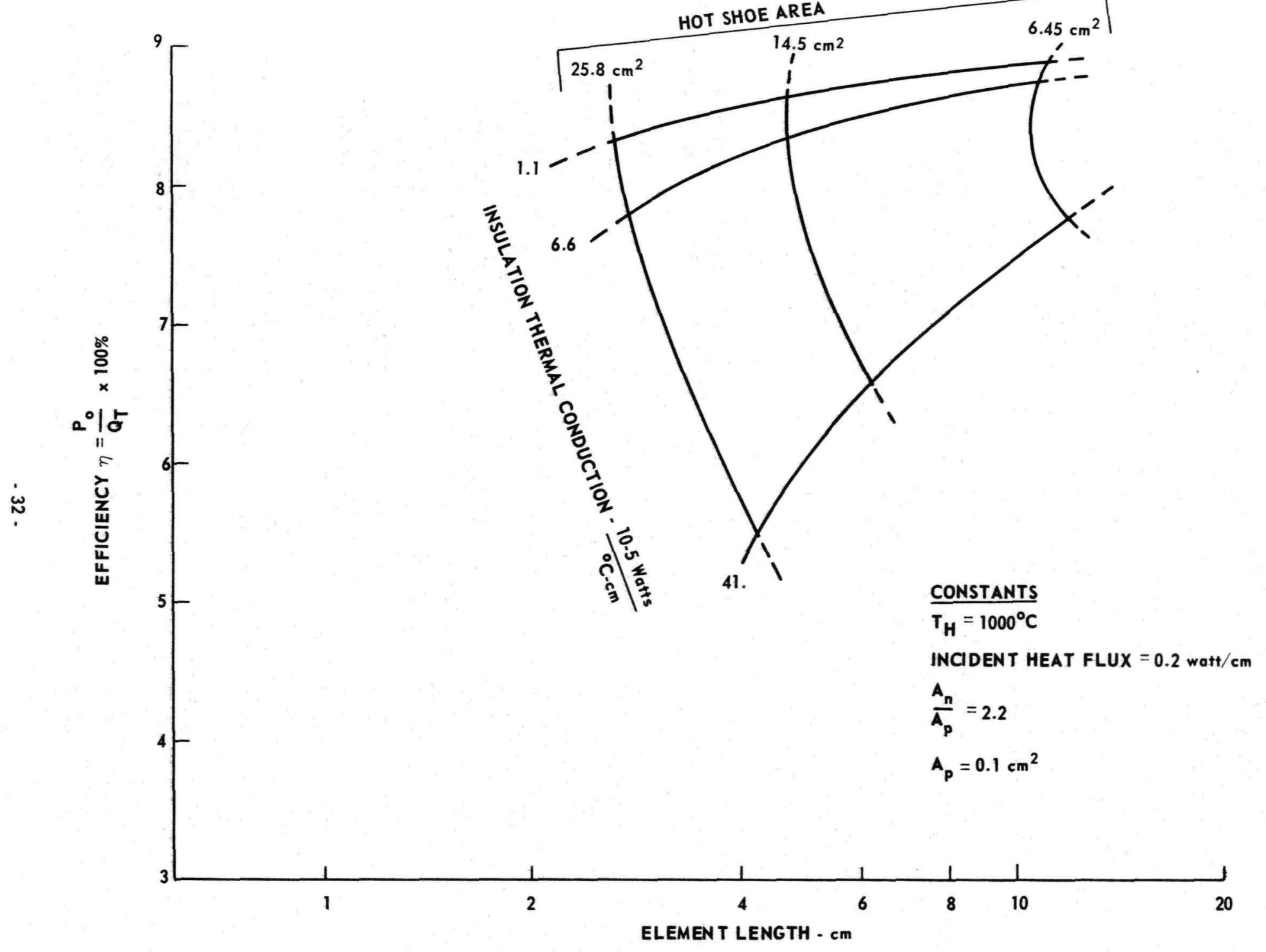

FIGURE 17. MODULE EFFICIENCY AS A FUNCTION OF ELEMENT LENGTH (L/A) FOR A RANGE OF HOT SHOE SIZES, AND INSULATION THERMAL CONDUCTION PLANAR DEVELOP. MENTAL DESIGNS IP AND 2P 


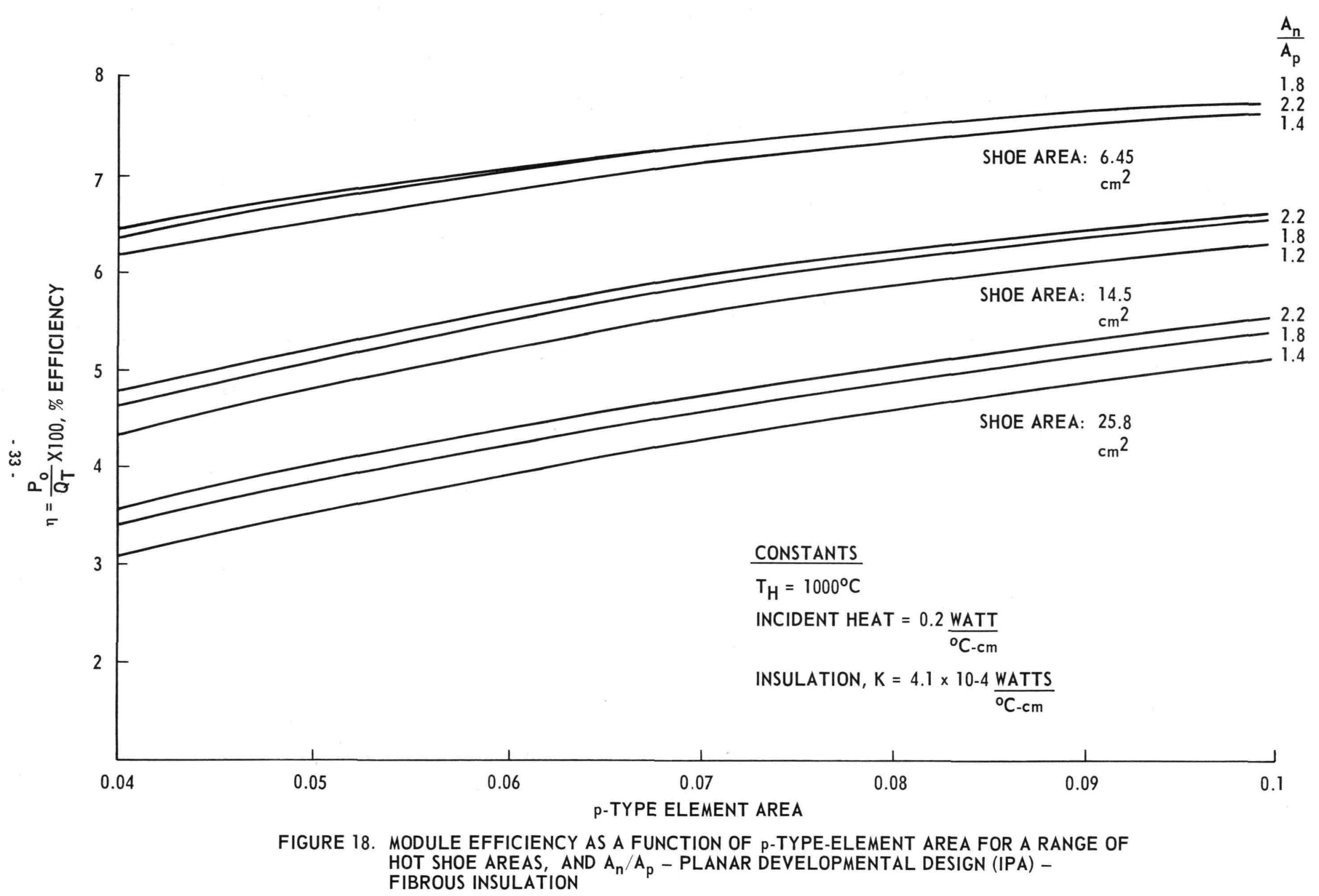


held constant, the lowering of efficiency with decreasing element area reflects the increase of the percentage heat shunt loss due to the greater cross-section ratio of insulation to element areas.

b. Developmental Design 3P. Application of the 3P design configuration was envisioned as providing maximum power for minimum weight (specific power) and operating with an incident heat flux density near 1 watt $/ \mathrm{cm}^{2}$. The thermocouple-to-aluminum cold plate (radiator) attachment was designed as an all-metallurgically bonded construction rather than by the fleximod approach which uses a threaded nut and screw. Benefits of this approach were a doubling of the thermal conductivity and a reduction of weight through the elimination of the screw and mounting nut used in previous designs. For this first analysis, further apparent weight-reducing considerations, such as waffling of cold plate and shaping of the hot shoe, were not explored. Such designs for further reduction in weight appear quite feasible and will be conducted when finalizing the design parameters.

The 3P design analysis used a metallurgically bonded cold stack with a thermal conductivity value of 0.87 watt/ ${ }^{\circ} \mathrm{C}-\mathrm{cm}$ and a composite density of $12.2 \mathrm{gm} / \mathrm{cm}^{3}$. Additional input constants of the analysis reflected the use of MIN-K 2020 insulation and the use of a p-type element area of $0.1 \mathrm{~cm}^{2}$.

The effect of element efficiency versus element length with the incident heat flux density and hot shoe area as parameters is shown in Figure 19. While the familiar gridplot structure is present as in the past planar analyses, there is an inversion of the grid patterm denoting a shift in first-order effects on efficiency. For example, with structures using a small hot shoe area of $2.32 \mathrm{~cm}^{2}$ or less, the incident heat flux values would be a first-order variable which affected efficiency. By contrast, incident heat flux would be secondary, because variation in hot shoe sizes greater than $20.9 \mathrm{~cm}^{2}$ in area would be the dominant factor affecting device efficiency.

Specific power is shown in Figure 20. Coupling this information with that in Figure 19, reveals that for particular design parameters yielding highest efficiency, the specific power is lowest. Consequently, a compromise was necessary to obtain near maximum specific power consistent with reasonable efficiency levels. A reasonable compromise would be to consider a device which had an element length of $1.5 \mathrm{~cm}$ and hot shoe area of $6.45 \mathrm{~cm}^{2}$ and operated at an incident heat flux density of one watt per $\mathrm{cm}^{2}$. This arrangement would result in a trade-off of specific power of 3 percent from optimum to attain a reasonably good device-efficiency of 5.4 percent. 


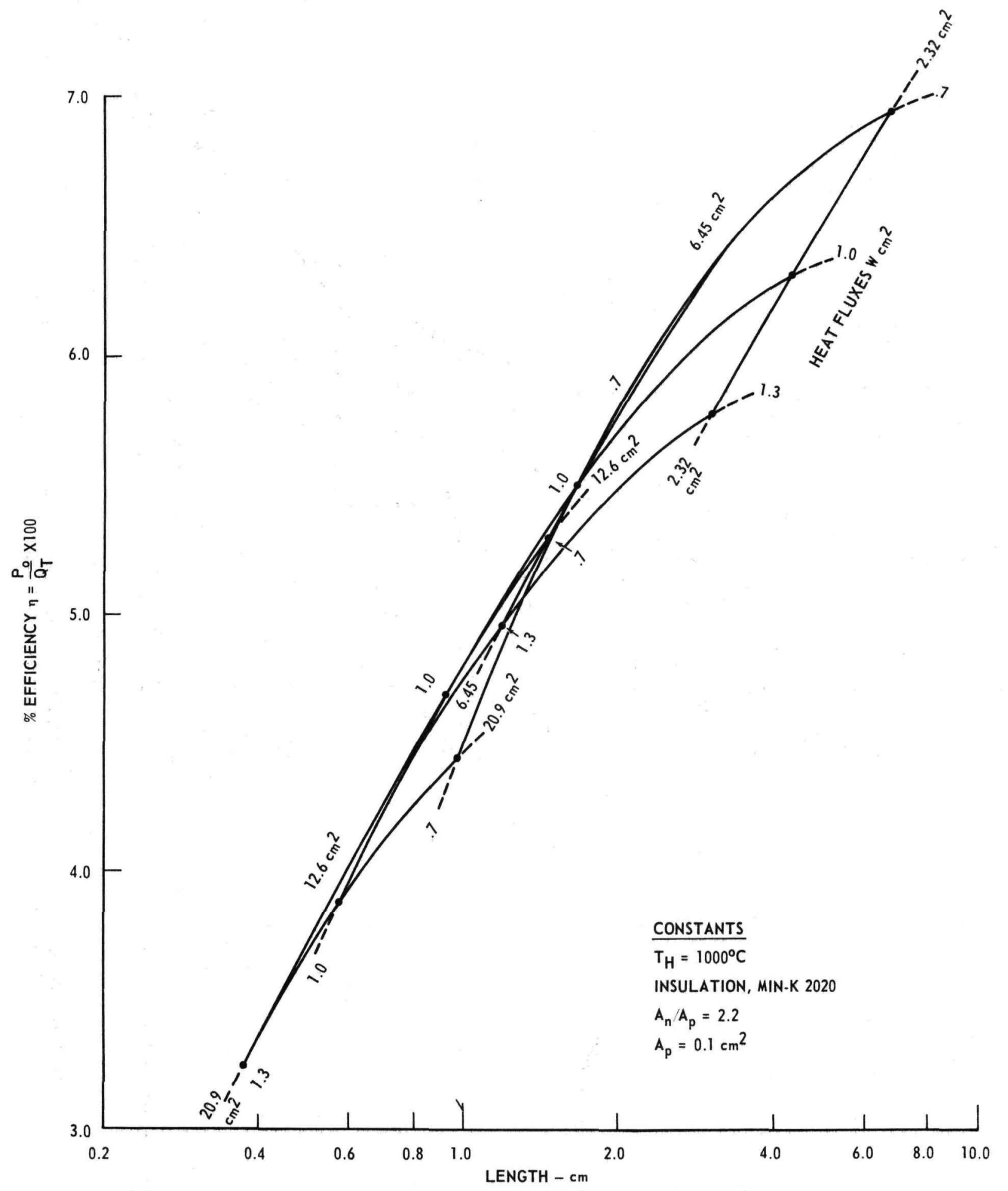

FIGURE 19. MODULE EFFICIENCY AS A FUNCTION OF ELEMENT LENGTH

(L/A) FOR A RANGE OF HOT SHOE SIZES AND HEAT FLUXES.

PLANAR DEVELOPMENT DESIGN (3P).

.35 . 


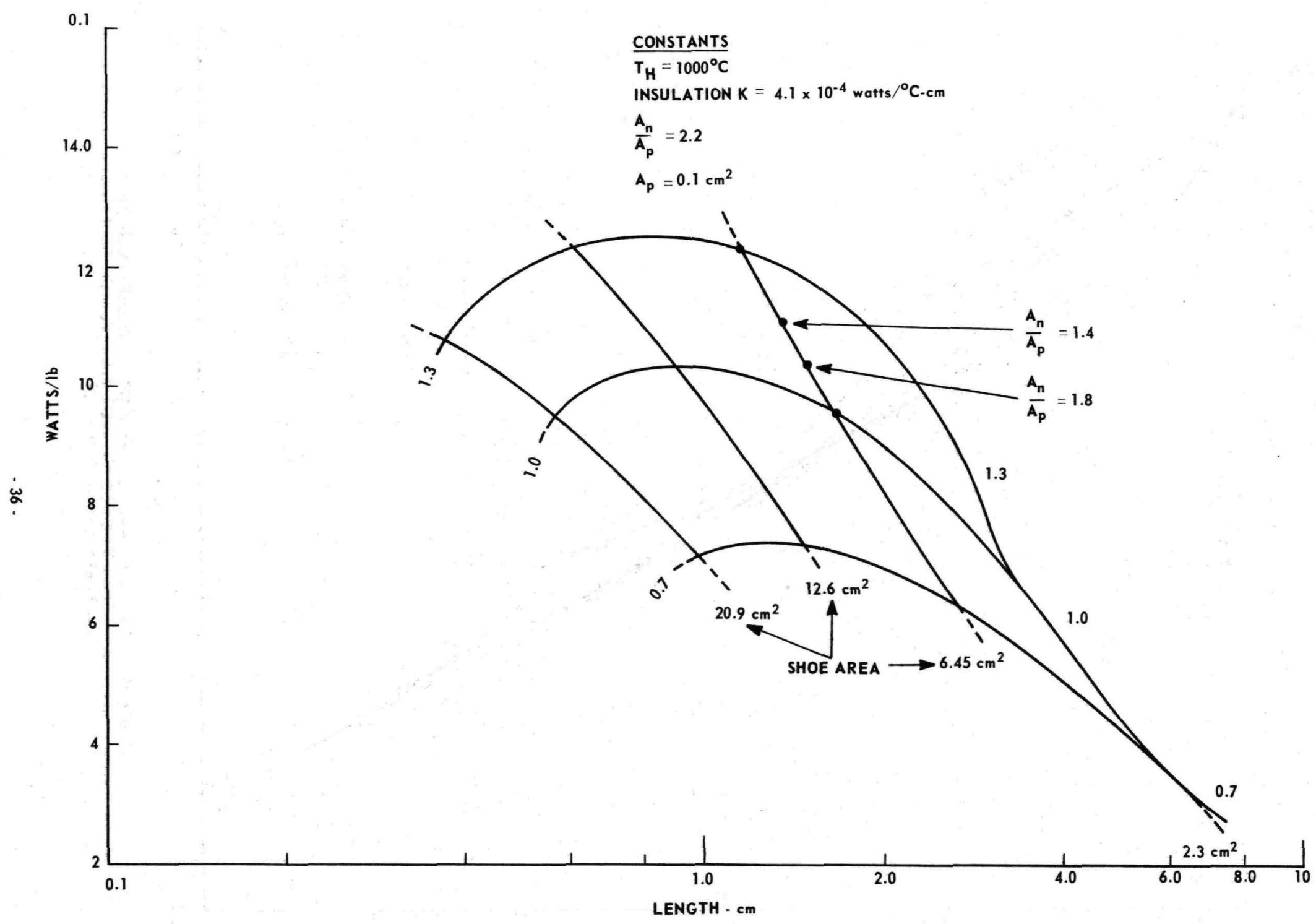

FIGURE 20. SPECIFIC POWER W/Ib AS A FUNCTION OF ELEMENT LENGTH FOR A RANGE OF HOT SHOE SIZES AND HEAT FLUXES. PLANAR DEVELOPMENT DESIGN (3P) 
As in previous design analyses, the effect on deviceefficiency as a function of element area ratios $\left(A_{n} / A_{p}\right)$ is shown in Figure 2l. For the parametric constraints already imposed, this plot shows that selection of a design using n-type to p-type element area ratios of 1.8 to 2.2 would be desirable. While an $A_{n} / A_{p}$ ratio between these values would not significantly affect efficiency, the lower ratio would reduce weight. Hence, while an $A_{n} / A_{p}$ ratio of 2.2 is optimum, dropping the ratio to 1.8 raises the specific power by about 4 percent while maintaining good device-efficiency. Ratios smaller than 1.8 would continue to raise specific power, but at a reduced efficiency•

c. Development Design 4P. In many respects, this design has constraints similar to those imposed on the initial planar developmental design, IP. While both design configurations point to an objective of high operating efficiency at low incident flux densities, the $4 \mathbb{P}$ design was conceived with long elements necessary for high efficiency, and was mechanically supported in a block insulation with the electrical connecting straps serving as its radiator. The prime practical considerations of this design was the attainment of an insulation which could be packed about the couple for its support; was stable at $1000^{\circ} \mathrm{C}$; and had low thermal conductivity.

The electrical connector radiating area imposed additional constraints on the design. The clearances about the connecting straps, a 0.020 -inch spacing between connectors and 0.050 -inch spacing between adjacent couple-connecting straps to prevent electrical short circuits, reduced the radiating area of the cold junction. This design decreased the efficiency approximately 0.1 percent compared to planar design IP.

Figures 22 and 23 indicate, respectively, the familiar gridplot of efficiency vs. element length and the effect of $A_{n} / A_{p}$ as a function of incident heat flux, efficiency, and hot shoe size. To achieve the high efficiencies envisioned, extremely long $\mathrm{L} / \mathrm{A}^{\prime} \mathrm{s}$ would have to be incorporated into the couple design with attendant uniform couple-bearing support from the insulation. Until the capabilities of practical couple-insulating-support materials are available, actual device performance cannot be predicted. The assumption is that $\mathrm{L} / \mathrm{A}^{\prime} \mathrm{s}$, exceeding 250 , would not be available unless the bearing support of the insulation made it possible.

\section{B. TASK 2. PROCESS, BOND, AND COMPONENT DEVELOPMENT}

1. Thermocouple 


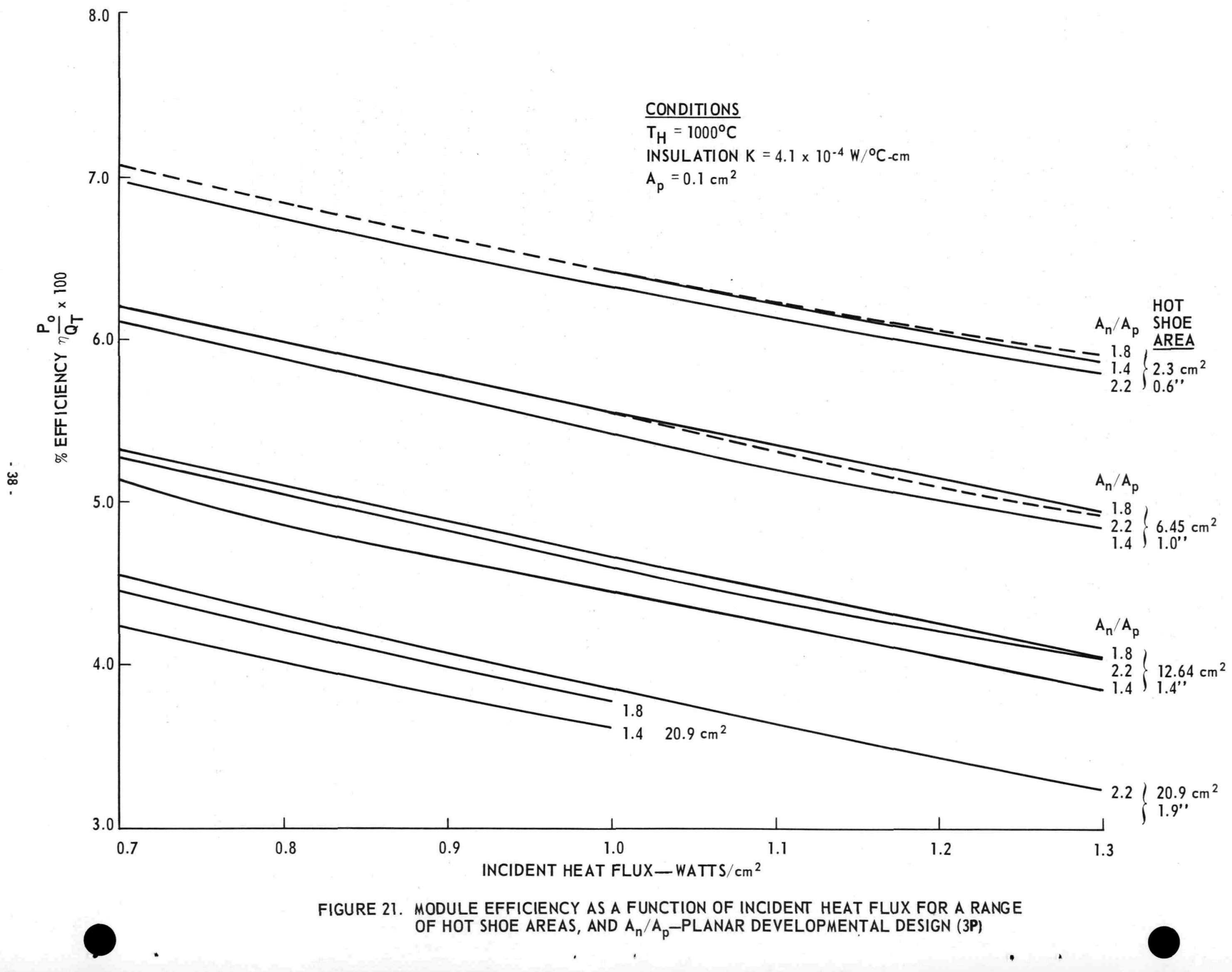




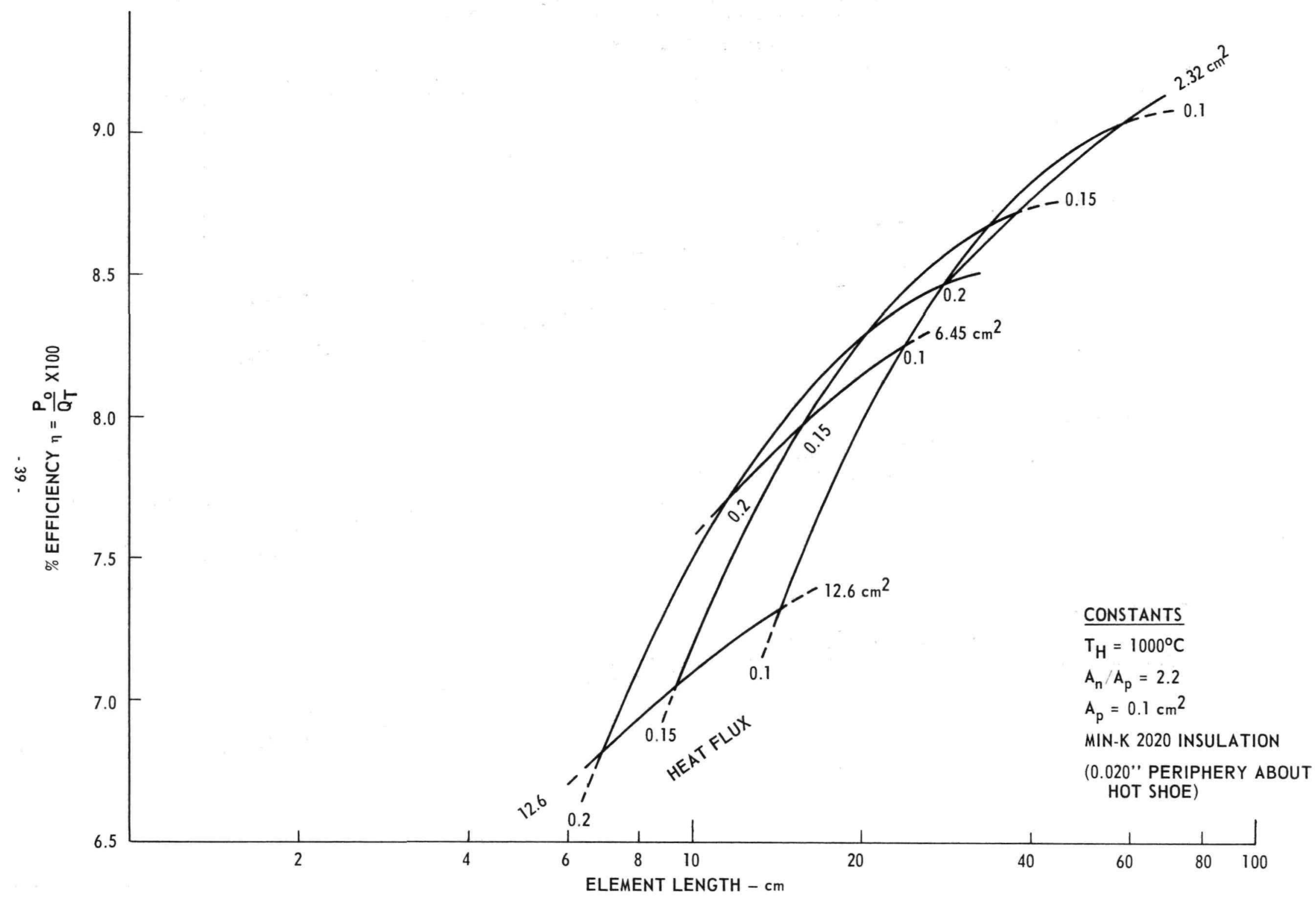

FIGURE 22. EFFICIENCY AS A FUNCTION OF ELEMENT LENGTH OVER A RANGE OF INCIDENT HEAT FLUXES AND HOT SHOE SIZES - PLANAR DESIGN(4P) 


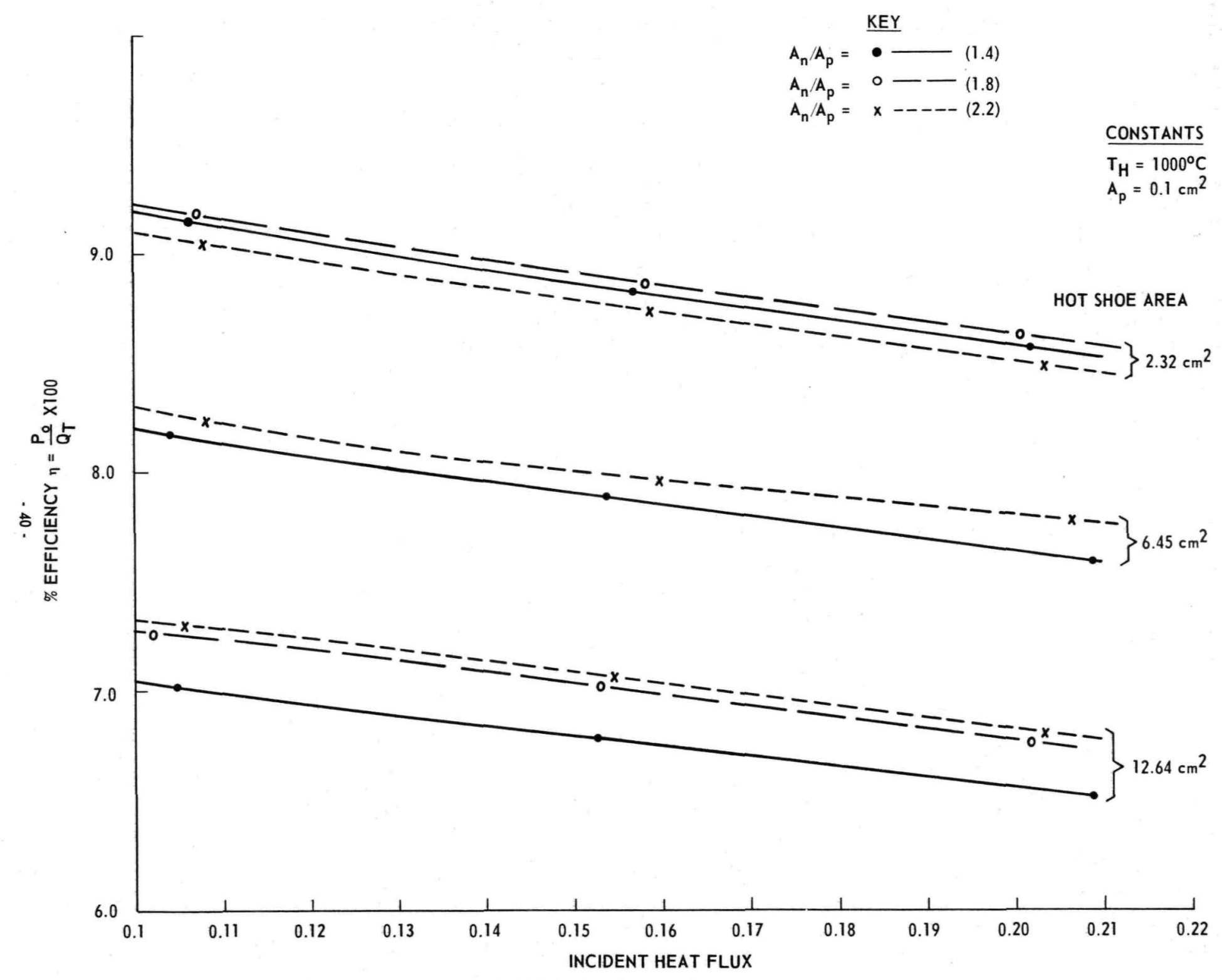

FIGURE 23. EFFICIENCY AS A FUNCTION OF INCIDENT HEAT FLUX FOR A RANGE OF SHOE SIZES AND $A_{n} A_{p}$ RATIOS. 
a. Reference Design

The fabrication of couples for the reference design modular array was completed during this quarter. Table II shows the as-bonded room temperature resistance measurements of the 181 physically acceptable couples. There is very little change from the results reported in the First Quarterly Report which was based on a much smaller quantity. Preliminary resistance limits which are based on the maximum bulk resistivity limits of the SiGe ingots and which will serve as guides for future couple development, have been established. The limits are:

Over-all Couple Resistance n-type Leg Including Joints p-type Leg Including Joints
42.0 milliohms-max. 21.0 milliohms-max. 21.0 milliohms-max.

Based on the couples fabricated to date, 94 percent of the physically acceptable couples would fall within the tentative electrical resistance limits. No changes have been made in the previously established tentative bonding schedule because of the continuing good results.

b. Developmental Designs

Work continued on the development of large length-to-area ratio ( $\mathrm{L} / \mathrm{A}$ ) couples for the developmental designs。 The T-bar couple has been temporarily shelved in favor of the frame-couple approach. Although mechanically feasible, the T-bar couple exhibited excessive n-type joint resistances. In addition, there was an inherent weakness in the region immediately adjacent to the bond. Although this problem could probably be overcome by extensive effort, the quicker and simpler frame-couple approach was selected. The frame couple consists of a pellet from whose center material has been removed to obtain the large L/A. (See Figure 24a) This approach was preferred because there were fewer parts involved; there was ease of assembly; and no extraneous material was introduced to affect the bond integrity. Although the cross section was reduced in the center of the pellet, the full cross section was available at the bonding interfaces, thus eliminating the causes of high joint resistance and the regions of inherent weakness.

P-type frame pellets were prepared by sandblasting the desired amount of SiGe. Couples were bonded, using those pellets that had effective $\mathrm{L} / \mathrm{A}^{\prime} \mathrm{s}$ of 45,55 , and 70 to 1 . Due to a slight mishap, the 70 to $1 \mathrm{~L} / \mathrm{A}$ couple broke in handling. Although the break was attributable to an accident, the couple was so inherently weak as to preclude practical handling and incorporation into a device. The other two couples, subjected to shock and vibration testing, were as strong as the reference design thermocouple. 
TABLE II

RESIST ANCE MEASUREMENT (m $\Omega$ )

\begin{tabular}{|c|c|c|c|c|c|c|c|c|}
\hline \multirow{3}{*}{$\begin{array}{l}\text { Total Couple } \\
\text { Resistance }\end{array}$} & \multicolumn{3}{|c|}{ **Measured Values } & \multicolumn{2}{|c|}{ Limits } & \multicolumn{3}{|c|}{ *Calculated Values } \\
\hline & Low & Avg. & High & -3 Iimits & +3 limits & Low & Avg. & High. \\
\hline & 34.0 & 38.0 & 43.0 & 33.0 & 42.5 & 36.3 & 39.6 & $47.8^{\circ}$ \\
\hline $\begin{array}{l}\text { n-Type Leg } \\
\text { \& Contacts }\end{array}$ & 15.0 & 18.0 & 22.5 & $14 \cdot 5$ & 22.5 & 17.9 & 19.6 & 20.7 \\
\hline $\begin{array}{l}\text { p-Type Leg } \\
\text { \& Contacts }\end{array}$ & 15.0 & 19.2 & 23.0 & 15.0 & 23.5 & 18.3 & 19.9 & 21.0 \\
\hline
\end{tabular}

*Based on Ingot Bulk Resistivity Values.

n-Type Ingot: 1.40 to 1.63 milliohms $/ \mathrm{cm}^{3} ; 1.54$ milliohms avg. p-Type Ingot: 0.93 to $1.08 \mathrm{milliohms} / \mathrm{cm}^{3} ; 1.02 \mathrm{milliohms} \mathrm{avg}$ • **Based on 181 Physically Acceptable Couples. 


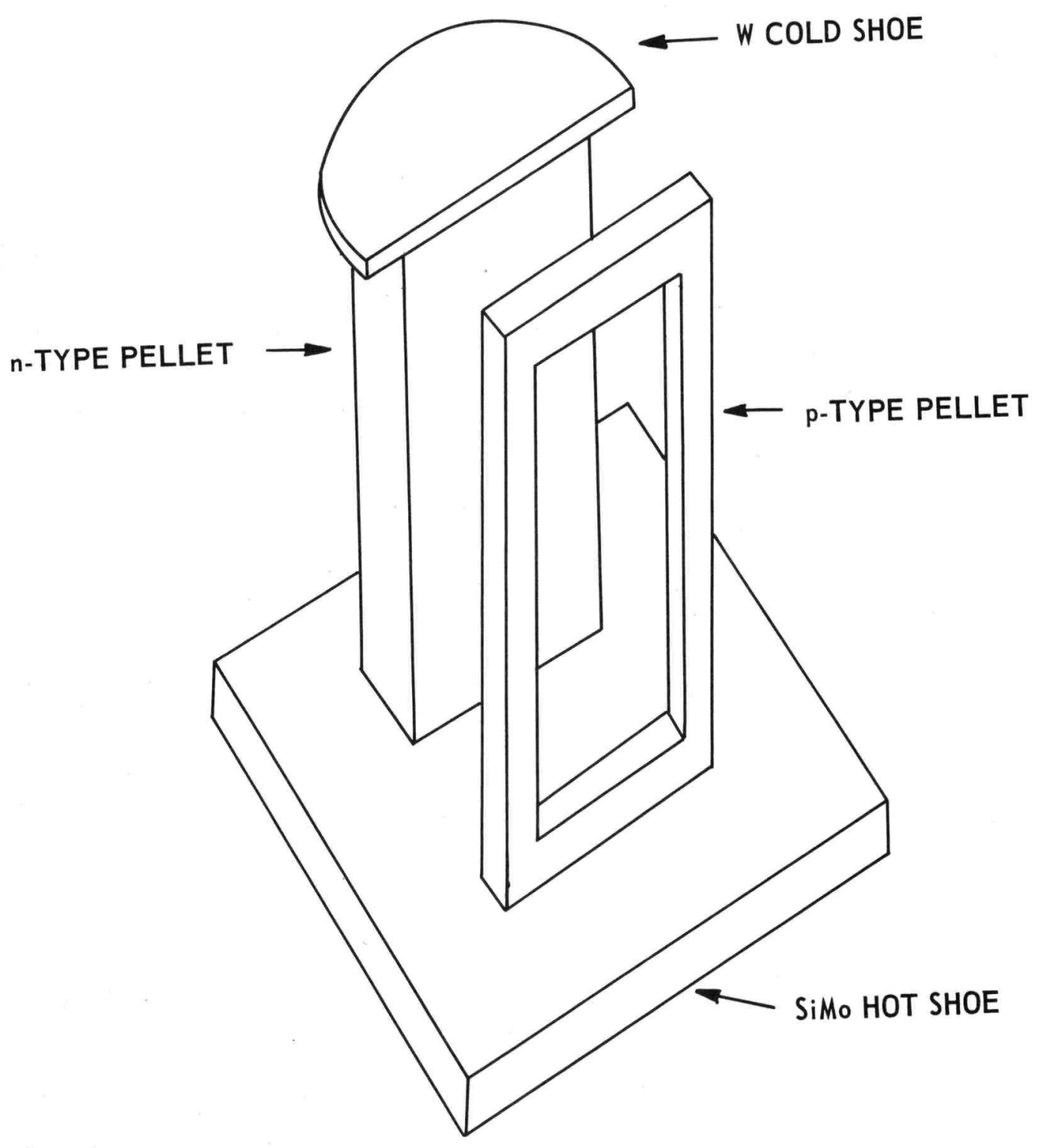

FIGURE 24. FRAME TYPE AIR-VAC THERMOCOUPLE. 
A more accurate method of fabricating reproducible pellets, other than sandblasting, is desired so that undercutting and rough edges could be eliminated. Efforts are being concentrated on ultrasonically machining the SiGe, but other machining methods are also being investigated.

\section{Measurement Techniques}

The investigation into the use of the Beta Scope as a substitute device for X-Ray analysis of SiGe pellets is almost complete. However, the initial promise expected of this device has not materialized. Although, on the average of many readings, this mode of measurement was more accurate than analysis achieved by density techniques, the readings were not reproducible. Any given sample tended to become erratic on any given set of readings. Homogenization of the SiGe material prior to measurement on the device did not help the reproducibility or accuracy of the data, either. However, the Beta scope is still useful for rapidly determining which end of any given pellet has the higher Si content. Samples of the SiGe material are being sent to the manufacturer of the device to determine if there is another beta-ray source or method available for assessing Si content with increased reliability, accuracy, and reproducibility.

\section{TASK 3. FABRICATION}

\section{Reference Design}

The fabrication of the reference design modular array was completed by June 12, 1968. In general, fabrication and assembly of the modular sections went very smoothly, encountering no major difficulties.

Figures 25 through 28 show the various stages of fabrication and assembly. After brazing, a forming mandrel was utilized to obtain the proper relationship between the two rows of the 20-couple module shown in Figure 25. Following this operation, the module was placed in its supporting outer shell section and secured by screws which anchored in the taper nuts located at the bottom of each stack (Figure 26). This process was followed by the application of instrumentation thermocouples and the packing of preformed MIN-K 2020 insulation. Figure 27 shows a completed module and shell section assembly. Three such sections plus end caps are mechanically and electrically connected to form the completed modular array, Figure 28, which is presently. being subjected to performance mapping。

In addition to the above array, one 4-couple module and 19 single-couples have been fabricated. These modules and couples are being utilized to obtain performance data on shock and vibration, air and subsequent vacuum operation, and on metallographic evaluation life data. 


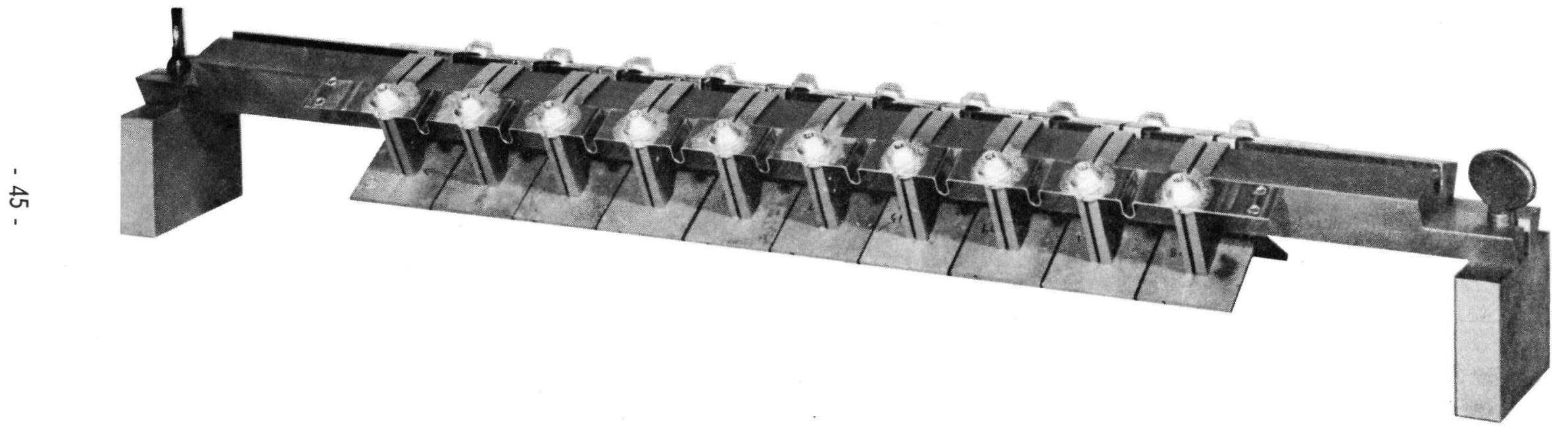

FIGURE 25. USE OF FORMING MANDREL TO OBTAIN PROPER RELATIONSHIP BETWEEN TWO ROWS OF 20-COUPLE MODULE 


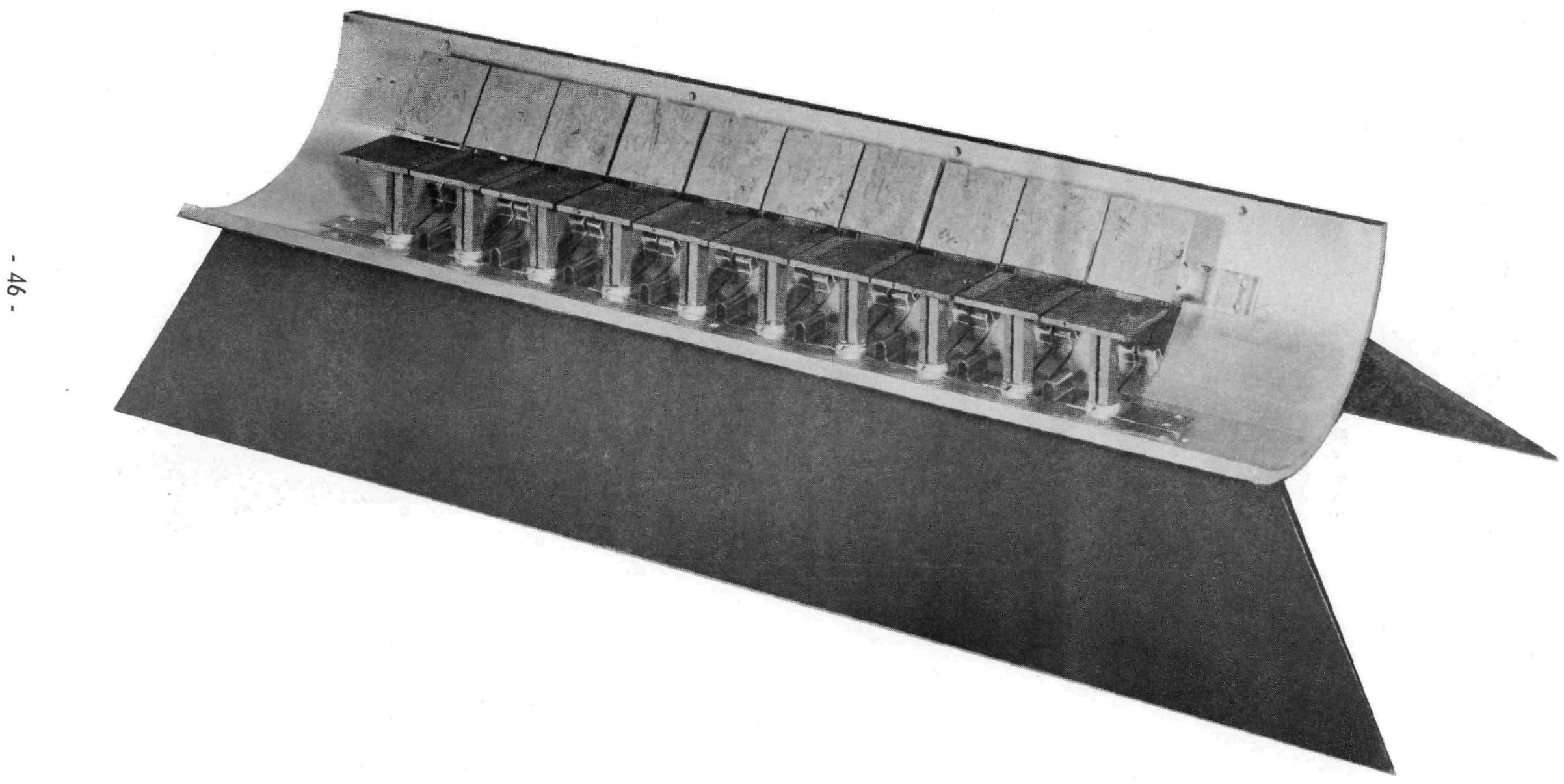

FIGURE 26. 20-COUPLE MODULE SECURED IN SUPPORTING OUTER SHELL SECTION 


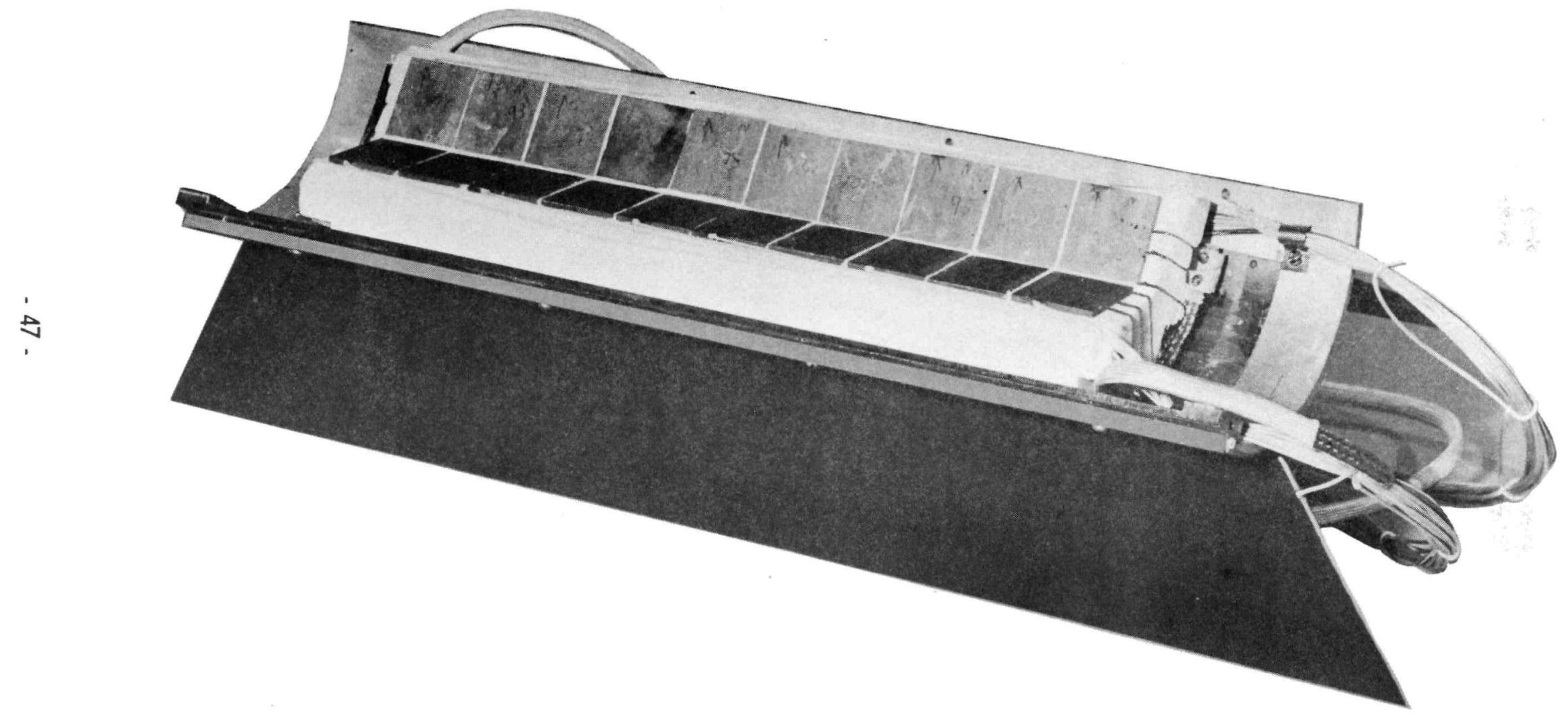

FIGURE 27. APPLICATION OF THERMOCOUPLES AND PACKED PREFORMED INSULATION 

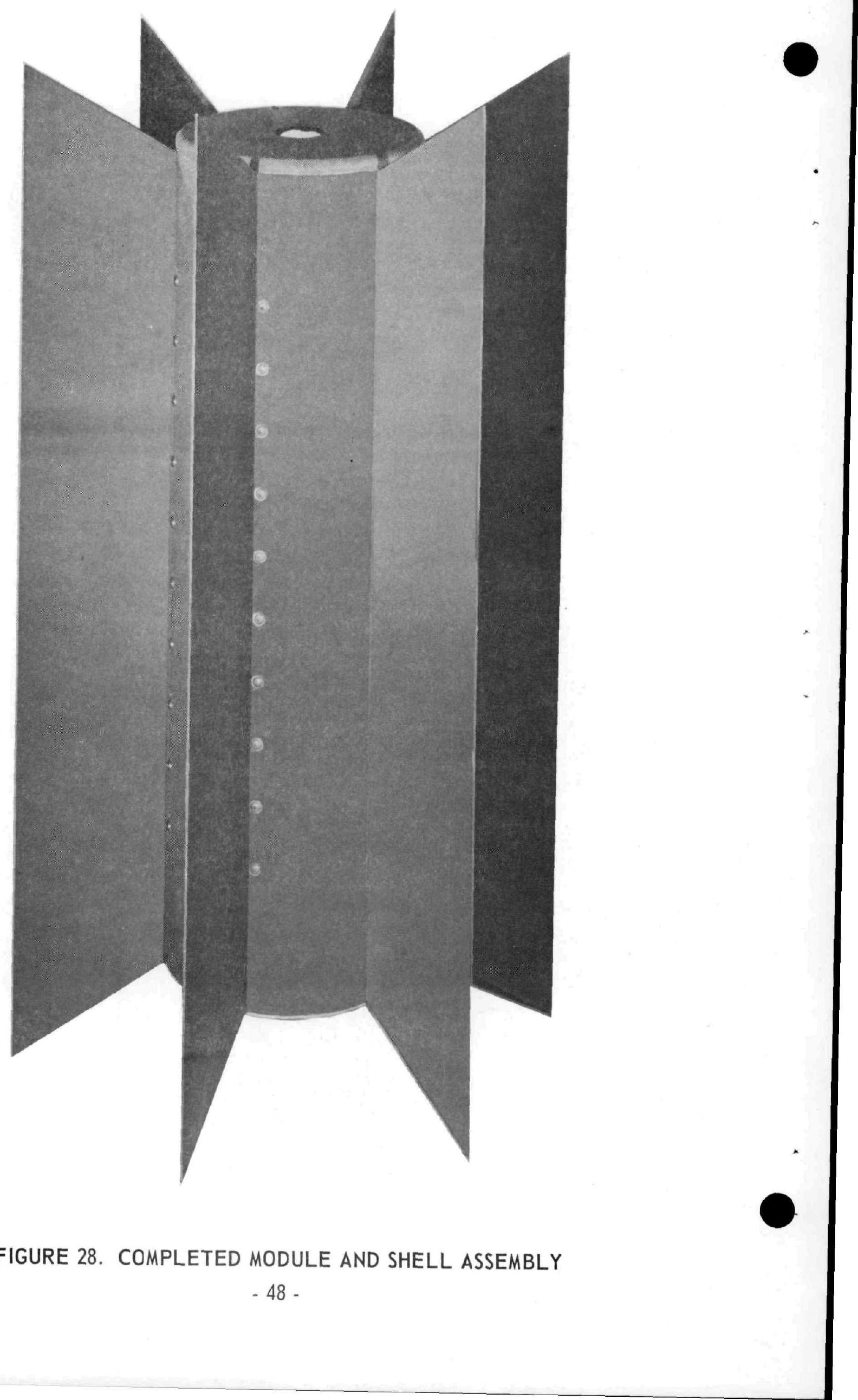

FIGURE 28. COMPLETED MODULE AND SHELL ASSEMBLY 


\section{Insulation}

A literature survey of available fibrous insulation showed MIN-K 2020 to be the most desirable. (See First Quarterly Report.) During this reporting period, a comparison test between Dynaquartz and MIN-K 2020 was conducted with the aid of a small, existing RCA 5-watt converter. From the test data, (discussed in Task 4) it was observed that the utilization of MIN-K 2020 resulted in a higher over-all efficiency. The significance of this test is that it supports the aforementioned selection which was based entirely on published data.

A meeting with the MIN-K vendor was held to discuss the feasibility of molding MIN-K 2020 around one or possibly several thermocouples during the MIN-K processing operation. Also discussed was the possibility of molding MIN-K around a single row module. As a result of this meeting, a feasibility program was proposed to investigate several design variations. These included the following: (1) molding MIN-K 2020 around the legs of a thermocouple, (2) encapsulating an entire thermocouple, and (3) encapsulating six thermocouples in one block of MIN-K 2020. The proposal is currently being reviewed.

During this reporting period, MIN-K 2002 was used to insulate a piece of test apparatus for high temperature operation. During the bakeout period, the 2002 insulation was subjected to an estimated $1200^{\circ} \mathrm{C}$. Upon removal from the unit, the MIN-K 2002 had fused and was severely distorted. In order to determine the amount of warpage as a function of time and temperature, blocks of MIN-K 2002 and 2020 insulation were tested in vacuum under a thermal gradient at or slightly above their respectively rated operating temperatures.

The blocks of insulation consisted of two half-inch thicknesses sandwiched between a Mo heat receptor plate and an Al heat rejector plate. The warpage was measured on the first halfinch block, located next to the heat source. For MIN-K 2002, the cold side ranged from $120^{\circ} \mathrm{C}$ to $160^{\circ} \mathrm{C}$ while the hot side temperature was varied from $800^{\circ} \mathrm{C}$ to $900^{\circ} \mathrm{C}$. No detectable amount of warpage was observed. (See Table III.)

Table IV contains data obtained on MIN-K 2020 insulation. Although no distortion occurred at the rated temperature of $1000^{\circ} \mathrm{C}$, distortion did occur at the elevated temperature and increased in magnitude with increased time at temperature. The conclusion drawn from this test was that the naximum safe operating temperature of MIN-K 2020 was $1000^{\circ} \mathrm{C}$. Short excursions ( $1 / 4$ to $I / 2$ hour) to $1050^{\circ} \mathrm{C}$ such as might occur because of an overshoot should not create any difficulty, if not repeated too often. 
TABLE III

MIN-K - 2002

\begin{tabular}{cccc}
\hline $\begin{array}{c}\text { Cold Side } \\
\text { Temp. }\end{array}$ & $\begin{array}{c}\text { Hot Side } \\
\text { Temp. }\end{array}$ & $\begin{array}{c}\text { Time at } \\
\text { Temp. }\end{array}$ & Condition of Insulation \\
\hline $120^{\circ} \mathrm{C}$ & $800^{\circ} \mathrm{C}$ & $16 \mathrm{hrs}$. & $\begin{array}{l}\text { No detectable change } \\
140^{\circ} \mathrm{C}\end{array}$ \\
$850^{\circ} \mathrm{C}$ & $16 \mathrm{hrs}$. & $\begin{array}{l}\text { No warpage; less than } 1 \% \\
\text { shrinkage in thickness }\end{array}$ \\
$160^{\circ} \mathrm{C}$ & $900^{\circ} \mathrm{C}$ & $16 \mathrm{hrs}$. & $\begin{array}{l}\text { No warpage; less than } 1 \% \\
\text { shrinkage in thickness }\end{array}$
\end{tabular}

TABLE IV

$\underline{M I N-K}-2020$

\begin{tabular}{|c|c|c|c|}
\hline $\begin{array}{l}\text { Cold Side } \\
\text { Temp. }\end{array}$ & $\begin{array}{l}\text { Hot Side } \\
\text { Temp. }\end{array}$ & $\begin{array}{l}\text { Time at } \\
\text { Temp. }\end{array}$ & Condition of Insulation \\
\hline *NA & $800^{\circ} \mathrm{C}$ & $70 \mathrm{hrs}$. & No Change \\
\hline$* \mathrm{NA}$ & $1000^{\circ} \mathrm{C}$ & $24 \mathrm{hrs}$. & No Change \\
\hline $190^{\circ} \mathrm{C}$ & $1050^{\circ} \mathrm{C}$ & $165 \mathrm{hrs}$. & $\begin{array}{l}\text { Some distortion; less than } \\
\text { 1\% change in thickness; } \\
\text { approximately } 4 \% \text { change in } \\
\text { width. }\end{array}$ \\
\hline $190^{\circ} \mathrm{C}$ & $1050 \circ \mathrm{C}$ & $335 \mathrm{hrs}$. & $\begin{array}{l}\text { Significant distortion; } \\
\text { approximately } 1.2 \% \text { in thick- } \\
\text { ness; } 7.4 \% \text { in width. }\end{array}$ \\
\hline $190^{\circ} \mathrm{C}$ & $1050 \circ \mathrm{C}$ & $500 \mathrm{hrs.}$ & $\begin{array}{l}\text { Significant distortion; } \\
\text { approximately } 2.8 \% \text { in thick- } \\
\text { ness; } 9.7 \% \text { in width. }\end{array}$ \\
\hline${ }^{*} \mathrm{NA}$ & $1100^{\circ} \mathrm{C}$ & $24 \mathrm{hrs}$. & Significant distortion \\
\hline
\end{tabular}

*Not Available 
D. TASK 4. TEST PROGRAM - MODULE AND CONVERTER LEVEL

\section{Test Program}

The test program outlined in the First Quarterly Report was revised to incorporate a more realistic appraisal of the fabrication schedule for the required couples and modules. This revision left the testing to be done on the reference design and developmental design couples essentially the same, but shifted the schedule so that the designs which required development effort before fabrication would be tested later in the program, while those designs fabricated from parts not requiring development would be tested earlier.

\section{Test Results}

\section{a. 5-Watt Converter}

A small converter was assembled from parts avallable from earlier programs, primarily to check out the heater and instmumentation techniques to be used on the reference design converter.

The device contained 6 rows of 3 couples each, mounted on a hexagonal frame around a center cavity for a heater. The heater consisted of a hollow graphite cylinder with a double helical groove to obtain a long current path and thus a reasonably high electrical resistance. Power was fed to the heater through 1/8-inch diameter graphite rods. Small thermocouples were imbedded in each of these rods, one as close as possible to the heater and the second about one inch from the heater. Heat loss from the heater along these rods was calculated from

$Q=\frac{\left(\mathrm{T}_{1}-\mathrm{T}_{2}\right) \mathrm{KA}}{\ell}-I / 2 \mathrm{EI}$

where

$Q=$ Heat flow (per lead)

$\mathrm{T}_{1}=$ Temperature at hot end of lead

$\mathrm{T}_{2}=$ Temperature at cold end of lead

$\mathrm{K}=$ Thermal conductivity of lead

$A=$ Area of lead

$\ell=$ Distance between thermocouples

$E=$ Voltage between thermocouples

$I=$ Heater current.

The first term represents heat conduction along the leads, while the second term accounts for the I2R heat generated by the flow of heater current in the leads. At $1000^{\circ} \mathrm{C}$ nominal hot shoe temperature, the loss along both heater leads was 
3.8 watts, or 3.6 percent of gross heater input power. This correction is the only one made in deriving device efficiency from the measured electrical power output and gross electrical heater input.

This small converter was operated at a series of temperatures and under various load conditions while insulated with Dynaquartz. It was then reinsulated with MIN-K 2020 and operated under the same temperature and load conditions. Because the converter was instrumented to allow measurement of device efficiency, the two series of tests allowed direct compartson of the two types of thermal insulation under conditions typical of an Air-Vac thermoelectric converter.

Performance of the 5-watt converter with the two types of thermal insulation is shown in Figure 29. These performance curves indicate an increase of approximately 10 percent in efficiency which resulted from the substitution of MIN-K 2020 for Dynaquartz. To date, the converter has operated over 1000 hours with MIN-K 2020 insulation with no degradation in efficiensy or power output.

The operation of the heater, beater lead arrangement, and instrumentation appeared satisfactory, and a scaled-up version was used for the reference design modular array.

\section{b. Reference Design Modular Array}

The reference design nodular array is being operated in vacuum at a series of increasing temperature levels, with a set of all parameters being measured at several load resistances from open to short circuit. The results of the first two of these "load swings" are show in Figures 30 and 31. Power output agrees with the values predicted for the temperatures achieved. Efficiency is slightly better than the predicted values, probably indicating a lower conductivity in the thermal insulation than the value used for the calculations. A detailed analysis of the array performance will be included in the next quarterly report.

Each module of the array is instrumented in the No. 1, 3, $5,6,8$, and 10 couple, counting from top to bottom, on both the hot and cold sides. Tungsten-rhenium measurement thermocouples are imbedded in holes drilled into the edges of the SiMo hot shoes; chromel-alumel thermocouples are spot welded to the copper electrical interconnects. Including shell and heater lead thermocouples, the array has approximately 100 measurement thermocouples to obtain performance data.

The module heater consists of a hollow graphite cylinder, similar to that described in Section D, 1, a for the 5-watt 


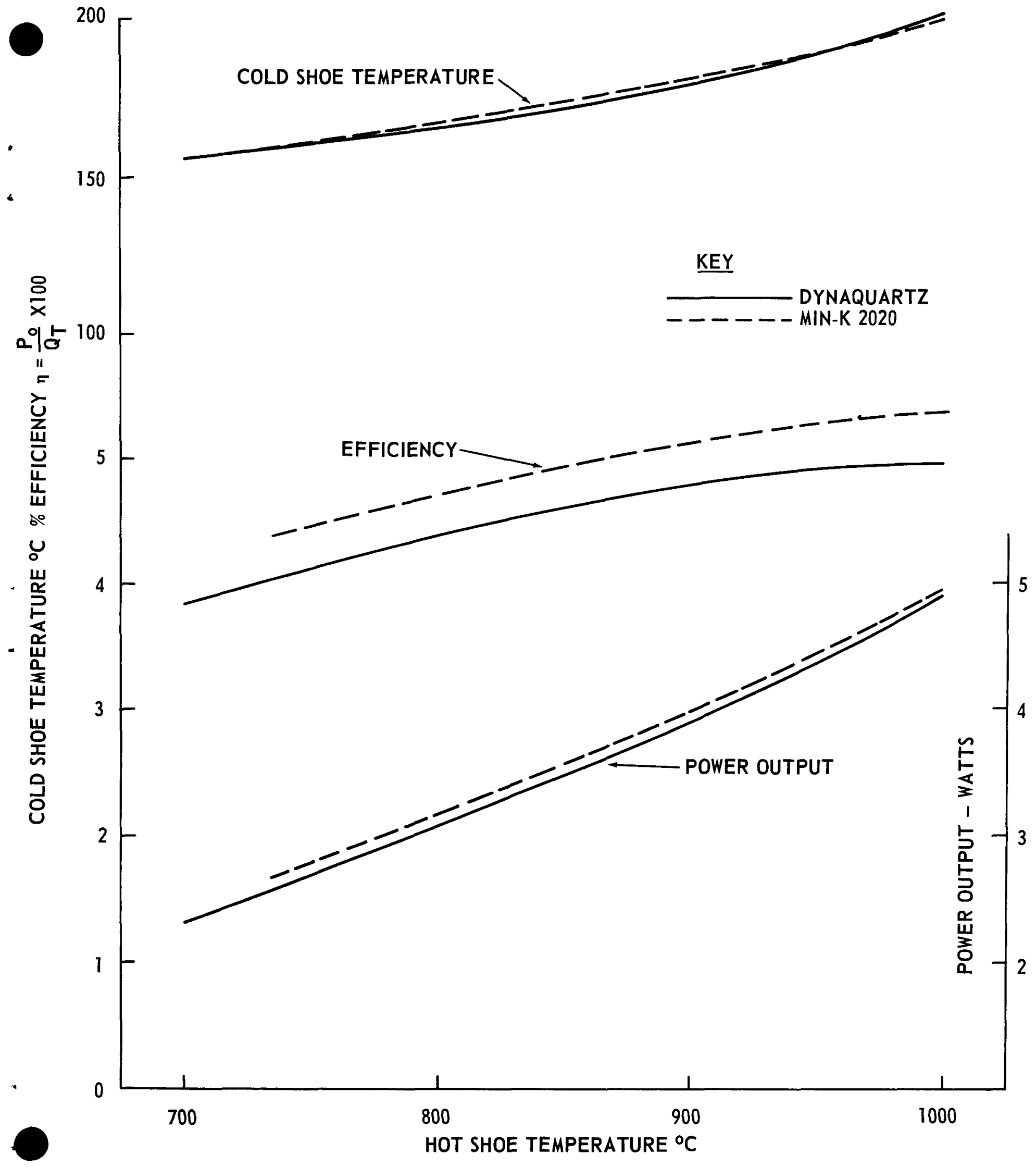

FIGURE 29. 5-WATT AIR-VAC CONVERTER EFFICIENCY, POWER OUTPUT, COLD SHOE TEMPERATURE VS. HOT SHOE TEMPERATURE. 


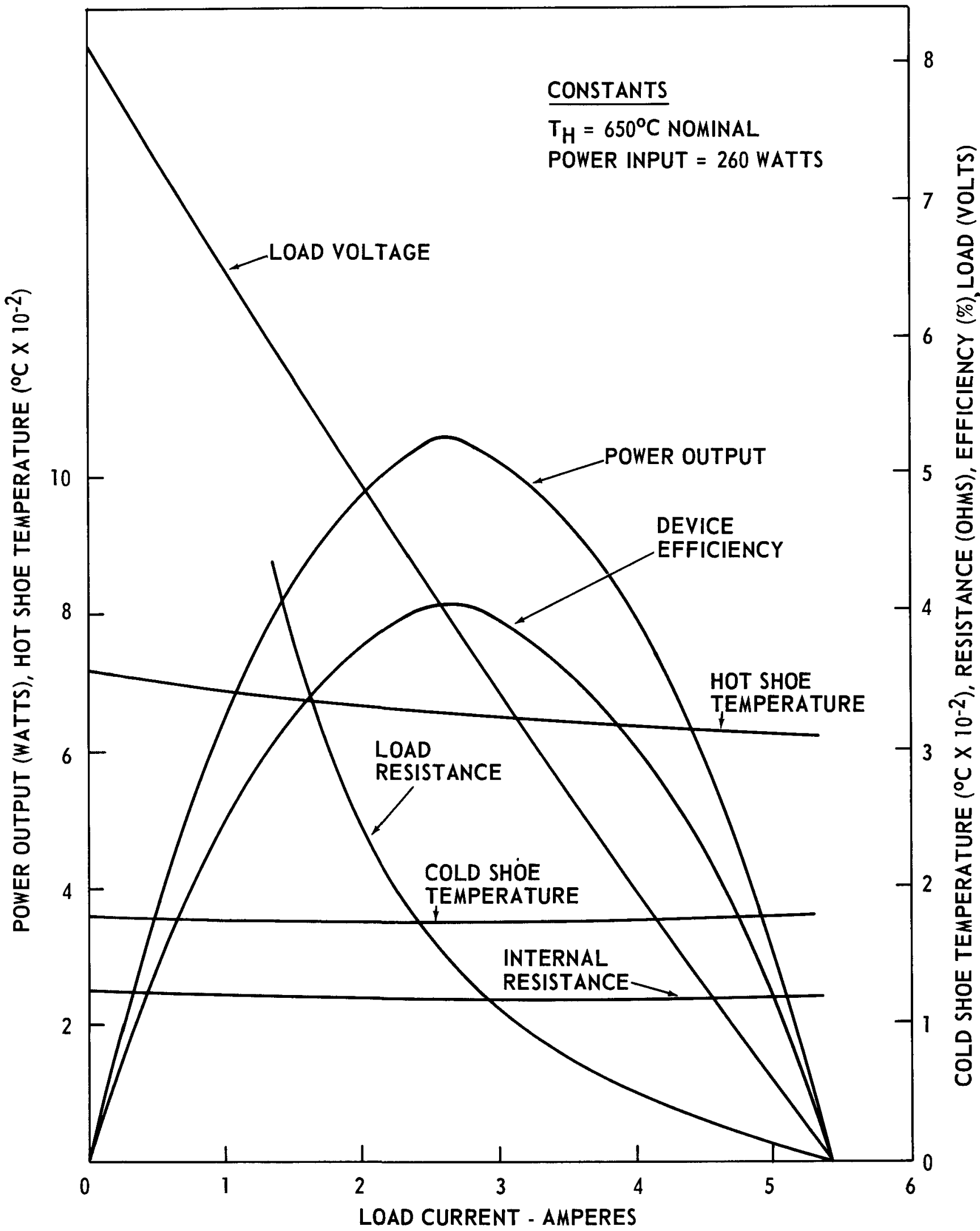

FIGURE 30. REFERENCE DESIGN CONVERTER PERFORMANCE VS. LOAD CURRENT. 


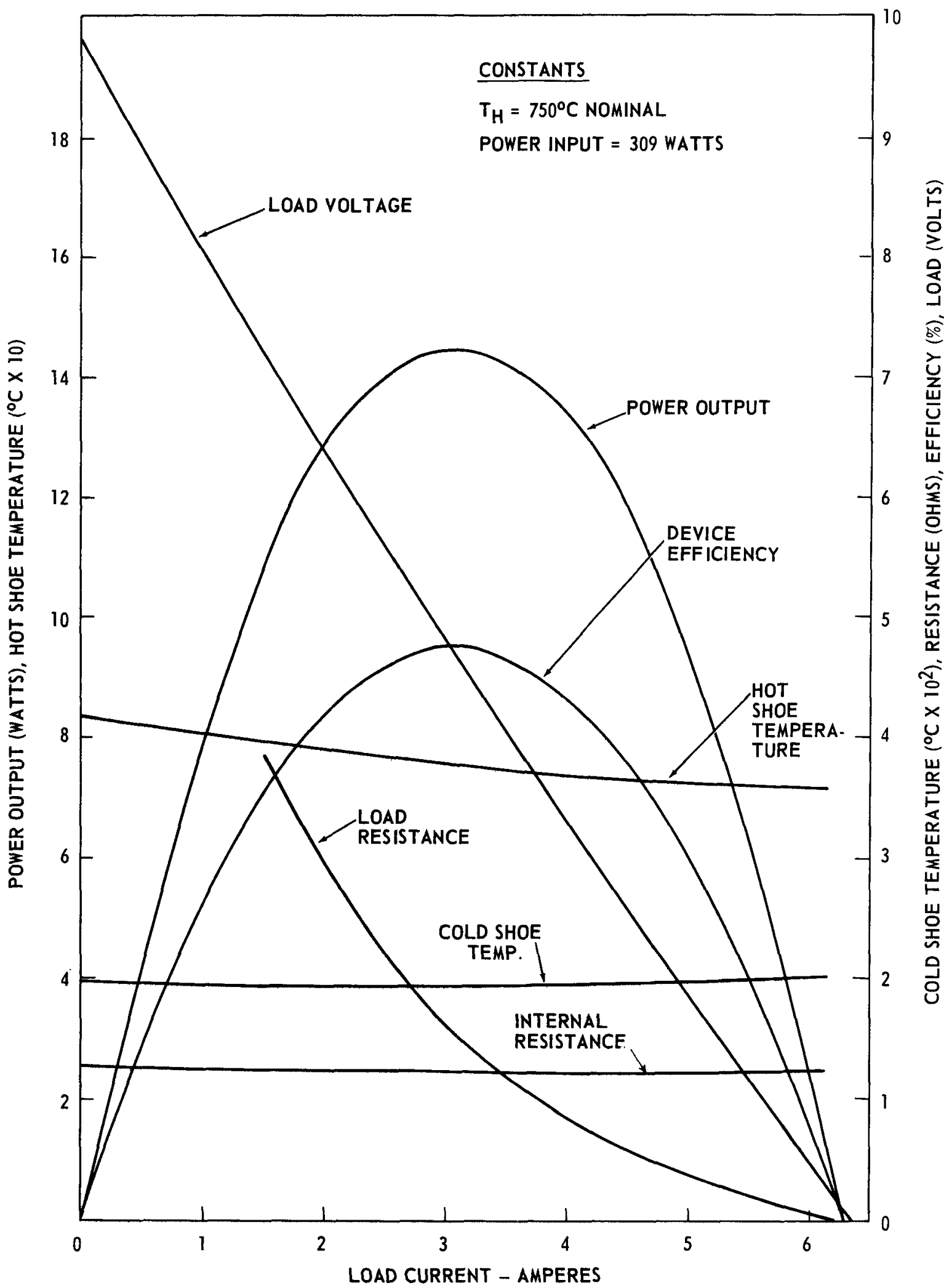

FIGURE 31. REFERENCE DESIGN CONVERTER PERFORMANCE VS. LOAD CURRENT .55 . 
converter, except larger. The same system of evaluating the heat loss along the graphite heater legs was used as described for the 5-watt converter. Because of the large number of hot shoe temperature-measuring thermocouples, the heat conducted along them was also included in calculating the losses not chargeable against converter efficiency. These losses were approximately equal to the heater lead loss. The efficiency plotted in Figures 30 and 31 is net efficiency, after these two losses are subtracted from heater input power.

c. 4-Couple Module Test in Air and Vacuum

A 4-couple reference design module was operated in air for 164 hours, followed by 5 thermal cycles, then 366 additional hours of steady state operation. The module was then removed from the air furnace and mounted in a vacuum life test station where it has operated for 465 hours. The total operating time is 1005 hours.

Table $V$ shows the calculated operating values as well as the measured operating conditions in both air and vacuum. The module was operated on open circuit during the air testing and into an approximately matched load in vacuum testing. Hot shoe temperature in air was measured with an optical pyrometer, and in vacuum by W-Re thermocouples in holes in the hot shoes.

The previous test was intended primarily to determine whether air operation and thermal cycling before vacuum operation, as might result from a pre-launch checkout, would cause degradation or other problems. Of particular interest was the temperature drop from cold shoe to radiator across the mounting stud - base plate interface. The test results indicated no problems in this or other areas.

Figure 32 shows the heating and cooling curves for the airthermal cycling. Cycling was done by completely removing heater power to the frame for cooling, and switching the furnace on at full power for heating.

d. Couple Shock and Vibration Testing

Shock and vibration testing was carried out during this reporting period on reference design thermocouples and one developmental design couple. General test conditions were as follows:

$\begin{array}{ll}\text { Vibration: } & \text { Waveform } \\ \text { Sweep } & \text { - Sine } \\ \text { Frequency } & -50 \text { to } 2000 \mathrm{~Hz} \\ \text { Axes } & -3 \text { perpendicular axes, unless } \\ & \text { otherwl se stated }\end{array}$


TABLE V

PERFORMANCE OF 4-COUPLE REFERENCE DESIGN MODULE IN AIR AND VACUUM

T Hot Shoe - $\mathrm{OC}$

T Cold Shoe - oC

T Radiator - $\infty$

$E_{\mathrm{OC}} \mathrm{mv}-{ }^{\circ} \mathrm{C}$

Mod. Resistance - ohms.

Load Resistance - ohms.

$E_{o c} 2 / 4 R$ - watts

E Load - mv

$E_{L}^{2} / R_{L}$ - watts

$\Delta T$ (Hot shoe-Cold shoe - ${ }^{\circ}$ )

Normalized Power Output

$\left(E_{o c}^{2} / \angle R\right)\left(\frac{\Delta T^{2} \text { Calculated }}{\Delta T^{2} \text { Actual }}\right)$

$\Delta T$ (Cold Shoe - Radiator)
$0 \mathrm{hrs}$. $4 \mathrm{lhrs}$. $164 \mathrm{hrs}$.

$292 \mathrm{hrs}$.

531 hrs. 1005 hrs.

\begin{tabular}{|c|c|c|c|c|c|c|}
\hline Calculated & $\begin{array}{c}\text { Initial } \\
\text { Air }\end{array}$ & Air & $\begin{array}{l}\text { Pre-Cycling } \\
\text { Air }\end{array}$ & $\begin{array}{c}\text { Post Cycling } \\
\text { Air }\end{array}$ & $\begin{array}{l}\text { Initial } \\
\text { Vacuum }\end{array}$ & $\begin{array}{l}\text { Latest } \\
\text { Vacuum }\end{array}$ \\
\hline 1008 & 1002 & 1022 & 1019 & 1020 & 1000 & 995 \\
\hline 190 & 187 & 201 & 206 & 202 & 245 & 245 \\
\hline 174 & 174 & 186 & 191 & 186 & 229 & 231 \\
\hline 1.724 & 1.625 & 1.664 & 1.667 & 1.663 & 1.610 & 1.606 \\
\hline 0.350 & 0.304 & 0.358 & 0.364 & 0.368 & 0.380 & 0.388 \\
\hline- & - & - & - & - & 0.372 & 0.388 \\
\hline 2.12 & 2.17 & 1.93 & 1.91 & 1.88 & 1.70 & 1.66 \\
\hline- & - & - & - & -- & 808 & 802 \\
\hline- & - & - & - & - & 1.75 & 1.73 \\
\hline 818 & 815 & 821 & 813 & 818 & 755 & 750 \\
\hline 2.12 & 2.19 & 1.91 & 2.01 & 1.89 & 2.01 & 2.06 \\
\hline 16 & 13 & 15 & 15 & 16 & 16 & 14 \\
\hline
\end{tabular}




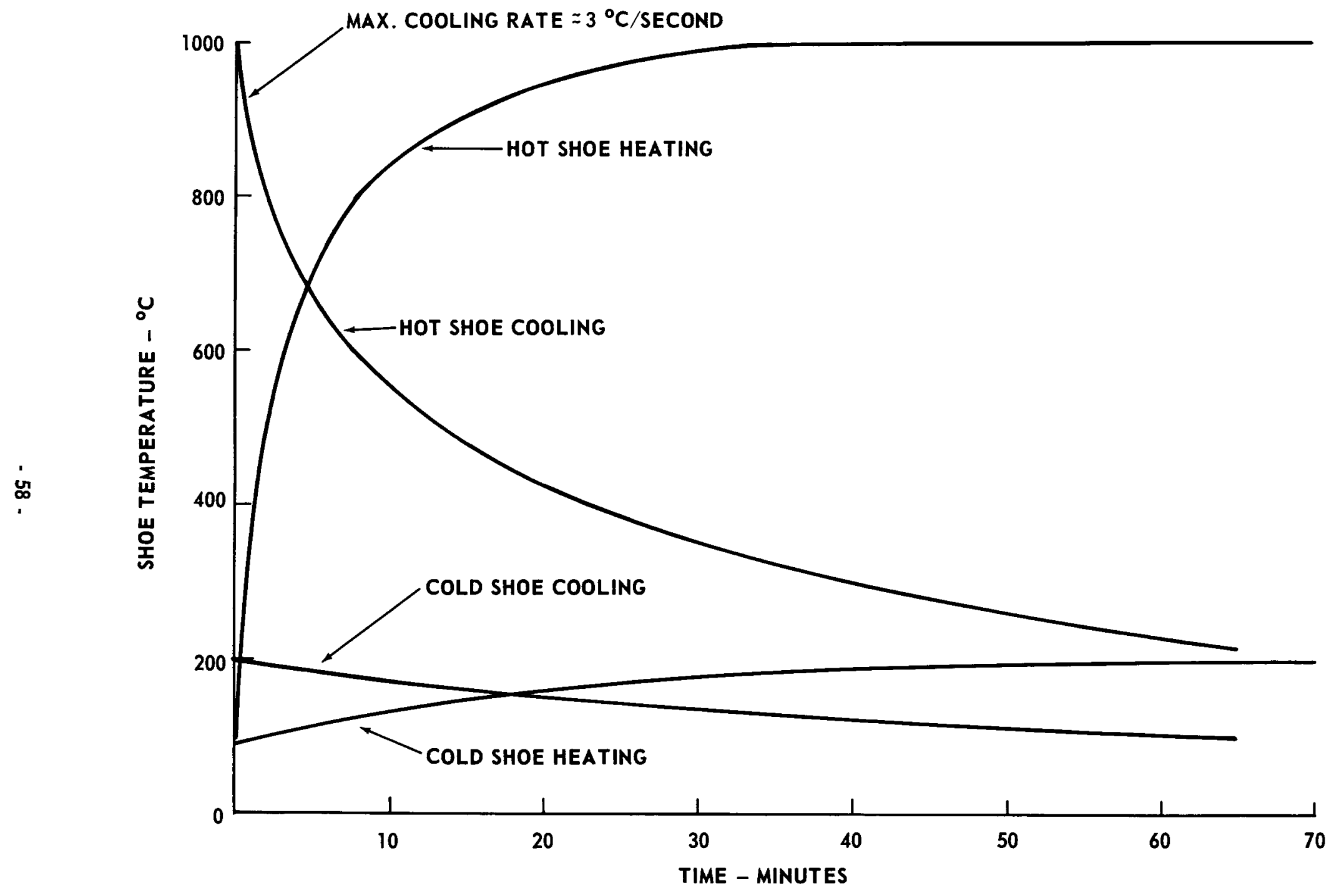

FIGURE 32. HEATING-COOLING CURVES - AIR THERMAL CYCLING TEST OF 4-COUPLE REFERENCE DESIGN AIR-VAC MODULE 


Shock: $\begin{array}{ll}\text { Waveform } & -1 / 2 \text { Sine } \\ \text { Duration } & -11 \text { milliseconds or } 6 \text { milliseconds } \\ \text { Axes } & - \pm 3 \text { perpendicular axes } \\ \text { Blows } & -3 \text { per axes }\end{array}$

Details of the tests performed to date are shown in Table VI.

While there are no levels specified for shock and vibration for the current Air-Vac program, specifications from other programs and the shock and vibration levels of potential launch vehicles indicate a minimum acceptable vibration tolerance of 10 to $20 \mathrm{~g}^{\prime} \mathrm{s}$, and a shock level of approximately $40 \mathrm{~g}$ 's. Those reference design couples which did not achieve these levels had visual indications of inferior bonds, and the large spread in the data indicates a lack of process uniformity rather than a basically weak design. Further testing will be required in this area to be sure that satisfactory vibration pərformance can be consistently achieved.

The frame-type couple, $\mathrm{SB}_{2}$, which broke at $3 \mathrm{~g}^{\prime} \mathrm{s}$, had a defective cold shoe bond, the failure occurring at the cold end of the n-type pellet which is not cut away. Frame-type couple SB-1 withstood both the $3-g$ and 5-g vibrations, but after the $10-g$ test showed a crack just above the point where the 2 p-type legs join at the cold end. The successful 5-g test indicated that it should be possible to develop a high L/A couple having satisfactory mechanical performance.

\section{Test Facilities}

During the past quarter, work continued on establishing the test facilities required for the Air-Vac Test Program, viz., the construction of new equipment and the modification of existing facilities. The major items accomplished during the period are as follows:

a. Single-Position VS-9 Test Stations

Two vacuum life test stations, each sultable for testing a single Air-Vac module, were completed during this quarter. Each consisted of a Veeco VS-9 vacuum station, glass bell jar, a West programmable reactor power supply for the module heaters, and suitable instmumentation leads. Hot shoe thermocouples were $W-R e$, while cold shoe thermocouples were chromel-alumel.

b. Test Stands

Test stands to mount the Air-Vac modules in vacuum life test stations were designed and are under construction. These stands consist of a small plug-in fumace, using graphite 
TABLE VI

SHOCK AND VIBRATION TESTS RESULTS

\begin{tabular}{|c|c|c|c|}
\hline $\begin{array}{l}\text { Couple } \\
\text { Design }\end{array}$ & $\begin{array}{l}\text { Couple } \\
\text { No. }\end{array}$ & Test & Results \\
\hline \multirow[t]{7}{*}{ Reference } & 18 & $\begin{array}{l}\text { Vib. }-10 \mathrm{~g}^{\prime} \mathrm{s} \\
\text { Vib. }-20 \mathrm{~g}^{\prime} \mathrm{s} \\
\text { Vib. }-38 \mathrm{~g}^{\prime} \mathrm{s}\end{array}$ & $\begin{array}{c}\text { ok } \\
\text { ok } \\
\text { Crack at cold end of n-type leg }\end{array}$ \\
\hline & $\mathrm{H}_{4} 4$ & $\begin{array}{l}\text { Vib. }-38 g^{\prime} s \\
\text { (one axis only) }\end{array}$ & Both legs broke at cold end \\
\hline & 5 & Vib. $-20 g^{\prime} s$ & Crack at cold end of n-type leg \\
\hline & 37 & $\begin{array}{l}\text { Vib. }-10 \mathrm{~g}^{\prime} \mathrm{s} \\
\text { Vib. }-20 \mathrm{~g}^{\prime} \mathrm{s}\end{array}$ & Crack at cold end of n-type leg \\
\hline & 9 & $\begin{array}{l}\text { Vib. }-10 g^{\prime} \mathrm{s} \\
\text { Vib. }-20 g^{\prime} \mathrm{s}\end{array}$ & Crack at cold end of p-type leg \\
\hline & 26 & $\begin{array}{l}\text { Shock } 40 \mathrm{~g}^{\prime} \mathrm{s}, 11 \mathrm{~ms} \\
\text { Shock } 60 \mathrm{~g}^{\prime} \mathrm{s}, 11 \mathrm{~ms} \\
\text { Vib. - } 20 \mathrm{~g}^{\prime} \mathrm{s}, \\
\text { Shock } 100 \mathrm{~g}^{\prime} \mathrm{s}, 11 \mathrm{~ms} \\
\text { Shock } 200 \mathrm{~g}^{\prime} \mathrm{s}, 6 \mathrm{~ms} \\
\text { Vib. - } 38 \mathrm{~g}^{\prime} \mathrm{s}\end{array}$ & $\begin{array}{l}\text { ok } \\
\text { ok } \\
\text { ok } \\
\text { ok } \\
\text { ok } \\
\text { ok }\end{array}$ \\
\hline & 11 & $\begin{array}{l}\text { Shock } 50 \mathrm{~g}^{\prime} \mathrm{s}, \quad 6 \mathrm{~ms} \\
\text { Shock } 100 \mathrm{~g}^{\prime} \mathrm{s}, 6 \mathrm{~ms} \\
\text { Shock } 150 \mathrm{~g}^{\prime} \mathrm{s}, 6 \mathrm{~ms} \\
\text { Shock } 200 \mathrm{~g}^{\prime} \mathrm{s}, 6 \mathrm{~ms} \\
\text { Vib. - } 10 \mathrm{~g}^{\prime} \mathrm{s}, \\
\text { Vib. - } 20 \mathrm{~g}^{\prime} \mathrm{s}, \\
\text { Vib. - } 38 \mathrm{~g}^{\prime} \mathrm{s},\end{array}$ & $\begin{array}{l}\text { ok } \\
\text { ok } \\
\text { ok } \\
\text { ok } \\
\text { ok } \\
\text { ok } \\
\text { ok }\end{array}$ \\
\hline \multirow[t]{2}{*}{ Frame Type } & $\mathrm{SB}-1$ & $\begin{aligned} \text { Vib. }-3 & g^{1} \mathrm{~s} \\
5 & \mathrm{~g}^{\prime} \mathrm{s} \\
10 & \mathrm{~g}^{\prime} \mathrm{s}\end{aligned}$ & $\begin{array}{c}\text { ok } \\
\text { ok } \\
\text { Crack at cold end }\end{array}$ \\
\hline & $S B-2$ & Vib. $-3 g^{\prime} \mathrm{s}$ & Crack at cold end \\
\hline
\end{tabular}


heaters and MIN-K and Dynaquartz thermal insulation. Thermal strips for thermocouples are also provided. The first stand has just been received for evaluation at the time of writing; all major parts have been fabricated for the remaining test stands.

c. Turbo Pump Station Modified for Air-Vac Converter Test

An existing vacuum life test station was modified during the quarter to permit testing the Air-V8.c reference design array. The station consists of a Welsh Scientific turbomolecular pump and an 18-inch double-wall, water-cooled stainless steel bell jar. The modifications consisted of 1) replacing the thermocouple feed-through's with W-Re feed-through's, 2) replacing the load resistance with one suitable for the higher output of the converter, 3) changing the heater power supply from a constant temperature type to a constant power type, and 4) changing the intermal mounting arrangement to accept the reference design array. The converter is operating satisfactorily in the modified station.

d. Four-Position Turbo Pump Life Test Station Modification

A vacuum life test station sinilar to that described in section e. for the reference design array is being modified to permit testing four lir-Vac modules. The major modification required is the replacement of chromel-alumel feed-through's with those of W-Re for the hot shoe temperature measurements. This station will be used with the test stands described previously. Work on this station is about 80 percent complete and it is expected to be operational early in the 3rd quarter.

e. Air Life Test Station

A Iife test station was set up for operating Air-Vac modules in air. This station comprised two quartz-bulb, tubular tungsten coil heat lamps, fire brick and fibrous thermal insulation, and a West power supply for the heaters. The heaters and the module radiator plate were mechanically supported by the fire bricks. A jet of air was blown over the ends of the heat lamps to keep the seals within safe temperature limits. This test station was used to test a four-couple Air-Vac module in air with a hot shoe temperature of approximately $1000^{\circ} \mathrm{C}$.

f. Shock and Vibration Fixtures

Fixtures were designed, fabricated, and checked out for shock and vibration testing of Air-Vac couples at room temperature. The fixtures appeared to have no significant resonances below $2000 \mathrm{~Hz}$. 
g. Relative Efficiency Test Stands

The design of a test stand suitable for measuring relative efficiency of modules (as contrasted to full arrays) was completed and fabrication was begun. The design consists of a module heated by a flat electrical heater with provisions for measuring the input power and electrical output power. Two inches of foil insulation having very low thermal conductivity are used to minimize the heat loss from the back of the heater. The heat which flows through the insulation is collected by a metal box of known temperature and radiated to a second box at a known temperature. The surfaces of both boxes will be covered with a coating of known emissivity, so that the flow through the insulation can be measured. The other major heat loss not chargeable against the module under test is the heat conducted through the heater leads. This loss will be evaluated by measuring the temperature gradient along leads of known thermal conductivity.

Most parts have been fabricated except for the foil insulation which was due from the vendor in early July. The test stand should be operational early in the 3rd quarter. 


\section{CASCADED CONVERTER DEVEIOPMENT PROGRAM}

\section{A. INTRODUCTION}

The objective of this program includes the development of accurate analytic techniques and the parametric performance characterization of SiGe hot stages when cascaded with either a $\mathrm{PbTe}$ flat-plate or tubular module as the low temperature stage. Subsequent referral to the parametric data will enable the selection of hot stage configurations that, subject to any given set of input conditions, yield optimum device performance in terms of either efficiency or specific power. Some of these selected configurations will be the bases of detailed designs which will subsequently be fabricated into actual modules and then into hot stages for experimental evaluation. The ultimate objective will be the mating and testing of these optimized SiGe hot stages with $\mathrm{PbTe}$ cold stages in the form of cascaded systems.

\section{Analytical Techniques}

The programming of the performance and design equations of the planar-cascaded thermoelectric generator for solution on a high speed computer was completed during the present reporting period. Although it was originally anticipated that the parametric studies using these equations would also be conducted during this reporting period, the effort devoted to other portions of the program prohibited this activity.

In the previous quarterly report, a general discussion was given on analytical techniques which are commonly used in calculating the performance of cascaded thermoelectric generators. An explanation was also given for the need to develop a new and improved technique for such calculations because of the shortcomings of most existing methods. A short summary of the resultant development follows.

The planar-cascaded generator, consisting of a Si-Ge hot stage and a $\mathrm{Pb}-\mathrm{Te}$ cold stage, is characterized by component configurations and materials. The configuration of components that yield optimum performance for any desired set of input parameters, incident heat flux density, and fuel capsule temperature, is determined through the variation of the generator component dimensions that have a first-order bearing on performance. These dimensions are the thermoelement lengths, the thermoelement cross-sectional areas, and the heat collector and radiator areas.

The heat collector and radiator areas of each stage are assembled to be equal and, moreover, to have equal total areas. However, the number of couples in each stage is variable.

The operating temperatures and performance of the generator are not initially known and must be calculated from generator 
configuration, component material properties, and the heat incident on the heat collector of the hot stage. To do this, it is necessary to initially assume arbitrary values for generator temperatures. These values are used to initially define the physical properties of all component materials. By the use of component dimensions and thermal conductivity values, the thermal conductances of all thermoelectrically passive components are calculated. The thermoelectric properties of the thermocouple leg materials are averaged by integrating over the assumed temperaturas.

The electrical resistances of both stages, including contributions from contacts and passive current-carrying members, are determined and the load is set at some value close to but slightly higher than the total internal resistance of the device. A subsequent variation of load resistance about this value permits the determination of the load resistance that optimizes device performance. The outputs of both stages are dissipated in the same load, with the two stages electrically connected either in series or in parallel.

The thermocouples of each stage may be either series-or parallelconnected. The heat collection area, augmented by the incident heat flux, determines the total heat processed through the generator. Because the performance of the generator is initially unknown, the total heat entering the device is assumed to be rejected at the cold side. This assumption enables the first approximation calculation of the radiator temperature. Cold junction temperatures of the cold stage follow immediately from the values of thermal conductances of components between the radiator and the cold junctions and the heat throughput. The total heat balance equation for the thermocouples of the cold stage permits the calculation of the corresponding hot junction temperatures. The use of the hot and cold junction temperatures of the cold stage thus obtained now enable the calculation of the shunt heat that bypasses the thermoelements by flowing through the thermal insulation surrounding the thermocouple legs. The thermal conductances of the passive members on the hot side of the cold stage, added to the total heat flowing through the stage determine the temperature of the outer surface of the cold stage heat collector. This surface acts as the sink for radiation emitted by the hot stage radiator. The temperatures of the hot stage are determined in a manner analogous to that of the cold stage.

Once all of the temperatures are established, the power output of the device can be calculated and used to correct the total heat rejected by the radiator of the cold stage. The calculated temperatures are used for obtaining new values of all physical properties, including the integrated values of thermoelectric properties of the two stages. The complete calculation is then repeated and will continue to be repeated until the temperatures 
of the device change less than some prescribed amount between successive calculations. In effect therefore, the problem is solved by successive approximations. Once the final temperatures are established, it is then a simple matter to finish the calculation by determining the performance characteristics of the device. As already stated, the device configuration that yields optimum performance for a set of input criteria is finally determined by the variation of those device parameters that have a first-order bearing on device performance.

Although not discussed previously, a more sophisticated version of the program also accounts for the effects of transverse heat flow in the heat collector and radiator surfaces of the device. 